Portland State University

PDXScholar

Spring 6-5-2013

\title{
Teachers' Negative Comments Toward Youth in Foster Care with Disabilities: How Do They Relate to Youths' Problem Behaviors, School Attitudes, and School Performance?
}

\author{
Sunghwan Noh \\ Portland State University
}

Follow this and additional works at: https://pdxscholar.library.pdx.edu/open_access_etds

Part of the Disability and Equity in Education Commons, Social Work Commons, and the Special Education and Teaching Commons Let us know how access to this document benefits you.

\section{Recommended Citation}

Noh, Sunghwan, "Teachers' Negative Comments Toward Youth in Foster Care with Disabilities: How Do They Relate to Youths' Problem Behaviors, School Attitudes, and School Performance?" (2013). Dissertations and Theses. Paper 1082.

https://doi.org/10.15760/etd.1082

This Dissertation is brought to you for free and open access. It has been accepted for inclusion in Dissertations and Theses by an authorized administrator of PDXScholar. Please contact us if we can make this document more accessible: pdxscholar@pdx.edu. 
Teachers' Negative Comments Toward Youth in Foster Care with Disabilities:

How Do They Relate to Youths' Problem Behaviors, School Attitudes, and School Performance?

by

Sunghwan Noh

A dissertation submitted in partial fulfillment of the requirements for the degree of

Doctor of Philosophy

in

Social Work and Social Research

\author{
Dissertation Committee: \\ Laurie E. Powers, Chair \\ Junghee Lee \\ Sarah Geenen \\ Jong Sung Kim
}

Portland State University

2013 


\section{Abstract}

A large proportion of youth in foster care receive special education services, and poor educational outcomes are one of the most important difficulties facing these youth. One potential risk affecting the low educational achievements of youth in foster care and special education could be teachers' negative and stigmatizing comments toward them. Teachers' negative and stigmatizing comments could have negative effects on youths' behaviors, school attitudes and school performance. Yet, research on the nature and the impact of teachers' negative and stigmatizing comments remains limited.

Based on labeling and attribution theories, this study investigated the nature and impact of teachers' negative and stigmatizing comments on the school performance of 123 youth in foster care and special education. Qualitative analysis of the youths' IEP documents was conducted, along with longitudinal quantitative analysis of the associations of negative and stigmatizing IEP comments and the youths' school attitudes, behavior, and performance.

Qualitative findings revealed that almost three-fourths of the IEPs included one or more negative comments, and that a substantial proportion of teachers' negative comments specifically included stigmatizing features that could convey negative attitudes or perceptions about the youth to others, including subjective or judgmental comments, biased reports from other teachers, low expectations, and little attention to context or reason.

Findings from structural equation modeling showed that teachers' negative comments indirectly predicted youths' school absences through a mediational effect of youths' problem behaviors, and the relationship between current and future youth 
absences was partially mediated through a complex mechanism incorporating both direct and indirect pathways involving youths' school attitudes and problem behaviors. The findings highlight the important predictive and potentially protective roles of teachers' negative comments and youths' school attitudes and problem behaviors on youths' absenteeism. 


\section{Dedication}

This dissertation is dedicated to God Almighty who has been my eternal rock and hope, and kept me all through the journey of completing this work.

To my father and mother who have provided unconditional love, support, and prayer.

To my wife who has supported me with patience and prayer.

To my daughter who has never ceased to bring me a lot of joy from the day she was born until now. 


\section{Acknowledgements}

This dissertation is not my accomplishment alone, but the result of those who stand alongside me. With that in mind, I want to thank all who made this dissertation possible.

First and foremost, I want to thank each member of my dissertation committee who provided helpful feedback, guidance, and encouragement throughout my doctoral program and this dissertation process. Specially, I am thankful to Dr. Laurie Powers, the chair of my dissertation committee, who served as my advisor throughout my doctoral program and provided valuable advice, mentoring, and meticulous editing on the numerous versions of my dissertation. Words cannot express my gratitude for all the support given over the years. I am grateful to Dr. Sarah Geenen, who graciously helped me access and understand data for this dissertation. I also appreciate Drs. Junghee, Lee, and Jongsung Kim, who advised me on issues of methodology and data analyses on the dissertation. I am grateful to Dr. Daniel Coleman who was a former member of my dissertation committee and mentor, and who encouraged and gave me opportunities to develop data analysis expertise.

I want to thank all the others who helped in all phases of the dissertation study. I am grateful to Celina Kishna who helped me analyze qualitative information on my dissertation. I also appreciate Connie Loesch who was willing to help me to edit the formatting of my dissertation.

Lastly, I want to thank those who helped fund and support my work through the doctoral program. I am grateful for the support provided by the School of Social Work at 
Portland State University including graduate research assistantships, scholarships, and awards. 
Table of Contents

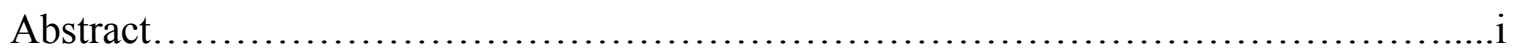

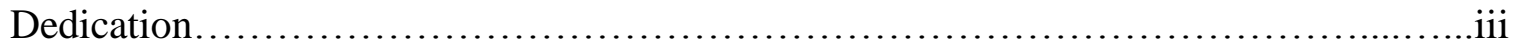

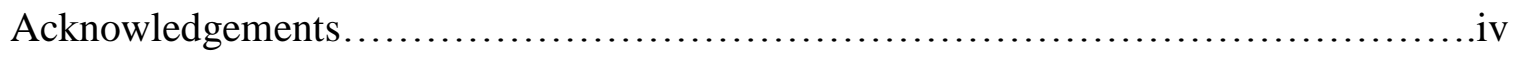

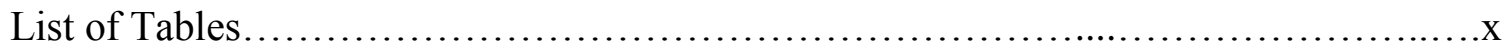

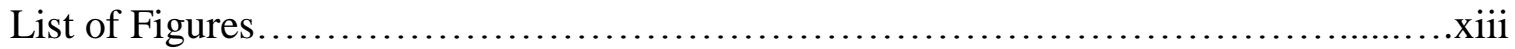

\section{Chapter 1}

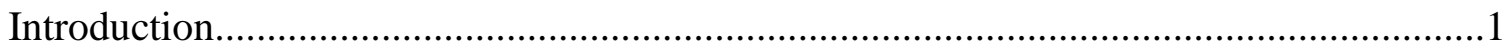

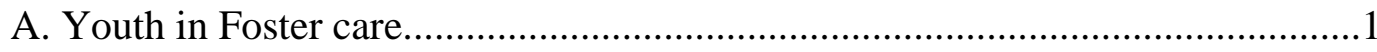

B. Educational Problems of Youth in Foster Care.................................................2

C. Potential Role of Teachers' Negative Attitudes...............................................3

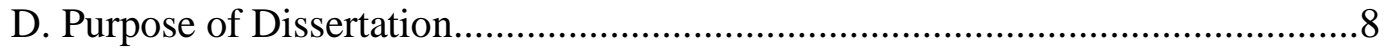

E. Importance to Social Work and Education.................................................

Chapter 2

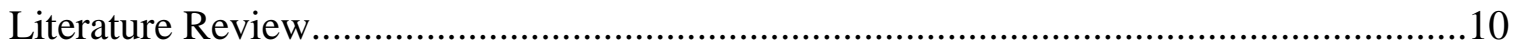

A. Definitions of Stigma.......................................................................... 10

B. Theories Related to Stigmatization............................................................12

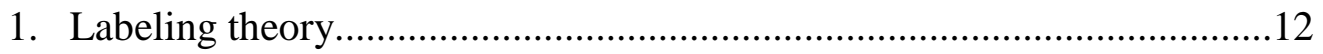

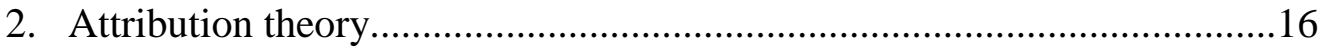

3. Integration of labeling and attribution theory...................................22

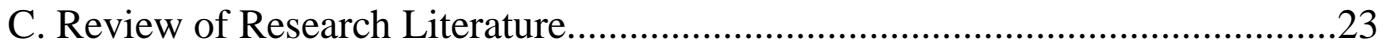

1. Exposure to public stigma and self-stigma.........................................23 
vii

2. Stigma related to gender, race, and ethnicity.....................................26

3. Expression of negative attitudes through written comments...................27

4. Impact of teachers' negative attitudes on youths' school performance.......31

5. Impact of teachers' negative attitudes on youths' school attitudes.............34

6. Impact of teachers' negative attitudes on youths' problem behaviors........36

7. Association of youths' school attitudes and school performance...............37

8. Association of youths' problem behaviors and school performance.........39

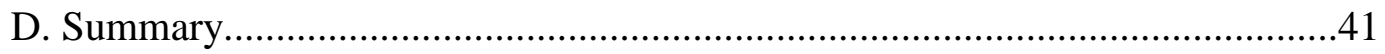

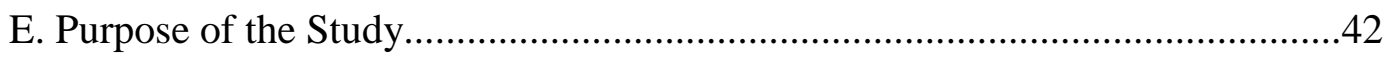

\section{Chapter 3}

Methodology.....

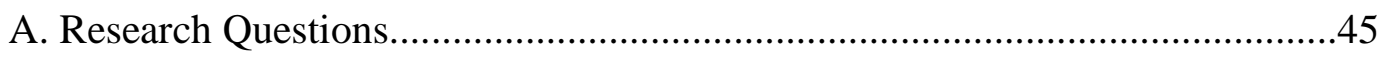

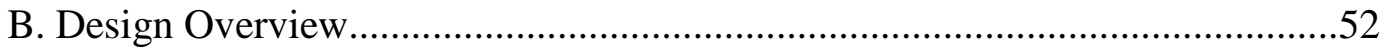

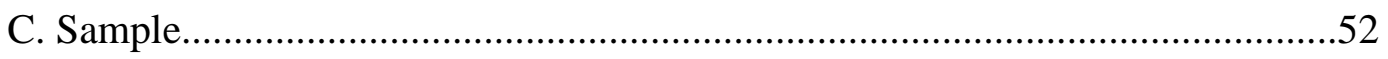



1. Teachers' negative comments in IEP documents................................55

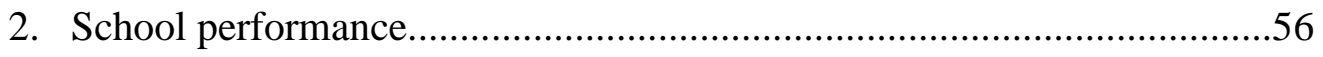

3. Problem behavior............................................................................5



5. Participation in the IEP meeting ......................................................5

6. Participation in the self-determination intervention.............................59

7. Race, ethnicity and gender..........................................................60

8. Demographic characteristics.....................................................60 
viii

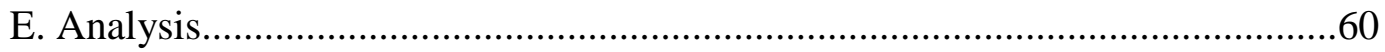

1. Qualitative analysis.....................................................................6 60

2. Quantitative analysis.....................................................................63

Chapter 4

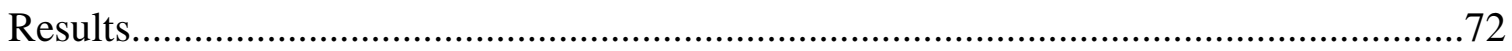

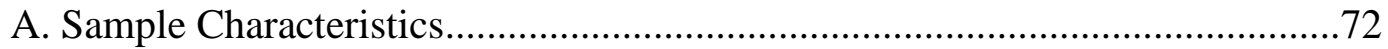

B. Teachers' Negative Comments on IEP Documents.......................................75

C. Teachers' Stigmatizing Negative Comments on IEP Documents....................80

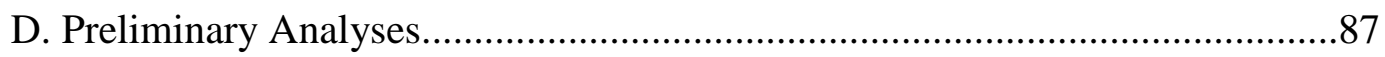

E. Bivariate Analyses Examining Difference in Teachers' Negative Comments by Race/ethnicity and Gender of the Youth...................................................89

F. Bivariate Analyses Examining Difference in Teachers' Stigmatizing Negative Comments by Race/ethnicity and Gender of the Youth..............................93

G. Bivariate Relationships between Teachers' Negative Comments and Youths'

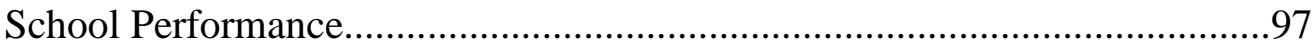

H. Bivariate Relationships between Teachers' Stigmatizing Negative Comments and Youths' School Performance .103

I. The Mediational Effect of Youths' School Attitudes and Problem Behaviors on the Relationship between Teachers' Negative Comments on Youths' School Performance. 107

J. The Mediational Effect of Youths' School Attitudes and Problem Behaviors on the Relationship between Teachers' Stigmatizing Negative Comments on Youths' School Performance. 
Chapter 5

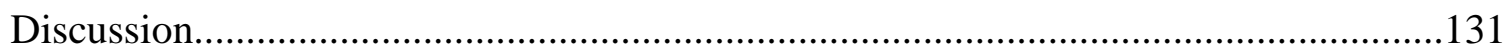

A. Major Findings.............................................................................. 131

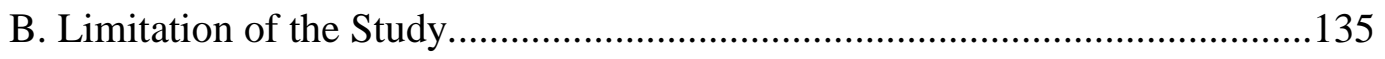

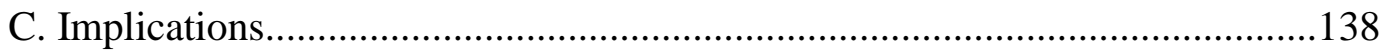

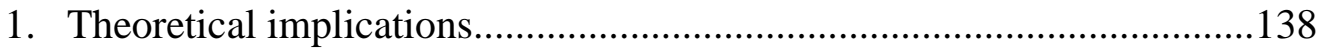

2. Practice implications.............................................................. 140

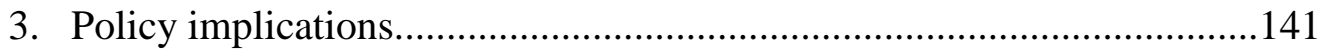

4. Research implications............................................................ 143

5. Suggestions for future research.................................................. 144

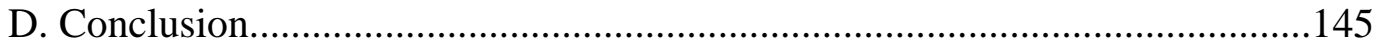

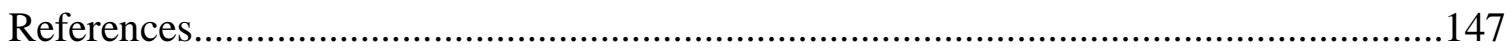




\section{List of Tables}

Table 1. The Types of Attributions Communicated through Stereotype, and the

Consequences.

Table 2. Type and Timeline of Study Measures. .54

Table 3. The Simplified Formulae for t-test, ANCOVA, Moderation, and Mediation

Model....... .71

Table 4. Demographic Characteristics of the Participants............................................73

Table 5. Agreement of Coding Negative Comments between Coders.............................76

Table 6. Established New Rules of Coding Comments...............................................77

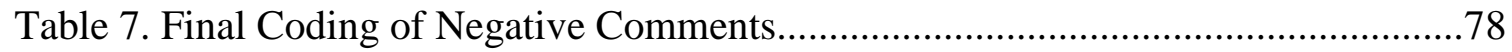

Table 8. Agreement for Coding Stigmatizing Comments between Coders.....................81

Table 9. Case Numbers of School Performance Data.................................................88

Table 10. Teachers' Negative Comments Descriptives................................................90

Table 11. Teachers' Stigmatizing Negative Comments Descriptives.............................94

Table 12. School Performances Descriptives............................................................98

Table 13. Correlation Analyses for Teachers' Negative Comments and Other

Variables

Table 14. Hierarchical Regression Analysis for Moderation Effects of Youths'

School Performance Previous to Study Entry

Table 15. Correlation Analyses for Teachers' Stigmatizing Comments and Other

Variables.

Table 16. Hierarchical Regression Analysis for Moderation Effects of Youths'

School Performance Previous to Study Entry .106 
Table 17. School Attitudes and CBCL Descriptives

Table 18. Correlation Analyses for Teachers' Negative Comments and Other

Variables

Table 19. Fit Indices for Direct Effects of the Predictors on School Performance at

Time 2

Table 20. Parameter Estimates of Direct Effects of the Predictors on School

Performance at Time 2

Table 21. Fit Indices for Direct Models on School Performance at Time 2.

Table 22. Parameter Estimates of Direct Effects of the Predictors on School

Performance at Time 2

Table 23. Model Comparisons of Direct Model with Mediational Model

with Youths' Problem Behaviors

Table 24. Parameter Estimates of All Paths in the Mediational Model of Youths' Problem Behaviors on the Relationship between Teachers' Negative

Comments and Absences at Time 2

Table 25. Model Fit Comparisons of 3 Models

Table 26. Parameter Estimates of All Paths in the Mediational Model of Youths' School Attitudes and Youths' Problem Behaviors on the Relationship between Teachers' Negative comments and Absences at Time 2..124

Table 27. Fit Indices of Models for Direct Effects of Teachers' Stigmatizing Negative Comments and Other Predictors on School Performance at

Time 2 126 
Table 28. Parameter Estimates of Direct Effects of Teachers' Stigmatizing Negative Comments and other Predictors on School Performance at Time 2...................128 


\section{List of Figures}

Figure 1. Research model depicting the associations among teachers' negative comments, youths' school attitudes, problem behavior and school performance

Figure 2. The multiple regression model of mediation effect of youths' school attitudes between teachers' negative comments, and youths' school performance at Time 2

Figure 3. The multiple regression model of mediation effect of youths' problem behaviors between teachers' negative comments and youths' school performance measured at Time 2 . 50

Figure 4. The final model depicting the associations among teachers' negative comments, youths' school attitudes, problem behavior and school performance measured at Time 2 .

Figure 5. The multiple regression model of direct effects of teachers' negative comments and youths' school attitudes on youths' school performance measured at Time 2

Figure 6. The multiple regression model of direct effects of teachers' negative comments and youths' problem behaviors on youths' school performance measured at Time 2

Figure 7. The multiple regression model of mediation effect of youths' problem behaviors between teachers' negative comments, and absences at Time 2

Figure 8 . The mediational model of youths' problem behaviors on absences at Time 2 
Figure 9. The simultaneous model of mediation effect of youths' school attitudes, problem behaviors on the relationship between teachers' negative comments,

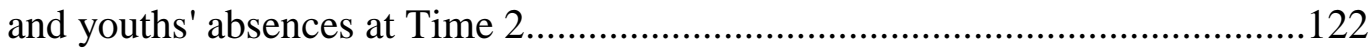

Figure 10. The simultaneous model of youths' school attitudes and problem

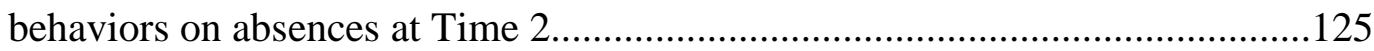

Figure 11. The multiple regression model of direct effects of teachers' stigmatizing negative comments and other predictors on youths' school performance measured






\section{Chapter 1: Introduction}

\section{Youth in Foster care}

Over the past two decades, the number of children and youth in foster care has increased from 302,000 in 1980 to 400,540 in 2011 (U.S. Department of Health and Human Services [DHHS], AFCARS Preliminary FY 2011 Report, 2012). Of those children in foster care in 2011, 41 percent were identified as Caucasian, 27 percent as African-American, 21 percent as Hispanic, and 13 percent as other races or multiracial. Boys in foster care (52\%) were slightly more represented than girls in foster care (DHHS, 2012).

Children and youth in foster care live in various types of placement settings and move among or between settings while they are in care. Of the estimated 400,540 children in foster care, approximately 47 percent were placed in non-relative foster homes, 27 percent were in relative foster care, 9 percent were in institutions, and the rest were in group homes or pre-adoptive homes (DHHS, 2012). One-quarter of youth experienced only one placement whereas over two-fifths experienced four or more placements (Courtney, Terao, \& Bost, 2004).

In 2011, approximately 27,673 youth aged out of the foster care system through emancipation or running away (DHHS, 2012). After aging out of the foster care system, youth often have little financial resources and supports from family and community, and they may face harsh situations. For example, the Midwest Evaluation study found that approximately 14 percent of the males and 10 percent of females experienced homelessness at least one night within one year after leaving foster care (Courtney, Piliavin, Grogan-Kaylor, \& Nesmith, 2001). Approximately one-third to half of foster 
youth were found not to be employed after exiting out of care (Courtney et al., 2004;

McMillen \& Tucker, 1999). The unemployment rates of these youth were approximately three times higher than those who had never been in care (Cheung \& Heath, 1994).

Further, Courtney and Dworsky (2006) found that 39 percent of young people

emancipated from foster were enrolled in higher education at age 19, compared to 59

percent of youth in the general population.

Prior to entering foster care, most youth have been exposed to harmful conditions including poverty and maltreatment (Chipungu \& Bent-Goodley, 2004; Harden, 2004;

Wertheimer, 2002). Associated with their exposure to these harmful conditions, youth in foster care are more likely to experience behavioral and emotional problems and poor physical health, compared to youth not in foster care (Bilaver, Jaudes, Koepke, \& George, 1999; Blome, 1997; Chernoff, Combs-Orme, Risley-Curtiss, \& Heisler, 1994; Chipungu \& Bent-Goodley, 2004; Kortenkamp \& Ehrle, 2002; Zima et al., 2000).

\section{Educational Problems of Youth in Foster Care}

Among a variety of problems, poor educational outcomes is one of the most important difficulties facing youth in foster care. Although successful schooling is very important for all youth, it may be particularly critical for youth in foster care who must successfully transition into adulthood after aging out of the child welfare system. Evidence reveals that youth in foster care are less likely to complete high school (Kortenkamp \& Ehrle, 2002; Runyan \& Gould, 1985; Sawyer \& Dubowitz, 1994; Vandivere, Chalk, \& Moore, 2003), and they are more likely to have poor school achievement (Blome, 1997; Sawyer \& Dubowitz, 1994), compared to youth not in foster care. Moreover, many youth in foster care are not afforded sufficient educational 
opportunities for academic achievement, which impacts motivation to pursue further education (Emerson \& Lovitt, 2003).

Educational difficulties may be even more serious for foster youth with disabilities. Studies have shown that approximately 30 to 47 percent of youth in foster care receive special education services (Center for Education, 2009; Weinberg, Zetlin, \& Shea, 2001; 2003). Recent findings from Hill (2012) suggested that 60 percent of older youth in foster care receive special educational services. Researchers have found that foster youth with disabilities are more likely to have lower GPAs, to earn fewer credits toward graduation, and to change schools more frequently than youth just in foster care or youth just in special education (Geenen \& Powers, 2006; Goerge, Van Voorhis, Grant, Casey, \& Robinson, 1992). For example, Geenen and Powers (2006) found that youth in foster care and special education had poorer academic performance than youth in foster care or special education alone. There exist few empirical studies that have examined the reasons for these problems. Contributing factors could include lack of persistent advocates for the youth, lack of awareness and knowledge of educators and foster parents, and lack of appropriate educational services tailored to the needs of foster youth in special education (Emerson \& Lovitt, 2003; Geenen \& Powers, 2006).

\section{Potential Role of Teachers' Negative Attitudes}

One potential influence on the poor outcomes of foster youth in special education may be school staffs' attitudes or perceptions toward them. Teachers' negative attitudes could have negative effects on youths' behaviors, attitudes toward school and school performance. Teachers' negative attitudes could include stigmatizing attitudes toward the youths. The concept of stigma incorporates a variety of negative aspects of attitudes 
toward other people or groups such as labels, stereotypes, prejudice, or discrimination (Crocker, 1999; Link \& Phelan, 2001). Teachers' stigmatizing attitudes may be communicated to youth in foster care and special education and, in turn, have negative influence on these youth's academic performance.

Communication of negative comments through IEP documents. One source of information about school staff' attitudes toward youth in foster care and special education may be found in their individualized education plans (IEPs). The IEP is the legal document that describes the plan for supports and services for youths in special education, including the following information; (a) current educational performance; (b) goals that the youth can achieve in a year; (c) special education and related services to be provided; (d) the extent to which the youth will participate with other youths with disabilities and without disabilities in the regular classroom and other school activities, and (e) information about the state and district-wide test, dates and location of service delivery, necessary transition services, age of majority, and measured progress (U.S. Department of Education, 2000, p. 9-10).

Through IEP documents, teachers may communicate their perceptions about a youth's performance and behaviors, which have been developed through past observation and interaction and, in some cases, bias, stereotypes and prejudices about the youth formed outside of direct interaction. Therefore, rather than merely objectively describing youths' problem behaviors, teachers' negative comments could reflect their subjective and judgmental attitudes toward youths. Preliminary findings from a pilot study suggest that teachers' negative comments are common in the IEP documents of youths in foster care and special education (Noh, Powers, \& Powers, 2013). Described in greater detail in the 
following chapter, these negative comments extend beyond objective descriptions of youths' behaviors to expressions of judgment that suggest negative or stigmatizing attitudes toward the youths. Additional research is needed to investigate the extent to which teachers' negative comments reflect stigmatizing attitudes toward foster youth receiving special education services, and the effects of these comments on these youths' school performance.

\section{Effect of teachers' negative attitudes on youths' school performance.}

Unfortunately, limited information exists about the nature of school staff's attitudes or perceptions toward youth in foster care and special education or the effects of their attitudes on youths' school performance. Westwood (1984) theorized a vicious cycle of teachers' low expectations associated with youths' poor academic performance. Low expectations toward youths with disabilities can lead to reduced learning opportunities. Reduced opportunities can further produce lower academic performance and, in turn, lower teachers' expectations. In this cycle, youths with disabilities adopt negative attitudes and opinions toward themselves and their abilities (Westwood, 1984). Youth in foster care have reported that they experienced restricted educational opportunities due to teachers' low expectations (Conger, Rebeck, \& Vera Institute of Justice, 2001; Jackson, 1994), and that they did not attend school due to humiliation by teachers (Blome, 1997; Carlen, Gleeson, \& Wardhaugh, as cited in Conger et al., 2001). Furthermore, studies have demonstrated an association between teachers' low expectations and negative attitudes and youths' poor school performance (Brown \& Lee, 2005; Brown \& Pinel, 2003). Further research is needed to clarify to the extent to which teachers' negative 
comments reflecting stigmatizing attitudes precede or follow youths' school poor performance.

\section{Effect of teachers' negative comments on youths' attitudes toward school.}

Another possible influence on the poor outcomes of youth in foster care and special education, which could be affected by teachers' negative comments, is youths' attitudes toward school. In general, youths' school attitudes play an important role in their academic attainment. Findings indicate that youths with negative attitudes toward school are more likely to have poor school performance (Diaz, 1998; Mandel \& Marcus, 1988; Majoribanks, 1992; Reis \& McCoach, 2000), and high dropout rates (Battin-Pearson et al., 2000; Simon-Morton, Crump, Haynie, \& Saylor, 1999).

Youths' school attitudes could be influenced by teachers' negative comments. Findings indicate that when teachers criticize youths' poor school performance and attribute their poor outcomes to youths' abilities, youths will exhibit less effort at school, negative attitudes toward school and teachers, and low motivation toward school work (Dweck, Davidson, Nelson, \& Enna, 1978; Montague \& Rinaldi, 2001; Simonson \& Strein, 1997).

In sum, it is possible that teachers' negative comments may negatively influence youths' attitudes toward school, and that youths' attitudes toward school may mediate the impact of teachers' negative attitudes on youths' academic performance. Teachers' negative comments and low expectations reflected in IEP documents could undermine youths' attitudes toward school, and, in turn, youths' lowered school attitudes could lead to poor academic performance. Unfortunately, despite general acknowledgement of the importance of youths' school attitudes on their school performance (Battin-Pearson et al., 
2000; Diaz, 1998; Mandel \& Marcus, 1988; Majoribanks, 1992; Reis \& McCoach, 2000;

Simon-Morton et al., 1999), little is known about the school attitudes of foster youth with disabilities or the influence of their school attitudes on their academic performance.

Effect of teachers' negative comments on youths' problem behaviors. Another possible influence on the poor school outcomes of foster youth in special education, that could be associated with teachers' negative comments, is youths' problem behaviors. Research indicates that approximately 30 to 54 percent of youth in foster care are diagnosed with emotional or behavioral disabilities (Choice et al., 2001; Goerge et al., 1992; Pecora et al., 2006; Westat, 1991). Youth in foster care demonstrate a variety of behavioral problems at school ranging from externalizing behaviors including aggressive, demanding, disruptive, and hyperactive behaviors to internalizing behaviors including withdrawal, anxiety, and depression. Empirical studies consistently report that approximately 30 to 70 percent of foster youth show both externalizing and internalizing behaviors (Clausen, Landsverk, Ganger, Chadwick, \& Litrownik, 1998; Courtney et al., 2004; Stein, Evans, Mazumdar, \& Rae-Grant, 1996; Thompson \& Fuhr, 1992). Findings have verified that both internalizing and externalizing problem behaviors are negatively linked to youths' school performance (DeBaryshe, Patterson, \& Capaldi, 1993; Masten et al., 1995; Rapport, Denney, Chung, \& Hustace, 2001; Rousseau, Drapeau, \& Corin, 1996).

Youths' problem behaviors could be influenced by teachers' negative comments and attitudes. If a youth is often labeled as a problem youth by teachers, a negative identity may be formed into the mindset of the youth. In turn, the youth's negative identity could increase his or her external problem behaviors (Ray \& Downs, 1986). 
However, empirical studies are needed to support the theoretical link between teachers' negative comments and attitudes and youths' problem behaviors.

Taken together, these findings suggest that teachers could communicate negative attitudes and perceptions toward youth in foster care and special education, including stigmatizing features that could convey negative attitudes or perceptions to others. Furthermore, teachers' negative attitudes and perceptions could impair youths' attitudes toward school and increase youths' problem behaviors. In turn, youths' negative school attitudes and problem behaviors could lead to poor academic performance and ultimately inhibit their transition to adulthood.

\section{Purpose of Dissertation}

To further explore these associations, this dissertation study investigated the extent to which teachers' negative comments are reflected in IEP documents, and examined the potential influence of teachers' negative comments on youths' school performance, both directly and through mediation by youths' school attitudes, and problem behaviors.

\section{Importance to Social Work and Education}

Special education is an important means of preparing youth in foster care with disabilities to successfully transition into adulthood. Helping these youth receive an appropriate education tailored to their needs is directly connected to social work's values of social justice, empowerment, and equality. Within a school context, the role of school staff, including social workers, is to assist youth in foster care and special education and to help staff and foster parents address various family and educational issues that affect

the school performance of these youths. In particular, school staff play important roles in 
planning and implementing Individualized Education Plans (IEP) of youth in foster care and special education.

The study was designed to yield findings that social workers and other school personnel could use to improve practices for youth in foster care and special education, including useful information related to structuring IEP documents and factors that affect youths' school behaviors, attitudes and performance. It was hoped that the findings could inform training of school personnel in providing improved services for youth in foster care and special education, and in assisting staff to examine and recognize misconceptions they could have about these youth.

The study was designed to advance research knowledge related to teachers' comments in IEP documents, and the relationship between teachers' negative and stigmatizing comments and other factors that could affect youths' school performance, such as their problem behaviors and school attitudes. Most specifically, the study was designed to examine the mediating influence of students' school attitudes and problem behaviors on the relationship between teachers' negative comments and the academic performance of youth in foster care and special education. Knowledge gained related to the impact of teachers' negative comments on the attitudes, behaviors, and school performance of youth in foster care and special education also could be important for advancing empirical and theoretical understanding of the impact of these factors on marginalized youth overall. 
Chapter 2: Literature Review

The literature that guided the dissertation study was drawn from theories and research relating to stigma, school attitudes, problem behavior, and school performance. The review provides the foundation for understanding the impact of teachers' negative comments reflecting their stigmatizing attitudes, beliefs, and low expectations on the school attitudes, problem behaviors and academic performance of youth in foster care and special education. The chapter begins by discussing definitions of stigma.

\section{Definitions of Stigma}

Traditional definitions of stigma focus on labels that identify a person for blame and condemnation. When a person is stigmatized by others, he or she is socially devalued and avoided (Crocker, 1999). In the book "Stigma: Notes on the Management of Spoiled Identity," Goffman (1963) referred to stigma as "an attribute that is deeply discrediting" (p. 3), and emphasized "the situation of the individual who is disqualified from full social acceptance" (p. 9). This attribute is a physical characteristic or behavioral abnormality that deviates from what is accepted as normal to others in society (Goffman, 1963; Schur, 1971).

Since Goffman, a variety of alternatives or modified definitions of stigma have appeared. For example, Stafford and Scott (1986) indicated stigma "is a characteristic of persons that is contrary to a norm of a social unit" (p. 80). Crocker, Major, and Steele (1998) defined stigmatized individuals as people who "possess (or are believed to possess) some attribute, or characteristic, that conveys a social identity that is devalued $\mathrm{n}$ a particular social context" (p.505). However, these definitions of stigma have been challenged by some social scientists, in particular those who have investigated stigma 
from the point of view of persons who are stigmatized (Fine \& Asch, 1988; Sayce, 1998; Schneider, 1988). Other scientists criticized these definitions of stigma for being so adhered to scientific theories and research techniques that they could not incorporate the lived experience of the people who are stigmatized (Link \& Phelan, 2001; Schneider, 1988).

Recent definitions of stigma incorporate a variety of aspects of stigma such as labeling, stereotypes, prejudice, or discrimination that contribute to understanding what defines a stigmatized group in a society that has uniform social norms, context, cultural beliefs, cognition and values. For example, Dovidio, Major, and Crocker (2000) defined stigma as "a social construction including two fundamental components; "the recognition of difference based on some distinguishing characteristic, or 'mark', and a consequent devaluation of the person" (p. 3). Leary and Schreindorfer (1998) described stigma as "a shared characteristic of a category of people that becomes consensually regarded as a basis for disassociating from (that is, avoiding, excluding, ostracizing, or otherwise minimizing interaction) individuals who are perceived to be members of that category" ( $\mathrm{p}$. $15)$.

Link \& Phelan (2001) suggested labeling, stereotyping, separation, status loss, and discrimination as the elements of stigma. First, labeling is used to give salience to the differences. In the context of disability, for example, an individual can receive the recognition that a characteristic such as disability is unusual in comparison to a norm that has social significance (Green, Davis, Karshmer, Marsh, \& Straight, 2005). Second, stereotyping is an aspect of stigma that attributes perceived differences to undesirable characteristics. For example, people who are labeled as mental patients are often linked 
with a stereotyped belief that people with mental illness are dangerous, so they ought to be segregated from society (Link \& Phelan, 2001). The third factor defining stigma, separation, is to place the labeled people into different categories to distinguish "us" from "them" (Link \& Phelan, 2001). According to Estroff (1989), for example, when individuals refer to a person as "schizophrenic", they are not describing the person as having schizophrenia, but indicating that the person is a schizophrenic itself. This language reflects that the people labeled as schizophrenic are fundamentally different from "us". Fourth, individuals experience a status loss and discrimination when they are interrupted or disadvantaged in community. People who lose status experience an enacted stigma when they are discriminated against because of their labeled differences.

According to Link \& Phelan (2001), stigma can be directly enacted upon when there is a power differential between those with the undesirable characteristic and those without it.

\section{Theories Related to Stigmatization}

Two theories were selected to enrich our understanding of how teachers' negative comments reflecting stigmatizing attitudes could influence youth' school attitudes, problem behaviors and academic performance.

Labeling theory. One explanation for stigma comes from labeling theory, which is drawn from the symbolic interactionist perspective, and is the most promising approach to explain how social groups define deviant behaviors and impose deviant labels onto other groups. According to Becker (1963), who provided the most influential formulation of labeling theory, "Social groups create deviance by making the rules whose infraction constitutes deviance and by applying those rules to particular people and labeling them as outsiders." (p. 9) In general, according to labeling theorists, social 
groups have considered their own definitions of deviance as absolute and undebatable and have reflected these definitions of deviance into the legal system. Labeling theory emphasizes a power inequality between those who impose labels and those who are labeled. Labeling theorists also emphasize social control process, showing how judgments given by social control were related to offenders' characteristics including class and ethnicity rather than the nature of violating behaviors (Plummer, 2001; Ritzer, 2005). For example, in education settings, a teacher may more negatively label a youth who is living in a high crime neighborhood for his or her problem behaviors than another youth in low crime neighborhoods for the same problem behaviors.

However, labeling theory has been criticized that it cannot provide any explanation about the initial motivations towards deviance (Ritzer, 2005). Labeling theory also is criticized for not being easily testable or, if tested, providing insufficient empirical evidence about its arguments (Ritzer, 2005). Finally, other sociologists criticize labeling theory for being overly sympathetic to deviants, justifying violating behaviors. Despite these critiques, labeling theory contributes to opening up the field of inquiry about socially marginalized people who are stigmatized or neglected in a society, including people with disabilities (Plummer, 2001).

Influence of stigma. Labeling theory suggests stigma has a powerful influence on an individual's future deviant behavior. Lemert (1951) explained the influence of stigma with the concepts of primary deviance and secondary deviance. Primary deviance such as criminal or illegal behavior is initially labeled deviant by others in society. Secondary deviance happens when people who are labeled are differently treated with prejudice and restrictions, and consequently transforms their behaviors to be consistent with the 
negative label. Lemert (1951) suggested a strong internal process concerning her or his self-identity, which leads to justification for the deviant behavior: "I do these things because I am this way." (p. 75).

The labeled person also feels isolated from non-labeled groups in society, which can strengthen his or her deviance (Lemert, 1951). Lemert noted, "When a person begins to employ his deviant behavior or a role based on it as a means of defense, attack, or adjustment to the overt and covert problems created by the consequent societal reaction to him, his deviation is secondary" (Lemert, 1951, p 75-76). Moreover, the stigmatized person experience social exclusion, which may lead to entering a subculture (e.g., gang), which, in turn, leads to more exclusion from people that are considered normal (Burnberg, Krohn, \& Rivera, 2006; Leary \& Schreindorfer, 1998). Therefore, labeling theory indicates that negative societal reactions will further reinforce deviant behaviors (Burnberg et al., 2006).

Labeling theory and teachers' negative attitudes toward youth in foster care and special education. In educational settings, teachers play a role in imposing labels on youths. Teachers may negatively label students based on students' characteristics including disability and ethnicity (Alioa, Maxwell, \& Alioa, 1981; Alioa \& MacMillan, 1983; Center \& Ward, 1987; Rolison \& Medway, 1985). In particular, teachers can have negative perceptions and lower expectations for youths with disabilities (Alioa \& MacMillan, 1983; Center \& Ward, 1987). Teachers differently label students with disabilities depending on the severity and kind of disability. For example, teachers were more likely to positively label students with physical disability, compared to those with 
learning disability and mental disability (Parish, Eads, Reece, \& Piscitello, 1977; Rolison \& Medway, 1985).

Teachers also label students based on their initial impression of the students' attractiveness and academic and behavioral potential (Ferguson, 2003; Good, 1987; Good \& Brophy, 1974), prior experiences, or biased information obtained indirectly from other teachers or school documents (Babad \& Inbar, 1981; Babad, Inbar, \& Rosenthal, 1982; Good, 1987; Graham, 1991; Kelley \& Michaela, 1980).

Based on labeling theory and related research findings, youth in foster care and special education who have more behavioral and emotional problems, and poorer school performance, may be more vulnerable to teachers' stigmatization, compared to youth not in foster care and special education. A teacher may impose overtly or covertly a negative label on a youth in foster care and special education as a low-achieved student or a problem student based on his or her initial impression of the youth' school performance or behaviors, prejudices toward students with disabilities, or biased information obtained from other teachers or written documents. Teachers also may not consider certain personal motives or environmental causes of poor school performance, and emotional and behavioral problems of the youth (Lemert, 1951).

As labeling theory suggests, stigma which is overtly or covertly conveyed by teachers, could negatively influence self-identity and behaviors of youth in foster care and special education (Lemert, 1951). A youth who is labeled as a problem student could perceive the negative label through teachers' negative comments or discriminative behaviors, and then could internalize the perceived negative label. Furthermore, a teacher's stigmatization may influence other teachers' and youths' perceptions and 
attitudes toward youth in foster care and special education. For example, youth in foster care and special education may recognize teachers' negative perceptions and stigmatizing attitudes when they hear first-hand negative statements in the IEP meetings. The youth also can be stigmatized by other IEP members who may have not had direct contact with the youth but have indirectly obtained negative information about the youth in the IEP meeting.

As a result, the youth who is stigmatized could strengthen or justify her or his deviant behaviors as a means of defense or adjustment in response to teachers' and peers' negative attitudes or comments, which, in turn, may lead to social exclusion. Thus, labeling theory enhances our understanding of how teacher' negative stigmatization of youth in foster care and special education could influence youth's behaviors, attitudes and, ultimately, their school performance.

Attribution theory. Attribution theory provides a second useful framework for understanding teachers' attitudes and responses toward youth in foster care and special education.

Attributions include a three-dimensional taxonomy: locus of causality, controllability, and stability (Weiner, 1985). According to attribution theory (Weiner, 1985), the analysis of the causality begins with an internal-external locus of causes. For example, causes of a youth's poor school performance can be perceived as internal if they are rooted in something about the youth such as traits, lack of will or efforts for better performance, while causes can be perceived as external if they are rooted in something outside the youths such as conflicts with family members, and harmful educational circumstances. 
The second dimension of attribution is stability, which refers to causes either perceived to be constant or more variable, changing from moment to moment or from period to period (Weiner, 1985). With regard to causes of a youth's poor school performance, among internal causes, ability is considered as stable or constant capacity; in contrast, other causes including effort, laziness, or hard work is considered as unstable. Among the external causes, a youth's poor school performance can be perceived as due to task difficulty (stable) or conflicts with parents (unstable).

Finally, the controllability dimension refers to causes either controllable or uncontrollable (Weiner, 1985). With regard to causes of a youth's poor school performance, for example, both effort and fatigue are internal and unstable causes. However, while effort can be perceived as controllable, fatigue can be considered as uncontrollable.

Some empirical studies reveal teachers and peers' negative attributions about youths with disabilities (Walker, Coleman, Lee, Squire, \& Friesen, 2008; Woolfson, Grant, \& Campbell, 2007). For example, Walker and her colleagues (2008) examined youths' stigmatizing attitudes toward peers with mental health problems in a national sample of 1,318 children age 8 to 18 , and found that the youth were more likely to express negative attributions toward peers with depression and attentiondeficit/hyperactivity disorder (ADHD) than those with asthma, with regard to likelihood of antisocial behavior and violence. Woolfson and her colleagues (2007) conducted a cross-sectional study to examine teachers' attributions for youths' difficulties in learning, and compared three groups of teachers including 39 general mainstream class teachers, 35 mainstream learning support teachers, and 25 special school teachers. Compared to 
special school teachers, teachers working in the mainstream settings were more likely to perceive youth who needed specific support as having less control over their school performance.

Causal attribution is associated with specific emotions and behavioral responses following either positive or negative outcomes, as presented in Table 1. According to Reyna (2000), stereotypes, as a type of stigma, can convey one of three patterns; 1) internal / stable / controllable by the stigmatized person, 2) internal/stable/uncontrollable by the stigmatized person, and 3) external / stable / uncontrollable by the stigmatized person.

These attributional patterns could give important cues for understanding the nature of teachers' negative comments toward youth in foster care and special education as well as the effects of their negative comments on the youth's beliefs toward school and school works, problem behaviors, and school performance.

First, stereotypes that communicate internal, stable, and controllable attributional causes lead to a variety of consequences. For example, a teacher who considers the poor academic outcomes of a youth in foster care and special education to be the result of lack of effort would convey internal, stable, and controllable causes. If the youth's outcomes are positive, these attributions would lead to positive emotional and behavioral reactions from both the teacher and the youth. The teacher would trust the youth and give more rewards and opportunities to the youth, and the youth would have pride and beliefs in his or her competence, and exhibit motivation for school work. On the other hand, if the youth's outcomes are negative, these causes would result in the teacher's negative attitudes are conveyed through written statements, verbal or physical behaviors, the youth 
Table 1.

The Types of Attributions Communicated through Stereotype, and the Consequences.

\begin{tabular}{|c|c|c|}
\hline Attribution & Emotional/Beliefs & Behaviors \\
\hline Internal/Stable/ & If outcome is Negative: & If outcome is Negative: \\
\hline \multirow[t]{7}{*}{ Controllable } & Anger (Social); & Punishment, Denial of help (Social); \\
\hline & Guilt (Self) & Short-term motivation, long-term \\
\hline & & frustration and withdrawal from task (Self) \\
\hline & If outcome is Positive: & If outcome is Positive: \\
\hline & Positive affect: trust, beliefs in competence & Rewards, access to resources (Social); \\
\hline & (Social); & Increased motivation and valuing of the \\
\hline & Pride, beliefs in competence (Self) & task (Self) \\
\hline Internal/Stable/ & If outcome is Negative: & If outcome is Negative: \\
\hline \multirow[t]{7}{*}{ Uncontrollable } & Pity, sympathy (Social); & Short-term assistance, long-term denial of \\
\hline & Shame, embarrassment, lowered self- & scarce resources (Social); \\
\hline & esteem (Self) & Lowered confidence and beliefs in \\
\hline & & mastery, withdrawal from the task (Self) \\
\hline & If outcome is Positive: & If outcome is Positive: \\
\hline & Trust, beliefs in competence (Social); & Rewards, access to resources (Social); \\
\hline & Pride, beliefs in competence (Self) & Motivation, value of the task (Self) \\
\hline External/Stable/ & If outcome is Negative: & If outcome is Negative: \\
\hline \multirow[t]{6}{*}{ Uncontrollable } & Sympathy, no anger (Social); & Mitigating factors, person avoids blame, \\
\hline & Self-esteem is salvaged, anger toward & and receives support (Social); \\
\hline & environment (Self) & Blame environmental factors (Self) \\
\hline & If outcome is Positive: & If outcome is Positive: \\
\hline & Person doesn't get credit (Social); & No particular social consequence; \\
\hline & Trust environment as benevolent (Self) & Trust environment as benevolent (Self) \\
\hline
\end{tabular}


could be become frustrated, exhibit problem behavior which may reinforce the earlier attributions of the teacher, express negative attitudes toward the teacher and school, show poor motivation for school work and, in turn, have poor academic performance.

Second, teachers' stereotypes including internal, stable, and uncontrollable cause attributions lead to a different set of emotional and behavioral consequences. For example, if a teacher considers the poor academic outcomes of a youth in foster care and special education to be the result of disability or lack of academic ability, the stereotype would communicate internal, stable, and uncontrollable causes. If the youth's outcomes are positive, both the teacher and the youth would have positive emotional and behavioral consequences. In contrast, if the youth's outcomes are negative, these causes would elicit the teacher's pity, sympathy and short-term assistance. However, the teacher may be reluctant to provide continuous assistance and opportunities because the teacher may have a stigmatizing attitude that the youth's ability that is inalterable. When these negative attitudes are communicated through written statements, verbal or physical behaviors, the youth would have feelings of shame and lower self-esteem, exhibit negative attitudes toward school and teachers, exhibit problem behaviors, and, in turn, have poor school performance.

Finally, stereotypes can communicate external, stable, and uncontrollable attributions. For example, if a teacher considers the poor academic outcomes of a youth in foster care and special education to be the result of environment factors such as living conditions in foster care, the stereotype would communicate external, stable and uncontrollable causes. If the youth's outcomes are positive, the teacher would be more likely to trust environmental factors, including foster care services, than the youth's 
efforts. The youth would have positive beliefs and behaviors toward the environment. On the other hand, if the youth's outcomes are negative, these causes would lead to the teacher's sympathy and assistance, however the youth could exhibit anger, blame toward the environment and poor motivation for school work. In turn, the youth would be more likely to have poor school performance.

Another important issue related to stigma is the difference between actors and observers in the accuracy of their attribution. Jones \& Nisbett (1972) noted as follows: "there is a pervasive tendency for actors to attribute their actions to situational requirements, whereas observers tend to attribute the same actions to stable personal disposition" (p. 80). In educational settings, youths are more likely to depend on responsive attribution to situational or environmental cues, whereas teachers are more likely to attribute youths' actions to dispositions such as ability, traits, and attitudes. Several studies have indicated that observers cannot understand exactly actors' behaviors in particular situations because observers cannot know actually and sufficiently actors' psychological, social, and environmental situations (Jones \& Nisbett, 1972; Lay, Ziegler, Hershfield, \& Miller, 1974). Most importantly, attributing actors' dispositions including personality traits often leads to observers' biased judgments. Jones \& Nisbett (1972) indicated that "the widespread belief in their existence appears to be due to the observer's failure to realize that the samples of behavior that he sees are not random, as well as to the observer's tendency to see behavior as a manifestation of the actor rather a response to situational cues" (p. 93).

Applied to special educational settings for youth in foster care and special education, teachers often may fail to understand the behaviors of these youth as 
situational cues. For example, some teachers do not understand that a foster youth in special education may not do homework because there is not a quiet place to study in the foster home rather than because the youth does not want to do homework. This biased judgment could be conveyed to the youth through teachers' written statements, verbal or physical behaviors, and be internalized in the youth's mind. In turn, the youth would be more likely to be frustrated, have lower self-esteem, exhibit negative attitudes toward school and teachers, and problem behaviors in the classroom, and ultimately exhibit poor school performance.

Integration of labeling and attribution theory. Labeling and attribution theories provide useful explanations for teachers' negative attitudes and low expectations, which may influence the academic performance of youth in foster care and special education. However, there is little research that attempts to integrate two theories, even though they both address the question of "How do individuals or groups stigmatize others and themselves?" (Howard \& Levinson, 1985). Attribution theory focuses on stigmatization through the cognitive processes of individuals with little or no attention to their societal identities, while labeling theory derives from a symbolic interactionist tradition and was developed within the sociological field of deviance. Attribution theory has been criticized for overlooking the importance of dynamic interpersonal interaction, the social context in which behavior occurs, and the consequences of the judgment process (Kidd \& Amabile, 1981), while labeling theory has been criticized for lack of specific evidence (Ritzer, 2005).

Therefore, the integration of these two theories most likely provides the most complete theoretical explanation for the process of stigmatization. Attribution theory 
explains that certain negative traits, characteristics, or behaviors can stigmatize a person to whom they are attributed, and labeling theory, in turn, emphasizes the importance of context (Schlosberg, 2002).

In line with this theoretical formulation, the following section describes research findings pertinent to pubic and self-stigma, and the associations among teacher's negative comments and youth's school performance, attitudes toward school, and problem behavior. These research findings further inform our understanding of the potential associations of these variables with one another as well as with teachers' negative comments.

\section{Review of Research Literature}

Exposure to public stigma and self-stigma. Corrigan, 2004 and Corrigan \& Watson, 2000, has considered two types of stigma that could inform understanding of the impact of stigma on youth in foster care and special education; public stigma and selfstigma. Public stigma means the reaction of the general public toward individuals with certain labels. Public stigma is primarily transmitted through negative comments or expressions from the public in a society such as peers, family, teacher, caregivers, and medical personnel (Martz, 2004). Researchers have documented that the public has negative attitudes toward people with mental illness (Ben-Porath, 2002; Crisp, Gelder, Rix, Meltzer, \& Rowland, 2000), and perceives them as dangerous (Link, Cullen, Frank, \& Wozniak, 1987). For example, Ben-Porath (2002) conducted a cross-sectional study with 380 undergraduate students to investigate the nature and extent of stigmatization attached to people who seek outpatient psychotherapy for depression. He found that people who needed assistance for depression were considered as less confident than those 
who did not seek assistance for depression, $F(1,376)=6.56, \mathrm{p}<.02$. Link and his colleagues (1987), conducting a longitudinal study involving 152 people living in the Cincinnati area to investigate the labeling effects of "previous hospitalization" toward people with mental illness on their social rejection. They found that people with mental illness who were labeled with "previous hospitalization" were more likely to experience social distance from people who perceived people with mental illness to be dangerous ( $\beta$ $=.338, \mathrm{p}<.003)$.

Previous studies also indicate that people with stigmatizing attitudes have a tendency to withhold help from people with disabilities and to avoid social interaction with them (Corrigan \& Watson, 2002; Weiner, Perry, \& Magnusson, 1988). For example, in the 1996 General Social Survey (GSS) with 1,444 adults in the United States, a significant percentage of respondents expressed unwillingness to interact with people who had either schizophrenia (48.4\%) or depression (37.4\%). A majority of respondents (68.4\%) answered that they were unwilling to accept these people as either a family member $(68.4 \%)$ or coworkers (58.1\%) (Martin, Pescosolido, \& Tuch, 2000).

Research findings indicate that schools are not necessarily safe spaces from public stigma toward students with disabilities. Studies have found that teachers express negative attitudes and low expectations toward students with disabilities (Campbell, Gilmore, \& Cuskelly, 2003; Center \& Ward, 1987; Rolison \& Medway, 1985). For example, Rolison \& Medway (1985), in a cross-sectional study with 180 elementary teachers, found that teachers were more likely to underestimate the intellectual ability of students who were labeled with educable mentally retardation (EMR) than those who were not labeled, $\chi^{2}(6)=38.98, \mathrm{p}<.001$, and that teachers had lower expectations for the 
academic performance of students who labeled with EMR than those who were not labeled, $\mathrm{F}(2,162)=3.50, \mathrm{p}<.05$.

Researchers have documented that teachers may hold negative attitudes toward students with special needs (Center \& Ward, 1987; Weisel \& Tur-Kaspa, 2002). For example, Weisel and Tur-Kaspa (2002) conducted a longitudinal study with 36 teachers who had contact with low-achieving students attending special classes and 36 teachers who had no contact with these students. They found that teachers who had no contact with low-achieving students were more likely to express positive cognitions, $t(35)=2.40$, $\mathrm{p}<.05$, behavior, $\mathrm{t}(35)=2.47, \mathrm{p}<.05$, and emotions, $\mathrm{t}(35)=2.28, \mathrm{p}<.05$ toward students in special classes than those who had contact with these students.

In contrast to public stigma, self-stigma is the perception that individuals possess, viewing themselves as socially undesirable (Corrigan \& Watson, 2002; Ritsher \& Phelan, 2004; Vogel, Wade, \& Hackler, 2007). It means that people who are stigmatized internalize the devalued, negative image, and stereotypes that are widespread in the society or culture (Crocker et al., 1998; Steele, 1997). When negative images toward labeled people are internalized, they perceive themselves as inferior, inadequate or worthless (Corrigan, 2004; Nadler \& Fisher, 1986), blame or loath themselves and exhibit feeling of social isolation, withdrawal, and meaninglessness (Martz, 2004).

Some empirical studies have shown that the internalization of one's devaluation by stigmatization leads to low self-esteem, (Corrigan, Watson, \& Barr, 2006; Crocker, 1999), low self-efficacy (Corrigan et al., 2006), impaired social adaptation, alienation and withdrawal (Ritsher \& Phelan, 2004). For example, Ritsher and Phelan (2004) conducted a longitudinal study to examine the prevalence of self- stigma with 82 outpatients with 
severe mental illness (SMI) at baseline and 53 outpatients with SMI at follow-up 4 months later, using the Internalized Stigma of Mental Illness (ISMI) scale which is consists of five subscales including Alienation, Stereotype Endorsement, Discrimination Experience, Social Withdrawal, and Stigma Resistance. The findings indicated that 28 percent of participants at baseline, and 34 percent of participants at follow-up reported high levels of internalized stigma, defined as having an mean score above the midpoint of the possible range (2.5 on a 1-4 range) (Ritscher \& Phelan, 2004). Subscale changes were greater for Alienation (28 percent at baseline and 34 percent at follow-up) and Stereotype Endorsement (15 percent at baseline and 28 percent at follow-up). The percentage of participants reporting Stigma-Resistance decreased over time (29 percent at baseline and 24 percent at follow-up).

Stigma related to gender, race, and ethnicity. Several studies have examined stigma related to race and ethnicity, revealing that teachers are less likely to perceive African American students favorably on such measures as trait, personality and behavior, motivation to learn, school performance, and school adjustment, and they have lower academic expectations for African American students, compared to Caucasian students (Keller, 1986; Murray, 1996; Pigott \& Cowen, 2000; Plewis, 1997). In contrast to negative stigma associated with African American students, Asian American students have been shown to be perceived as hardworking and respectful to teachers and to have superior academic abilities, especially in mathematics and science (Kitano \& Sue, 1973). However, other studies have indicated that teachers are more likely to perceive Asian American as unassertive, unexpressive, and lacking in leadership skills (Bannai \& Cohen, 
1985), as more passive, quieter, and less interpersonally effective (Schneider \& Lee, 1990), and as over-controlled (Chang \& Sue, 2003), compared to Caucasian students.

Studies on stigma related to gender differences have found that males were more likely to be perceived as aggressive, assertive, and violent than females (Eagly \& Steffen, 1986; Hudley et al., 2001), and females were perceived as higher than males in extraversion, anxiety, sadness and tender-mindedness (Fischer, 1993; Frijda, Kuipers \& ter Schure, 1989; Oliver \& Toner, 1990). These findings suggest that race/ethnicity and gender influences are important to examine in stigma research.

Expression of negative attitudes through written comments. While most descriptions of public and self-stigma focus on verbal or physical behaviors, negative attitudes also could be transmitted through written statements. Within educational settings, youth could be labeled through diagnostic documents including information related to gender, behavior, family history, disability, environmental barriers, and services received. In turn, teachers may respond to youths' behaviors with biased attitudes based on the content of the documents (Babad \& Inbar, 1981; Kagan \& Tippins, 1991; Kedar-Voibodas, \& Tannenbaum, 1979). For example, Kagan and Tippins (1991) reviewed 94 students profiles written by five elementary teachers and seven secondary student teachers, and coded them for students and teachers' characteristics. The findings showed that 77 percent of profiles written by the elementary teachers, and 76 percent of profiles written by the secondary student teachers, included teachers' negative comments about students' behaviors, school performance, academic motivation, and personality. Elementary teachers were twice as likely to describe their students' behaviors, school performance, school motivation, and personality with psychological (cause-effect) 
reasoning, particularly describing their intervention efforts and success, compared to the secondary teachers. In contrast, the secondary teachers were six times more likely to describe students' characteristics with paradoxical statements. Another study by Babad and Inbar (1981) found that highly biased teachers were approximately two and half times more likely to make more dogmatic and value-laden statements than unbiased teachers in responding to a series of educational events involving students. Highly biased teachers also were more likely to describe students' behaviors in classrooms as being pessimistic, autocratic, distant, impulsive, and less trusting.

Preliminary research on teachers' negative written comments. Noh and his colleagues (2013) conducted a pilot study that was the first research to specifically examine teachers' negative written comments toward youth in foster care and special education. This pilot study examined the IEP documents of 53 youth in foster care and special education who participated in a project called Making a Life, the purpose of which was to evaluate the efficacy of a multi-component intervention designed to enhance youth's self-determination on the transition outcomes of youth in foster care and special education (Powers et al., 2012).

The IEPs of participants were reviewed and coded for negative comments using the School Archival Records Search (SARS; Walker, Block-Pedego, Todis, \& Severson, 1991). SARS offers a uniform system for obtaining information about youth's school experiences from school records including school attendance, achievement, retention, inschool and outside referrals for academic or disciplinary causes, placements outside the regular classroom or for special services, and negative narrative comments (Walker et al., 1991). Among the information, negative comments include teachers' written statements 
that describe problem related to a youth's performance and the necessity of special services for those problems. Negative behaviors identified by the SARS are categorized as externalizing or internalizing behaviors. The SARS provides behavioral indicators for identifying externalizing and internalizing behaviors, which are consist of nine indicators for externalizing behaviors and eight indicators for internalizing behaviors. Based on these behavioral indicators, four sub-categories of behaviors were created, including externalizing disruptive behaviors and rule-breaking behaviors, and internalizing problem behaviors and interpersonal relationship behaviors.

The IEPs of approximately 59 percent $(n=32)$ of the 53 youths included negative comments; 143 negative comments were identified, averaging 2.6 negative comments per youth. 58 percent $(n=83)$ of the negative comments referred to externalizing behaviors and 42 percent $(n=60)$ of the comments referred to internalizing behaviors.

Among 83 negative comments describing externalizing behaviors, approximately 41 percent $(n=67)$ included comments about youths' disruptive behavior and approximately 12 percent $(n=20)$ referred to rule-breaking behaviors that were related to school-imposed rules, such as attending class and finishing assignments. Among 60 negative comments described internalizing behaviors, approximately 22 percent $(n=35)$ referenced internal problem behaviors, such as being excessively shy and timid, and approximately 25 percent $(n=40)$ included comments referring to youths' inabilities to build or maintain satisfactory interpersonal relationships with peers and teachers and their difficulties in communicating with peers and teachers.

These findings offered important implications about teachers' stigmatizing attitudes toward youth in foster care and special education. First, some of the negative 
comments appeared to reflect teachers' judgments, subjective opinions, or biased reports noted from other teachers. For example, "She was known to level insults, direct profanity and kick and push items out of her way," and, "She was reported to be easily distracted by other youths and not to pay attention to explanations given in class."

Second, teachers failed to understand these behaviors of youth in foster care and special education as situational cues. For example, some teachers do not understand that a foster youth in special education may not do homework because there is not a quiet place to study in the foster home rather than because the youth does not want to do homework. Teachers also do not consider that a youth often may not prepare materials for classes if these youth cannot receive appropriate cares or advocates from foster parent.

Some teachers' negative statements reflected a lack of understanding about how a specific educational setting or living condition of the youth, and a variety of interactions with teachers or family members could affect a youth's behaviors and school performance.

Even though references to causes of internal problem behaviors were noted, some teachers' comments did not link the references to youth's specific internal behaviors. For example, when describing how a youth lost motivation to perform well in class, a teacher noted that the youth was abandoned by his mother, placed with his grandmother and rejected, and then returned to foster care. Nevertheless, the teacher concluded that "He needs to stop brooding and get on with his life."

Finally, there also were teachers' descriptions about youths' behaviors and poor school performance without reference to action plans to attempt to solve the problems. For example, a teacher noted the deterioration of a male youth's behavior after a winter break. "Since winter break, he has earned on the TLC Daily Point sheet have 
significantly lessened, the occurrences or time working outside of TLC for arguing have increased, and he has one suspension for smoking on school ground." However, there no exists the descriptions about the plan for reducing these problem behaviors.

In sum, the findings from this pilot study indicate that teachers' negative comments reflect a variety of patterns of stigmatizing attitudes toward youth in foster care and special education rather than merely objectively describing youths' negative behaviors.

Considered overall, the above mentioned research related to exposure to public stigma and self-stigma could have important implications for teachers' negative comments toward youth in foster care and special education as the findings indicate that youth who have disabilities or special needs are likely to be exposed to negative expressions including verbal, or written statements from peers, family, teacher, or caregivers, and then they are likely to internalize this stigmatization. Unfortunately, outside of the Noh et al pilot study, research has not been conducted to specifically investigate teachers' negative comments toward youth in special education and foster care. However, the emergent findings suggest that these youth may be at high risk for public and self-stigma, and further research is warranted.

Impact of teachers' negative attitudes on youths' school performance. It has long been known that teachers express negative and stigmatizing attitudes toward youth diversity and heterogeneity (Alioa \& MacMillan, 1983; Alioa et al., 1981; Buell, Hallam, Gamel-McCormick \& Scheer, 1999; Campbell et al., 2003; Center \& Ward, 1987; Rolison \& Medway, 1985). For example, Alioa and MacMillan (1983), in a longitudinal study with 1,114 regular-classroom elementary school teachers, found that teachers often 
labeled youths with disabilities as having low intellectual capacities and higher potential for problem behavior, based on initial impressions of the youths.

Studies also suggest that teachers predict youths' future performance from their initial impression of the youths' attractiveness and academic and behavioral potential (Good \& Brophy, 1974; Ferguson, 2003; Good, 1987; Hoge \& Butcher, 1984). For example, Good \& Brophy (1974) noted that first-grade teachers believed they could accurately predict youths' rank order on the first exam of second grade within the first few weeks of school. Teachers often infer the cause of negative outcomes of youths based on prior experiences or observations (Babad, Beriberi, \& Rosenthal, 1989; Babad \& Inbar, 1981; Babad et al., 1982; Dusek \& Joseph, 1983; Graham, 1991; Kelley \& Michaela, 1980).

Teachers' attitudes, beliefs, and expectations are important factors in youths' academic outcomes (Hastings, Hewes, Lock, \& Witting, 1996; Silva \& Morgado, 2004). Except for one study that documented the positive effect of teachers' perceptions on youths' behavior and schooling (Rosenthal \& Jacobson, 1966), previous studies have found that teachers' negative perceptions were most often associated with youths' negative school performance (Brophy, 1985; Good, 1987; Silva \& Morgado, 2004). Likewise, some empirical studies found that youths who are stigmatized are more likely to have poorer school performance (Brown \& Lee, 2005; Brown \& Pinel, 2003), although these studies are limited by the use of cross-sectional designs. For example, Brown and Lee (2005), in a cross-sectional study with 128 undergraduate youths, found that youths who highly recognized racial and academic stigmatization had lower GPA scores than those with low recognition of stigmatizations. 
There also exists empirical support for the effect of teachers' low expectation and bias on youths' school performance (Babad et al., 1989; Babad, 1982;). For example, Babad et al. (1982), in a cross-sectional study with 150 students and 26 physical education teachers, found that biased teachers are more likely to be susceptible to biasing information including parents' level of education, students' ethnic origin, age and gender. The findings of this study also indicate that while non-biased teachers did not discriminate against the students, $F(1,46)=.01, n s(\gamma=.02$, for contrast comparing high and low expectancy groups), high-biased teachers were more likely to behave dogmatically toward the students for whom the teachers had low expectations, $F(1,46)=$ $59.08, p<.001$ ( $\gamma=.85$, for contrast comparing high and low expectancy groups). In this study, the students for whom high-biased teachers had lower expectations and behaved more dogmatically, showed lower performance in classes than those for whom highbiased teachers had higher expectations and behaved less dogmatically, $F(1,48)=24.00$, $p<.001(\gamma=.71)$.

In another study with a correlational design, Babad et al. (1989) found a .85 Pearson correlation coefficients between high-bias teachers and the academic achievements of the students toward whom the teachers exhibited bias. These findings could have important implications for the academic performance of youth in foster care and special education as they suggest that biased teachers may be particularly sensitive to students for whom they have low expectations. Unfortunately, empirical studies have not been conducted longitudinal designs to investigate teachers' negative and stigmatizing attitudes and bias toward youths, especially youth in foster care and special education, and to examine the effects of teachers' negative and stigmatizing attitudes and bias on 
youths' school performance over time. In particular, further research is needed to investigate the direction of the associations between teachers' negative attitudes and youths' school performance, isolating whether youths' poor school performance is more likely to precede or follow teachers' negative attitudes.

Impact of teachers' negative attitudes on youths' school attitudes. Teachers' negative comments may influence youths' attitudes toward school and school work. When teachers criticize youths for poor performance and they attribute the poor outcomes to youths' abilities, youths may exhibit poor effort, poor attitudes, and low motivation toward their school work. Unfortunately, there is little direct evidence about the effect of teachers' stigmatizing attitudes on youths' attitudes toward school and school activities. Some studies related to the effect of teachers' criticizing feedbacks on youths' attitudes toward school offer important findings related to the potential influences of teachers' negative and stigmatizing and biased attitudes on youths' attitudes toward school (Dweck et al., 1978; Montague \& Rinaldi, 2001; Simonson \& Strein, 1997). For example, Montague and Rinaldi (2001) conducted a longitudinal study to investigate the effect of teachers' response toward academic performance and behaviors of children at risk for developing learning, emotionally, and behavioral disorders (LD/EBD) on children's school engagement and perceptions about teachers' expectation. Beginning with 32 elementary students with learning, emotionally, and behavioral disorders (LD/EBD) at baseline (Study 1), 20 students were followed up three years later (Study 2). The findings from Study 1 showed that students at risk for developing LD and EBD were more likely to receive negative feedbacks about their behaviors, $F(1,30)=4.92, p<.034$, and were more likely to be reluctant to engage in school activities, $F(1,25)=4.85, p=.037$ than 
those without risk for developing LD and EBD. The findings from Study 2 also showed that students at risk for developing LD and EBD were more likely to be reluctant to engage in school activities, $F(1,18)=11.42, p=.0003$, and were more likely to have negative perceptions about teachers' expectation toward themselves, $F(1,18)=9.51, p$ $<.006$ than those without risk for developing LD and EBD.

Baker (1999) conducted a cross-sectional study to examine the effect of teacherstudents interactions and relationship on school satisfaction with 61 African-American children, who were third through fifth graders living in poor and urban areas. Using a qualitative research design, the teachers' comments about the students' behaviors and academic works were coded into categories including positive and negative comments. The findings showed that the students who reported dissatisfaction about their school were five and half times more likely to receive teachers' negative comments about their behaviors than positive comments, while those with satisfaction about their school were three times more likely to receive teachers' negative comments than positive comments. The findings from self-reports also indicated that the students who were satisfied with their school $(\mathrm{M}=47.48, \mathrm{SD}=6.07)$ were more likely to report supportive interaction with teachers than those who were dissatisfied with their school $(\mathrm{M}=41.06, \mathrm{SD}=6.12 ; \mathrm{t}$ $=4.27, \mathrm{p}<.001)$.

Cooper (1977) conducted a longitudinal study of the relationship between teachers' criticizing feedback including negative comments, and anger and students' motivation for school performance with 104 elementary students. From an initial observation, this study initially found 12 students with 104 negative comments. These students were less likely to be motivated in their school works $(\gamma=-.097)$, but it was not 
statistically significant. This study repeated to observe 4 students who received negative comments and 4 students who were not received negative comments after 6 weeks. During the repeated observation period, these students had not received negative comments and differential treatments from teachers. This follow-up study showed that the partial regression coefficients between the students who received negative comments and the students' motivation toward school work were not statistically significant $(\gamma$ $=.116)$. However, a t-test of the difference between these partial correlation coefficients was significant $($ difference $=.213, \mathrm{t}(42)=1.45$, one tailed $\mathrm{p}<.08)$, indicating the relationship between teachers' negative comments and seeking out behaviors toward school work was changed from the initial observation to the repeated observation. In other words, the results showed that the removal of teachers' negative comments increased youths' motivation toward their school works.

\section{Impact of teachers' negative attitudes on youths' problem behaviors.}

Teachers' negative attitudes may influence youths' problem behaviors including externalizing and internalizing behaviors. Externalizing problem behaviors include aggressive, disruptive, hyperactive, and delinquent behaviors, while internalizing problem behaviors include anxiety, depression, and severe withdraw. Unfortunately, there exist only a few empirical studies that have examined the effects of teachers' negative attitudes on youths' problem behaviors.

A small number of studies have verified the effects of teachers' negative comments on youths' problem behaviors. For example, in a cross-sectional study with 277 students in the midwest, Adams, Robertson, Gray-Ray, and Ray (2003) found that teachers' negative perceptions and expressions toward their students were associated with 
students' problem behaviors ranging from offensive behaviors to serious gang-related activities, with a .19 standardized regression coefficient $(p<.05)$, while parents' negative attitudes were not significantly associated with students' problem behaviors.

Alvidrez and Weinstein (1999), examining secondary data including 110 students participating in a longitudinal study, found that students who were underestimated by teachers were more likely to exhibit inappropriate emotional behaviors, and aggressiveness; to be easily victimized by others, show shyness and reserve; and to be indecisive and vacillating; Pearson correlation coefficients between teachers' early ratings and students behaviors ranged from .21 to .35 after controlling for SES. However, more empirical studies are needed to verify the effects of teachers' negative attitudes including stigmatizing attitudes and bias on youths' problem behaviors including externalizing problem behaviors and internalizing problem behaviors.

Association of youths' school attitudes and school performance. Previous research also has investigated the relationship between youths' school attitudes and performance. Most studies have indicated that youths with negative school attitudes are more likely to show poorer school performance (Diaz, 1998; Mandel \& Marcus, 1988; Marjoribanks, 1992; Reis \& McCoach, 2000), and higher rates of school dropout (BattinPearson et al., 2000; Simon-Morton et al., 1999). For example, Marjoribanks (1992) conducted a cross-sectional study to investigate the achievement scores and school attitudes of 980 students in Australia, and found that male students' affective attitudes toward their school were significantly correlated with their word knowledge $(\gamma=.11)$, word comprehension $(\gamma=.13)$, and mathematics $(\gamma=.16)$. Their cognitive attitudes toward school also were significantly correlated with their word knowledge $(\gamma=.24)$, 
word comprehension $(\gamma=.22)$, and mathematics $(\gamma=.13)$. A significant relationship between affective attitudes toward school and word knowledge $(\gamma=.20)$, word comprehension $(\gamma=.22)$, and mathematics $(\gamma=.11)$ was found for female students.

Battin-Pearson and colleagues (2000), in a longitudinal study using Structural Equation Modeling, found that low commitment and attachment toward school had a direct effect on poor school performance such as GPA, CAT scores, and grades, with a .18 standardized path coefficient $(\mathrm{p}<.001)$, and indirect effect on students' dropout, which was mediated by school performance, with a .10 standardized path coefficient (p <.001). Colangelo, Kerr, Christensen, \& Maxey (1993) conducted a cross-sectional study to examine the characteristics of gifted underachievers and high achievers with 30,604 high school juniors and seniors, and found that underachievers were less likely to be satisfied with class instruction ( $52 \%$ vs. $68 \%$ ), and overall guidance services in their school (44.4\% vs. $51.5 \%)$ than high achievers. Unfortunately, there exists little empirical research that used longitudinal research designs for examining the effects of youths' negative attitudes toward their school and school work on youths' school performance over time.

Overall, previous studies indicate that teachers' negative comments are linked to youths' attitudes toward school and school performance. While previous studies provided evidences of these associations, there exists little empirical evidence about the impact of teachers' negative comments on youths' school performance, controlling for previous school performance, or about the potential mediating effect of youths' attitudes toward school on the association between teachers' negative comments and youths' school performance. 
Association of youths' problem behaviors and school performance. Previously

studies indicate that both internalizing and externalizing problem behaviors are negatively linked to school performance. Child psychopathologists suggest that externalizing problem behaviors including aggressive, disruptive, hyperactive, and delinquent behaviors negatively influence school performance throughout the school years (Bardone, Moffitt, Caspi, Dickson, \& Silva, 1996; Chen, Rubin, \& Li, 1997; Masten et al., 2005). Several previous studies have verified the influence of students' externalizing behaviors on a variety of outcomes of school performance, including reading readiness (Fischer, Barkley, Edelbrock, \& Smallish, 1990; DeBaryshe et al., 1993; Frick, Kamphaus, Lahey, Loeber,\& Tannebaum, 1991; Maughan, Gray, \& Rutter, 1985; Richman, Stevenson, \& Graham, 1982), mathematics (Debaryshe et al., 1993; Frick et al., 1991), GPA (Masten et al., 1995), and school drop-out (Kupersmidt \& Coie, 1990).

With regard to the influence of internalizing problem behaviors on school performance, there exists less empirical evidence than for externalizing behaviors, and the results are not consistent (Coleman, Martin, Powers, \& Truglio, 1996; Masten et al., 1995; Roeser, Eccles, \& Sameroff, 2000). One reason for the inconsistent results is that internalizing behaviors might be less observed by teachers because these behaviors are less disruptive in educational environments (Achenbach, McConaughy, \& Howell, 1987; Kolko, \& Kazdin, 1993; Loeber \& Schmaling, 1985). However, most studies have verified that youths' internalizing behaviors such as anxiety and depression are linked to their academic outcomes (Masten et al., 2005; Mokros, Poznanski, \& Merrick, 1989; Rousseau et al., 1996; Sack, Angell, Kinzie, \& Rath, 1986). For example, Rousseau et al. (1996) using a cross-sectional design with 156 refugee children from Southeast Asia and 
Central America, found that depression, introversion, and somatization were significantly associated with learning difficulties and school performance in areas such as French and mathematics, finding Pearson correlation coefficients ranging from .18 to .22.

Fröjd and colleagues (2008), using a cross-sectional design with 2329 Finnish students between the ages of 13 and 17, examined the relationship between self-reported depression and school performance including changes in GPA from previous term, and perceived loading and difficulties of school works, and found that male students who felt depressed $(\mathrm{M}=7.1, \mathrm{SD}=.91)$ were more likely to have low GPA scores than those who did not report depression $(\mathrm{M}=7.7, \mathrm{SD}=.92, \mathrm{p}<.001)$, and female students who felt depressed $(\mathrm{M}=7.6, \mathrm{SD}=.79)$ were more likely to have low GPA scores than those without depression $(\mathrm{M}=8.0, \mathrm{SD}=.90, \mathrm{p}<.001)$. The findings also showed that male students who reported depression were approximately two and half times more likely to have higher declines (more than 1.0 points) in GPA scores compared to the previous term than those who did not report depression. Male students with depression were approximately four times more likely to feel over-loaded by school work, and were approximately seven times more likely to feel over-loaded by school works than those who did not report depression, while female students with depression were approximately three times more likely to feel over-loaded by school works than those without depression.

Likewise, Fletcher (2008) analyzed a nationally representative longitudinal data to examine the relationship between youths' depression and academic achievements including GPA scores. Beginning with in-school survey with 14,169 youths between 7 and 12 grades (Wave 1), the study followed up with in-home interview with 
approximately 13,000 youths one year (Wave 2) and six years (Wave 3) later. The findings from Wave 1 data showed that youths with high depression were 0.6 times more likely to achieve a lower GPA, compared to those without depression. Examining the relationship between indicators of depression during high school (Wave 1 and 2) and dropping out of high school in Wave 3, the findings indicated that female youths with depression are 3.5 percentage points more likely to drop out of high school, and 10 percentage points less likely to enroll in 4-year college than those without depression ( $p$ $<.001)$

While these previous studies provided evidence of these associations between internalizing and externalizing behavior and academic performance, there exists no direct empirical evidence about the impact of teachers' negative comments on youths' problem behavior, or about the potential mediating effects of youths' problem behaviors on the association between teachers' negative comments and youths' school performance.

\section{Summary}

Overall, previous studies indicate that teachers' negative comments reflect stigmatizing attitudes and perceptions toward youth in foster care and special education, and these negative comments are linked to youths' problem behavior, school attitudes, and school performance. While previous studies provide evidence of these associations, there exists no direct empirical evidence about the impact of teachers' negative comments on youths' school performance, controlling for previous performance, or about the potential mediating effects of youth problem behaviors and school attitudes on the association between teachers' negative comments and youths' school performance. Therefore, this dissertation study examined the direct effects of teachers' negative 
comments on school attitudes, problem behavior and school performance, controlling for previous school performance, and then investigated potential mediating effects of youth's problem behaviors and school attitudes on the association between teachers' negative comments and youths' school performance.

\section{Purpose of the Study}

Previous research and conceptualizations of teachers' negative comments, youths' school attitudes, problem behaviors, and school performance provide a comprehensive foundation for investigating the influence of teacher' negative comments on youth school performance, both directly and through mediation by school attitudes and problem behaviors. Therefore, this dissertation study examined a model, presented in Figure 1, which depicted the associations among teachers' negative comments, youths' school attitudes, problem behaviors, and school performance.



Figure 1. Research model depicting the associations among teachers' negative comments, youths' school attitudes, problem behavior and school performance. 
In association with investigating these associations, the current study further examined teachers' stigmatizing attitudes toward youth in foster care and special education, exploring teachers' negative comments in IEP documents. This exploratory research was needed to examine in more detail whether teachers' negative comments reflected subjective or judgmental attitudes rather than merely describing youths' negative behaviors and poor school performance.

A major purpose of the dissertation study was to build a model, based on theories and previous research findings, related to these associations between teachers' negative comments and the school attitudes, problem behaviors, and school performance of youth in foster care and special education. Therefore, the current study incrementally examined the potential impact of teachers' negative attitudes reflected in IEP documents on youths' school performance, as well as the potential mediating influence of youths' school attitudes and problem behaviors, on the association between teachers' negative comments and youths' school performance.

This dissertation study was distinguished from previous studies of the impact of teachers' comments and attitudes on youths' school performance both conceptually and methodologically. First, this study focused on youth in foster care and special education. Second, this study utilized a mixed methods design to explore teachers' negative and stigmatizing attitudes toward youth in foster care and special education through analysis of IEP documents. Using the procedures defined in the School Archival Records Search (SARS) manual, the qualitative analysis identified teachers' negative comments in IEP documents, and investigated how teachers' negative comments reflect stigmatizing attitudes perceptions. Third, this study used a structural equation modeling (SEM) to 
examine the impact of teachers' negative comments on youths' school performance, directly or through mediational effects of school attitudes and problem behaviors of youth in foster care and special education. This method provided a holistic knowledge of the direct and mediational effects of teachers' negative comments on school performance, with the associations testing both separately and in a comprehensive model. Fourth, this study used a longitudinal design in contrast to most previous studies that have used crosssectional designs. Specifically, by controlling for the effect of youths' previous school performance, youths' participation in the IEP meeting, and youths' participation in the self-determination intervention, the findings provided clearer knowledge of the relationship between teachers' negative comments and youths' school performance, as well as youths' school attitudes and problem behaviors. 


\section{Chapter 3: Methodology}

\section{Research Questions}

This study examined the following five major research questions.

Research Question I. To what extent were teachers' negative comments toward foster youth in special education reflected on IEP documents?

It was expected that more than half of IEP documents of youth in foster care and special education would include teachers' negative comments (Hypothesis \#1).

Research Question II. Was there a significant difference in teachers' negative comments included in IEP documents by race, ethnicity, and gender of youth in foster care and in special education?

With this research question, this study hypothesized that Caucasian youths would be less likely to have teachers' negative comments in IEP documents than other racial and ethnic groups including African Americans, Asians, Hispanics, and Native Americans, controlling for youths' problem behaviors (Hypothesis \#2).

This study also hypothesized that female youth would be less likely to have teachers' negative comments in their IEP documents related to externalizing behaviors, and be more likely to have teachers' negative comments related to internalizing behaviors than male youths (Hypothesis \#3).

Research Question III. To what extent did teachers' negative comments influence youths' school performance measured at Time 2, controlling for youths' participation in their IEP meeting, youths' participation in the self-determination intervention, and their school performance previous to entry into the study? 
With this research question, this study estimated the moderating effects of youths' participation in their IEP meeting, youths' participation in the self-determination intervention, and their school performance previous to study entry on the relationship between teachers' negative comments and school performance measured at Time 2 . To examine the moderating effects, the interaction terms that multiplied teachers' negative comments and youths' participation in the IEP meeting, teachers' negative comments and youths' participation in the self-determination intervention, and teachers' negative comments and youths' school performance previous to study entry were identified.

The first hypothesis for this research question was that youth who participated in the IEP meeting would be more likely to have higher level of effect of teachers' negative comments on their school performance measured at Time 2 than those who did not participate in the IEP meeting (Hypothesis \#4). In other words, teachers' negative comments would more adversely affect youths' school performance measured at Time 2 when youth participated in the IEP meeting, compared to when youth did not participate in the IEP meeting.

The second hypothesis for this research question was that youth who participated in the self-determination intervention would be more likely to have lower level of effect of teachers' negative comments on their school performance measured at Time 2, than those who did not participate in the self-determination intervention (Hypothesis \#5). In other words, teachers' negative comments would less adversely affect the Intervention group youths' school performance measured at Time 2, compared to youths in the Control group. 
The third hypothesis was that youth with lower level of school performance previous to study entry would be more likely to have higher level of effect of teachers' negative comments on their school performance measured at Time 2 than those with higher level of school performance previous to study entry (Hypothesis \#6). This hypothesis means that teachers' negative comments would more adversely affect youths' school performance measured at Time 2 for youths with lower level of school performance previous to study entry including GPA, attendance, credits, and failed classes, compared to youth with higher level of school performance previous to study entry.

Research Question IV. To what extent did youths' school attitudes mediate the impact of teachers' negative comments on their school performance measured at Time 2, controlling for youths' participation in their IEP meeting, youths' participation in the selfdetermination intervention, and their school performance previous to study entry?

This study estimated the influence of teachers' negative comments on youths' school performance through the mediational effect of youths' school attitudes. Baron and Kenny (1986) presented four steps for testing mediation: (a) the independent variable should have a significant influence on the dependent variable, (b) the independent variable must be significantly associated with the potential mediator, (c) the mediator should have a significant influence on the dependent variable, and (d) the significant relationship between the independent and dependent variable should be zero once the role of the mediator is accounted for in the process. If the final step is not met, then partial mediation is established. 
Based on these criteria presented by Baron and Kenny (1986), this study

hypothesized that teachers' negative comments would have a significant influence on each of four indicators (e.g., GPA, attendance, credits, and failed classes) of youths' school performance measured at Time 2, and on youths' school attitudes. Furthermore, youths' school attitudes would have a significant influence on each of four indicators of youths' school performance measured at Time 2 . This study also hypothesized that there would be a significant relationship between teachers' negative comments and each of indicators representing youths' school performance measured at Time 2 when the mediator, youths' school attitudes, was accounted for, as depicted in Figure 2.

Previous to Entry of Study

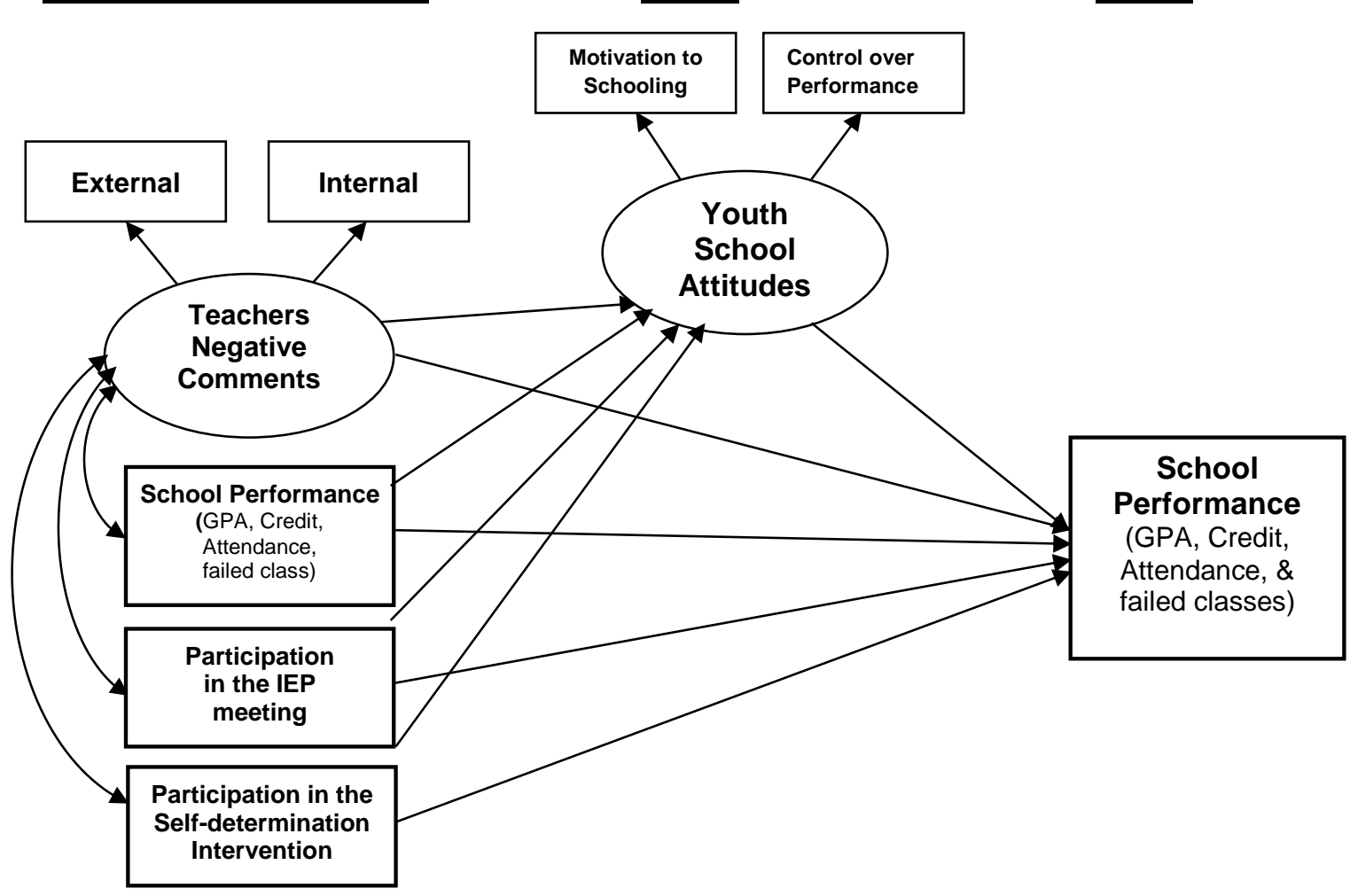

Figure 2. The multiple regression model of mediation effect of youths' school attitudes between teachers' negative comments, and youths' school performance at Time 2. 
Thus, youths' school attitudes would be a partial mediator in the relationship between teachers' negative comments and youths' school performance measured at Time 2, controlling for youths' participation in their IEP meeting, youths' participation in the self-determination intervention, and their school performance previous to study entry (Hypothesis \#7).

This mediated model was compared with the models of Research Question III to determine whether inclusion of two indirect paths to each of four indicators of youths' school performance through the mediational effect of youths' school attitudes would significantly improve model fit.

Research Question V. To what extent did youths' problem behaviors mediate the impact of teachers' negative comments on youths' school performance measured at Time 2, controlling for youths' participation in their IEP meeting, youths' participation in the self-determination intervention, and their school performance previous to entry into the study?

Based on these criteria presented by Baron and Kenny (1986), this study hypothesized that teachers' negative comments would have a significant influence on each of four indicators of youths' school performance measured at Time 2, and on youths' problem behaviors, and that youths' problem behaviors also would have a significant influence on each of four indicators of youths' school performance measured at Time 2. This study also hypothesized that there would be a significant relationship between teachers' negative comments and each of indicators representing youths' school performance measured at Time 2 when the mediator, youths' problem behaviors, was accounted for, as depicted in Figure 3. It means that youths' problem behaviors would be 
a partial mediator in the relationship between teachers' negative comments and youths' school performance measured at Time 2, controlling for youths' participation in their IEP meeting, youths' participation in the self-determination intervention, and their school performance previous to study entry (Hypothesis \#8).

\section{Previous to Entry of Study}



$\underline{\text { Time } 2}$ $\underline{\text { Time } 1}$

\section{School} Performance (GPA, Credit, Attendance, \& Failed class)

Figure 3. The multiple regression model of mediation effect of youths' problem behaviors between teachers' negative comments and youths' school performance measured at Time 2.

This mediated model was compared with the model of Research Question III to determine whether inclusion of two indirect paths to each of four indicators of school 
performance measured at Time 2 through the mediational influences of youths' problem behaviors would significantly improve model fit.

Furthermore, this study tested the final model that considered simultaneously the effects of all significant influences obtained in each of the models. It tested the overall fit of the final model including all extraneous construct and variable, and endogenous variables as shown in Figure 4.

Previous to Entry of Study

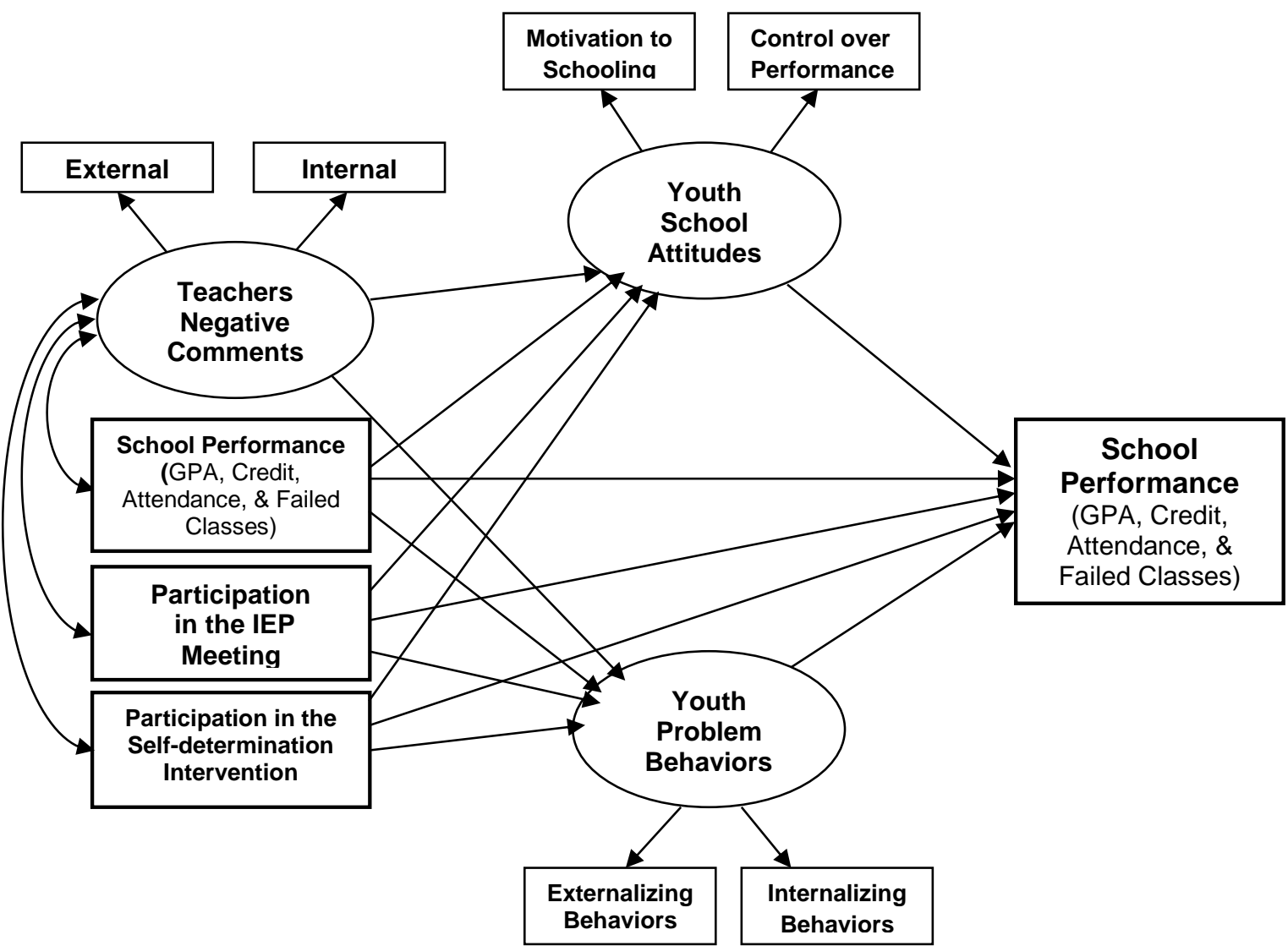

Figure 4. The final model depicting the associations among teachers' negative comments, youths' school attitudes, problem behavior and school performance measured at Time 2 . 
This final model was compared with the models of Research Questions IV, and V to determine whether inclusion of all indirect paths to each of four indicators of school performance measured at Time 2 through the mediational effects of youths' school attitudes and problem behaviors would significantly improve model fit.

Additionally, this dissertation study examined the nature of teachers' stigmatizing negative comments, and the impact of teachers' stigmatizing negative comments on youths' school performance measured at Time 2, both directly and through mediation by youths' school attitudes and problem behaviors, applying the same research questions, hypotheses, models, and analyses methods.

\section{Design Overview}

This dissertation study employed both qualitative and quantitative methods of analysis to examine teachers' negative comments in IEP documents and to examine the impact of teachers' negative comments on youths' school performance, both directly and through mediation by youths' school attitudes and problem behaviors.

The study used secondary data from Project Success, a randomized trial funded by the Institute on Educational Sciences (IES) within the U.S. Department of Education (Grant \# R324S060043). This project was conducted to test the efficacy of a selfdetermination intervention for improving the educational success of foster youth who received special education services in school districts in one region of Oregon. Youth were randomly assigned in three waves to either the intervention group or a control group. The intervention was conducted for nine months, followed by nine months of followalong for all participants (See Geenen, et al., 2012, for additional information).

\section{Sample}


A total of 128 foster youth in their Freshman, Sophomore and Junior years who were receiving special education services and enrolled in Project Success were included in the current study. For each study wave, all youth in foster care between the ages of 14 and 16 were identified by Multnomah County DHS Child Welfare. The list of potentially eligible youth was provided to the Project Liaison at a school district in Multnomah County who confirmed each youth's eligibility for the study, which was defined by current school enrollment, being at the targeted grade level, and receiving special education services. Study recruitment information was sent to all eligible youths and their foster parents. Orientation meetings were conducted with each student and foster parent, and 95 percent of eligible youth elected to join the study.

Attrition from the study at TIME 2, nine months post study entry, was five percent, yielding a sample size of 123 . Given this sample size, this exploratory research was estimated to have the potential to detect significant effects at the .05 alpha level with .93 observed power, considering 7 predictors on youths' school performance. Sixtythree youth were in the comparison group and sixty youth were included in the intervention group.

\section{Measurement}

As shown in Table 2, IEP documents of the youth were collected from annual IEP meetings conducted three to eleven months before they entered the project [previous to entry of study], from annual IEP meetings conducted in the school year during intervention [1 to 8 months from the end of the intervention period (TIME 1)], and from annual IEP meetings conducted during the nine month follow-along period of the following academic year (TIME 2). 
Table 2.

Type and Timeline of Study Measures.

\begin{tabular}{|c|c|c|}
\hline Construct & Measure & Time period \\
\hline Teachers' Negative & IEPs coded with SARS & Previous to entry of study ( 1 to 11 months \\
\hline \multirow[t]{5}{*}{ Comments in IEP } & & prior to entry) \\
\hline & GPA ( 0 to 4.0 scale $)$ & Time 2 (the term preceding the end of the \\
\hline & & intervention period) \\
\hline & Attendance (Total number of & Time 2 (the term preceding the end of the \\
\hline & days absent) & intervention period) \\
\hline \multirow{5}{*}{ School Performance } & Credit (Total number of credits) & Time 2 (the term preceding the end of the \\
\hline & & intervention period) \\
\hline & Failed classes & Time 2 (the term preceding the end of the \\
\hline & (failure of one or more classes & intervention period) \\
\hline & $($ yes/no $))$ & \\
\hline \multirow[t]{3}{*}{ Problem behaviors } & Child Behavior Checklist & Time 1 (at enrollment) \\
\hline & (CBCL: Achenbach, 1978; & \\
\hline & Achenbach \& Edelbrock, 1991). & \\
\hline \multirow[t]{3}{*}{ Attitudes toward school } & School Attitude Measure & Time 1 (at enrollment) \\
\hline & (SAM: Dolan, Enos, Wick \& & \\
\hline & Smith, 1991; Wick, 1990) & \\
\hline Previous school & GPA, attendance, credit, failed & Previous to entry of study (GPA, total absent \\
\hline performance & classes & days, total credits, failed classes) \\
\hline IEP meeting participation & Participation or not & Previous to entry of study \\
\hline Self-determination & Intervention group or control & Previous to entry of study \\
\hline intervention & group & \\
\hline
\end{tabular}


Academic data was collected for the term prior to study entry (TIME 1), for the term immediately preceding the end of the intervention period (TIME 2), and for the term preceding the end of the nine month follow-along period (TIME 3).

Teachers' negative comments in IEP documents. All comments recorded on youths' IEP documents were entered into a database created for this dissertation. Teachers' negative comments in the IEP documents were coded using the School Archival Records Search (SARS: Walker et al., 1991). The SARS provided criteria for the systematic coding of 11 variables related to youths' school behaviors and academic performance, which were extracted from school records. Among 11 variables, negative narrative comments, indicating a failure to meet teachers' expectations, were used to obtain information related to youths' past behaviors and academic performance (Walker et al., 1991). The SARS manual provided definitions of negative comments and practice exercises for scoring negative comments.

For testing the reliability of negative comment scoring, Walker and colleagues (1991) gathered 263 narrative comments from youths' school files and asked 10 staff to independently review negative comments, and to score each comment on the list as negative or non-negative. Each comment was differently scored, according to the degree of agreement of negative or non-negative, which is ranged from 0 to 100 percent. The results indicated a mean agreement level of $85 \%$, reflecting sufficient levels of reliability (Walker et al., 1991).

Negative comments identified by the SARS were categorized as externalizing or internalizing behaviors. Externalizing behaviors include indicators such as aggressive, noncompliant, hyperactive, distractible, and defiant behaviors. In contrast, internalizing 
behaviors are characterized as being excessively shy and timid or severely withdrawn, having a general pervasive mood of unhappiness or depression, demonstrating a tendency to develop physical symptoms or fears associated with personal or school problems, and having difficulty in maintaining interpersonal relationship with peers and teachers (Walker et al., 1991, p.84).

Walker and colleagues (1991) investigated the factorial, discriminant and concurrent validity, and interrater reliability of the SARS. A confirmatory factor analysis was conducted with samples of elementary youths in Oregon $(n=307)$ and Washington $(n$ =216). Three factors were identified in both samples: Needs assistance, Disruption, and Low achievement.

For both samples, the results revealed that externalizing behaviors were significantly more likely to load on disruption than were internalizing behaviors. In contrast, internalizing behaviors had significantly higher loadings than externalizing behaviors on needs assistance. This study also showed reliability values ranged from .94 to 1.00 for individual SARS variables. Reliability for the total of SARS variables was .96 .

The SARS has been recognized for its ability to identify youths who are at elevated risk for school dropout. For example, Block-Pedego (1990), in a study conducted with 105 youths in three school districts in the Midwest, found that achievement test scores, number of different schools attends, and absences in grades 7-10 predicted the dropout of youths in grades 11 and 12.

School performance. In this study, school performance was represented by GPA score, total number of credits obtained, total number of days absent, and failed classes, which were recorded in the Project Success dataset and extracted directly from school 
databases through ESIS as shown in Table 2. Among the four indicators, failed classes was dichotomized with the higher value (1) indicating failure of one or more classes and the lower value (0) indicating no failure of classes.

Problem behavior. The Project Success data included the teacher-completed Child Behavioral Checklist (CBCL) scores as a measure of youths' problem behaviors. As one of the most widely used instruments, the Child Behavior Checklist (CBCL) (Achenback, 1991; Achenbach et al., 1987) is designed to provide a standardized measure of behavior problems of children and youth ages 4 through 18 .

As shown in Table 2, the CBCL consists of two categories, externalizing and internalizing behaviors, with the 89 cross-informant items to which children and teachers respond; very (or often) true, somewhat (or sometimes) true, or not true. The internalizing behaviors scale is consist of 32 items with three subscales; withdrawn (9 items), somatic complaints (9 items), and anxious/depressed (14 items). Externalizing behaviors items are composed of 27 items with two subscales; delinquent behavior (8 items) and aggressive behavior (19 items). The CBCL has been verified to have good internal consistency and test-retest reliability. According to Achenbach (1991), the internal consistency reliability coefficients are .93 for externalizing behavior and .88 for internalizing behavior. The testretest coefficients are .89 for the internalizing behavior scale and .93 for the externalizing behaviors scale. Achenbach (1991) also obtained construct validity by correlating CBCL scales score with scores from the closest counterpart scales of the Conners-Parent Questionnaire (1973 as cited in Achenbach, 1991) and the Quay-Peterson Revised Behavior Problem Checklist (1983 as cited in Achenback, 1991). The correlation coefficients $(\gamma)$ of CBCL between the Conners scales and the Quay-Peterson scales is 
from .59 to .86 and from .59 to .88 , respectively. The CBCL has also demonstrated concurrent validity by showing statistically significant differences between referred and not-referred children (Achenbach, 1991).

School attitudes. The Project Success data also included the School Attitude Measure (SAM; Dolan et al., 1980; Wick, 1990) as the measure of youths' attitudes toward school. The SAM is designed to measure youths' thoughts, interests, feeling and attitudes toward their learning and educational environment. Of the five subscales included in the SAM, the Project Success used the "motivation for schooling scale" and the youth's "sense of control over performance scale" with responses on a 4-point scale of agreement ("never agree" to "always agree"). Dolan (1983), in validity analyses for the SAM with $5^{\text {th }}, 8^{\text {th }}$, and $11^{\text {th }}$ grade youths, showed that the internal consistency coefficients are ranged from .76 to .89 for the "motivation for schooling scale", and from .71 to 84 for the "sense of control over performance scale", using a test-retest method. Dolan also verified the SAM has a concurrent validity, showing the SAM is positively correlated with a variety of cognitive and affective criterion indices and SAM scores rated by teachers, parents, and peers. For example, developmental cognitive abilities are significantly correlated with both motivation for schooling $(\gamma=.31, p<.001)$ and control over performance $(\gamma=.29, \mathrm{p}<.001)$, and SAM ratings by teachers are also correlated with both motivation for schooling $(\gamma=.36, \mathrm{p}<.001)$ and control over performance $(\gamma$ $=.30, \mathrm{p}<.001)$

The present form of the SAM (Wick, 1990) was developed to be free of ethnic, gender, or regional bias by removing biased items. As shown in Table 2, the "motivation for schooling scale" consists of 16 items, which are concerned about the influence of the 
youths' reactions to past school experience on their motivation in school. The "youth sense of control over performance" consists of 10 items, which are related to youths' feelings that they are able to exercise control over situations that affect their school performance and to take responsibility for the outcomes related to school activities and performances (Wick, 1990). According to Wick (1990), the internal consistency reliability coefficients are .82 for the "motivation for schooling" and .80 for the "youth Sense of control over performance." Wick (1990) also verified the concurrent validity of the SAM, showing the intercorrelation between cognitive measures and the SAM, with $\gamma$ $=.56$.

Participation in the IEP meeting. Youth participation in the IEP meeting was used as a control variable to examine whether youth who actually participated in the IEP meeting were negatively influenced by exposure to teachers' negative comments, which were expressed verbally during the meeting and/or in writing on the IEP document developed during the meeting. Exposure to teachers' negative comments during the IEP meeting could, in turn, moderate the influence of teachers' negative comments on youths' subsequent school performance. Information about youths' participation in IEP meeting was taken from the Project Success questionnaire, which was administered to youth at study entry. Youth participation in the IEP meeting was considered with the higher value (1) indicating participation in IEP meeting and the lower value (0) indicating nonparticipation in IEP meeting.

Participation in the self-determination intervention. Youths were randomly assigned to either the intervention group or the comparison group at study entry; group assignment was entered in the Project Success dataset. Assignment to the self- 
determination intervention was considered as a control variable with the higher value (1) indicating assignment to the intervention group and the lower value (0) indicating assignment to the comparison group.

Race, ethnicity and gender. Race, ethnicity and gender were drawn from the Project Success Demographic Questionnaire, which was administered to youth at study entry. Race/ethnicity was included as a dichotomous variable, with the higher value (1) indicating Caucasian and the lower value (0) representing other ethnic groups. Gender was recorded with the higher value (1) indicating male youth in foster care and special education and the low value (0) indicating female youth in foster care and special education.

Demographic characteristics. Youths' foster care placement, length of time in foster care, and maltreatment type was gathered from Oregon's child welfare electronic database (FACIS); information on special education eligibility categories was obtained from youths' IEP documents; Information on who received developmental disabilities services was obtained from Multnomah County Developmental Disability Services; school placement was obtained from the school districts electronic database.

\section{Analysis}

Qualitative analysis.

SARS Coding. Using the procedures defined in the SARS manual (SARS: Walker et al., 1991), teachers' negative comments were analyzed. For coding teachers' negative comments in IEP documents, a M.S.W student and Ph.D. student at Portland State University were recruited to assist the investigator. For trustworthiness of analysis, the sub-category codes were established through a process of initial training with the SARS 
manual, followed by independent coding by the researchers, review of dissimilar results, adoption of rules for coding subtle interpretations, and independent re-coding.

Negative comments practice exercise. The coders were asked to independently review the definition of negative comments, and non-negative comments, and to complete practice exercises for coding teachers' negative comments, which the SARS manual (Walker et al., 1991) provides. Through the practice exercise, the coders became familiar with the definitions of negative comments and clarified any ambiguities or confusion before coding teachers' negative comments. When the coders scored $80 \%$ or better on the practice exercises, they were involved in coding and analyzing teachers' negative comments.

Coding teachers' negative comments. Teachers' negative statements were coded in the following domains: "work habit, compliance, social behavior or interaction with peers, teachers, and parents, speech, language, perceptual or motor problems, selfconcept, self-esteem, or emotional problems, any services being received, such as counseling or special instruction, descriptions of grade reassignments, retentions, and references to attendance problems" (Walker et al., 1991, p. 17). In contrast, negative statements did not include: "physical or medical problems, special medical treatment received, medications prescribed", problems related to "height, weight, or body size," ambiguous comments which could be regarded as "either positive or negative, such as quiet, serious, and unusual," and lack of academic skills (Walker et al., 199a, p. 18).

The coders independently reviewed all of the comments from each IEP document, coded negative comments on the list, and then coded relevant negative comments as referring to externalizing or internalizing behaviors. 
Externalizing behaviors include behavioral indicators such as aggressive, noncompliant, hyperactive, distractible, and defiant behaviors. In contrast, internalizing behavior is defined as "behavior problems that are directed inwardly and often involve behavioral deficits" (Walker et al., 1991, p. 84). Internalizing behaviors include behaviors characterized as being excessively shy and timid or severely withdrawn, having a general pervasive mood of unhappiness or depression or demonstrating a tendency to develop physical symptoms or fears associated with personal or school problems, and difficulty in maintaining interpersonal relationship with peers and teachers and difficulty in communicating with peers and teachers (Walker et al., 1991, p.84).

Validity and reliability of codes. For trustworthiness of analysis, this study followed the reliability procedures used in examining the reliability of the SARS (Walker et al., 1991). To reduce threats to validity including coders' bias and incorrect interpretation, the coders reviewed coding discrepancies, established rules for coding subtle interpretations, and then independently re-coded the comments. Using this iterative process, an inter-rater reliability of agreement of at least 90 percent achieved among the coders.

Coding teachers' stigmatizing comments. This study further examined teachers' stigmatizing attitudes toward youth in foster care and special education, exploring teachers' negative comments in IEP documents.

Based on the pilot study (Noh et al., 2013), teachers' stigmatizing negative comments were coded if teachers' negative comments met the following criteria: (1) teachers' subjective and judgmental opinions; (2) biased reports noted from other teachers; (3) teachers' low expectation about youths' academic potential and capacities for behavior 
change; and (4). negative comments with little reference to context or reason for negative behaviors or poor school performance.

To find teachers' stigmatizing attitudes and perception toward the youth, the coders independently reviewed and coded, using the same process of coding negative comments. The coders also reviewed coding discrepancies, established rules for coding subtle interpretations, and then independently re-coded the comments.

Quantitative analyses. Due to the small sample size and exploratory nature of the study, a p-value of $<0.10$ was considered significant in all statistical analyses.

Statistical analyses of teachers' negative comments. The following analyses were conducted with SPSS 17.0 software.

For addressing Hypothesis \#1 that more than half of IEP documents of youth in foster care and special education would include teachers' negative comments, descriptive statistics were used, including percentages, means and standard deviations.

For testing Hypothesis \#2 that Caucasian youth would be less likely to have teachers' negative comments in IEP documents than other ethnic groups, this study used a t-test to test mean difference of teachers' negative comments between Caucasian youths and other race/ethnic groups, and then used an analysis of covariance (ANCOVA) to control the effect of youths' internalizing and externalizing problem behaviors on the association of race/ethnicity with negative comments.

The ANCOVA procedure determined whether observed differences of teachers' negative comments among ethnic groups were accounted for by youths' problem behaviors or teachers' stigma related to youths' race and ethnicity. It was expected that there would be a significant mean differences of teachers' negative comments between 
Caucasian youths and other race/ethnic groups at the $p<.10$ level, when controlling or not controlling for youths' problem behaviors.

Race/ethnicity was dichotomized with the higher value (1) indicating Caucasian and the lower value $(0)$ representing other ethnic groups.

For testing Hypothesis \#3 that female youths would be less likely to have teachers' negative comments related to externalizing behaviors, and be more likely to have teachers' negative comments related to internalizing behaviors than male youths, this study used a t-test to test mean difference of teachers' negative comments between female and male youths, and then used an analysis of covariance (ANCOVA) to control the effect of youths' internalizing and externalizing problem behaviors on the association of gender with negative comments.

The ANCOVA procedure determined whether observed differences of teachers' negative comments between female and male youths were due to youths' problem behaviors or teachers' stigma related to youths' gender. It was expected that there would be a significant mean differences of teachers' negative comments between male and female youths at the $p<.10$ level, when controlling or not controlling for youths' problem behaviors.

Gender was dichotomized with the higher value (1) indicating male youth in foster care and special education and the low value (0) indicating female youth in foster care and special education.

Preliminary analyses: Data cleaning. Descriptive statistics and histograms were used to examine the distribution because hierarchical regression and structural equation modeling (SEM) assume that the scale scores of variables are normally distributed. 
Violating this assumption can result in an inflated or deflated chi square statistic (West, Finch, \& Curran, 1995). The analysis indicated overall normality, although some items displayed slight positive and negative skews. Analysis strategies using statistical estimation procedures, such as hierarchical regression, and SEM, are considered robust to minor violation of normality (Huba \& Harlow, 1987).

Univariate descriptive and bivariate analyses were conducted on continuous variables to ensure linearity and homoscedasticity, and to identify the presence and influence of outliers through the analysis of frequency distributions, histograms, scatterplots, and casewise diagnosis including studentized residuals, leverage, Mahalanobis distance value, and Cook's Distance. For the leverage values, one criterion that has been suggested for being overly large is if the leverage value exceeds $(2 k+2) / n$ ( $\mathrm{k}=$ the number of predictors, $\mathrm{n}=$ the number of cases). For this analysis, the critical value of leverage was a value of 0.011 . The Mahalanobis distance value for each case is considered an outlier if its p-value exceeds 0.001 . The cases with a Cook's distance value greater than 0.5 is considered an outlier.

Multicollinearity and singularity were assessed through bivariate correlation matrices (Pearson's r), Variance Inflation Factor (VIF), and tolerance. Multicollinearity is considered if Tolerance is below 0.1 , and VIF is greater than 10 or an average much greater than 1 .

\section{Moderation of youths' participation in the IEP meeting and self-determination} intervention, and school performance previous to study entry. Hierarchical multiple regression analyses were used to test the moderating effect of youths' participation in IEP meeting, youths' participation in the self-determination intervention, and youths' school 
performance previous to study entry on the relationship between teachers' negative comments and youths' school performance measured at Time 2. This study used dummy codes of the variables, including youths' participation in IEP meeting $(1=$ participation in IEP meeting, 0 = no participation in IEP meeting), and youths' participation in the selfdetermination intervention $(1=$ intervention group, $0=$ comparison group $)$. Youths' school performance was measured through GPA, credits, attendance, and failed classes, as shown in Figure 2. Among these variables, failed classes was used with dummy codes ( 1 = failed classes, $0=$ no failed classes $)$.

Aiken and West (1991) centering procedure was used as the predictor (teachers' negative comments), moderators (youths' participation in the IEP meeting, youths' participation in the self-determination intervention, and youths' school performance previous to study), and the interaction terms (teachers' negative comments X youths' participation in the IEP meeting, teachers' negative comments $\mathrm{X}$ youths' participation in the self-determination intervention, and teachers' negative comments $\mathrm{X}$ youths' school performance previous to study entry) were z-scored.

Addressing Hypothesis \#4, hierarchical regressions were used to examine the moderating effect of youths' participation in the IEP meeting on the linkage between the predictor (teachers' negative comments) and the four indicators of youths' school performance measured at Time 2 (grades, attendance, credits, and failed classes), examining the interaction effect of teachers' negative comments $\mathrm{X}$ youths' participation in IEP meeting. Blocks of variables were sequentially added into the regression analyses such that Block 1 entered teachers' negative comments, Block 2 entered youths' 
participation in IEP meeting, and Block 3 entered the interaction term (teachers' negative comments $\mathrm{X}$ youths' participation in the IEP meeting).

Addressing Hypothesis \#5, hierarchical regressions were used to examine the moderating effect of youths' participation in the self-determination intervention on the linkage between teachers' negative comments and the four indicators representing youths' school performance measured at Time 2 (grades, attendance, credits, and failed classes), examining the interaction effect of teachers' negative comments $\mathrm{X}$ youths' participation in the self-determination intervention. Blocks of variables were sequentially added into the regression analyses such that Block 1 entered teachers' negative comments, Block 2 entered youths' participation in the self-determination intervention, and Block 3 entered the interaction term (teachers' negative comments $\mathrm{X}$ youths' participation in the selfdetermination intervention).

Likewise, addressing Hypothesis \#6, hierarchical regressions were used to examine the moderating effect of the four indicators of youths' performance previous to study entry (grades, attendance, credits, and failed classes) on the linkage between teachers' negative comments and youths' school performance measured at Time 2, examining the interaction terms including teachers' negative comments $\mathrm{X}$ grades, teachers' negative comments $\mathrm{X}$ attendance, teachers' negative comments $\mathrm{X}$ credits, and teachers' negative comments $\mathrm{X}$ failed classes. Blocks of variables were sequentially added into the regression analyses such that Block 1 entered teachers' negative comments, Block 2 entered each of the four indicators of youths' performance previous to study entry, and Block 3 entered each of the interaction terms. 
These moderator hypotheses were supported if the interaction terms of the predictor and the moderators were significant at the $p<.10$ level.

Mediation of youths' school attitudes and problem behaviors on the relationship between teachers' negative comments and youths' school performance. For testing the impact of teachers' negative comments on youths' school performance, both directly and through mediation by youths' school attitudes (Hypothesis \#7), or youths' problem behaviors (Hypothesis \#8), this study used structural equation modeling (SEM). According to Zapf, Dormann, and Frese (1996), SEM technique has four advantages for testing longitudinal relationships. First, measurement errors can be controlled because SEM allows the causal relationships that are modeled between latent constructs to be error free. Second, SEM allows for complete and simultaneous testing of all the variables and relationships in the model. Third, when more than one dependent variable is tested or when a variable is present as both an independent and a dependent variable, SEM is useful. Finally, variable problems that account for the effect of unmeasured third variables can be modeled. With these advantages, this study used SEM technique to test the hypotheses (\#7 and \#8) using an AMOS 7.0 software.

Addressing Hypothesis \#7, this study tested SEM models that youths' school attitudes was modeled as the mediator between teachers' negative comments and each of the four indicators of youths' school performance measured at Time 2, controlling for each of the four indicators of youths' school performance previous to study entry, youths' participation in the IEP meeting, and youths' participation in the self-determination intervention as depicted in Figure 2. Youths' school attitudes, as a latent variable, was 
measured at Time 1, and consists of two indicators: Motivation to Schooling and Sense of Control over Performance.

Likewise, addressing Hypothesis \#8, this study tested SEM models that youths' problem behaviors was modeled as the mediator between teachers' negative comments and each of the four indicators of youths' school performance measured at Time 2, controlling for each of the four indicators of youths' school performance previous to study entry, youths' participation in the IEP meeting, and youths' participation in the selfdetermination intervention as depicted in Figure 3. Youths' problem behaviors, as a latent variable, was measured at Time 1, which consists of two indicators: Internalizing Problem Behaviors and Externalizing Problem Behaviors.

For the SEM analysis, the first step was to examine the overall fit of the models by examining several fit indices, including Chi-square statistic, Chi-square to degree of freedom ratio $\left(\chi^{2} / d f\right)$, the Comparative Fit Index (CFI), and the Root Mean Square Error of Approximation (RASEA). Traditional goodness-of-fit cut off scores are greater than .90 for the CFI (Newcomb, 1994), and a core of less than .05 for the RASEA (Browne \& Cudeck, 1993).

Model fit was assessed in two steps. First, the measurement models were tested by conducting a confirmatory factor analysis (CFA), where the relationships between the observed variables and their respective latent variable were assessed. The CFA identified the sufficiency of factor loadings and intercorrelations among the latent factors of the measurement models. Second, the structural model, including direct paths between latent variables, was tested. Once the overall fit of the models was acceptable, the individual 
path weights associated with the hypotheses were examined to see if the hypotheses were supported.

The purpose of this dissertation study was to incrementally explore a variety of models for a theory building, adding parameters related to theoretical associations. Therefore, the mediated models were compared with the models of the Research Question III to determine whether inclusion of indirect paths to each of three variables of school performance through the mediating influences of youths' school attitudes or youths' problem behaviors significantly improved model fit, calculating the difference of Chi-square, and Chi-square to degree of freedom ratio $\left(\chi^{2} / d f\right)$ between the models, and finding whether this difference reached statistical significance. The goodness-of-fit measures including CFI, and RMSEA were also used to compare model fit.

Finally, this study analyzed the final model that considered simultaneously the effect of all significant influences obtained in each of the models, as shown in Figure 1. This final model was compared with previous tested models to determine whether the final model had a better model fit as a comprehensive model including theoretical associations related to teachers' negative comments, youths' school attitudes, problem behaviors, and school performance. This study calculated the difference of Chi-square, and Chi-square to degree of freedom ratio $\left(\chi^{2} / d f\right)$ between the models, and found whether this difference reached statistical significance. The goodness-of-fit measures including CFI, and RMSEA were also used to compare model fit.

These analyses were conducted through the AMOS 7.0 (Arbuckle \& Wothke, 2007) program, using maximum likelihood (ML) estimation which generated estimates that calculate the full information at once (Kline, 2005). 
The simplified formulae of analyses that used in this study were showed in Table

3.

Table 3.

The Simplified Formulae for t-test, ANCOVA, Moderation, and Mediation Model.

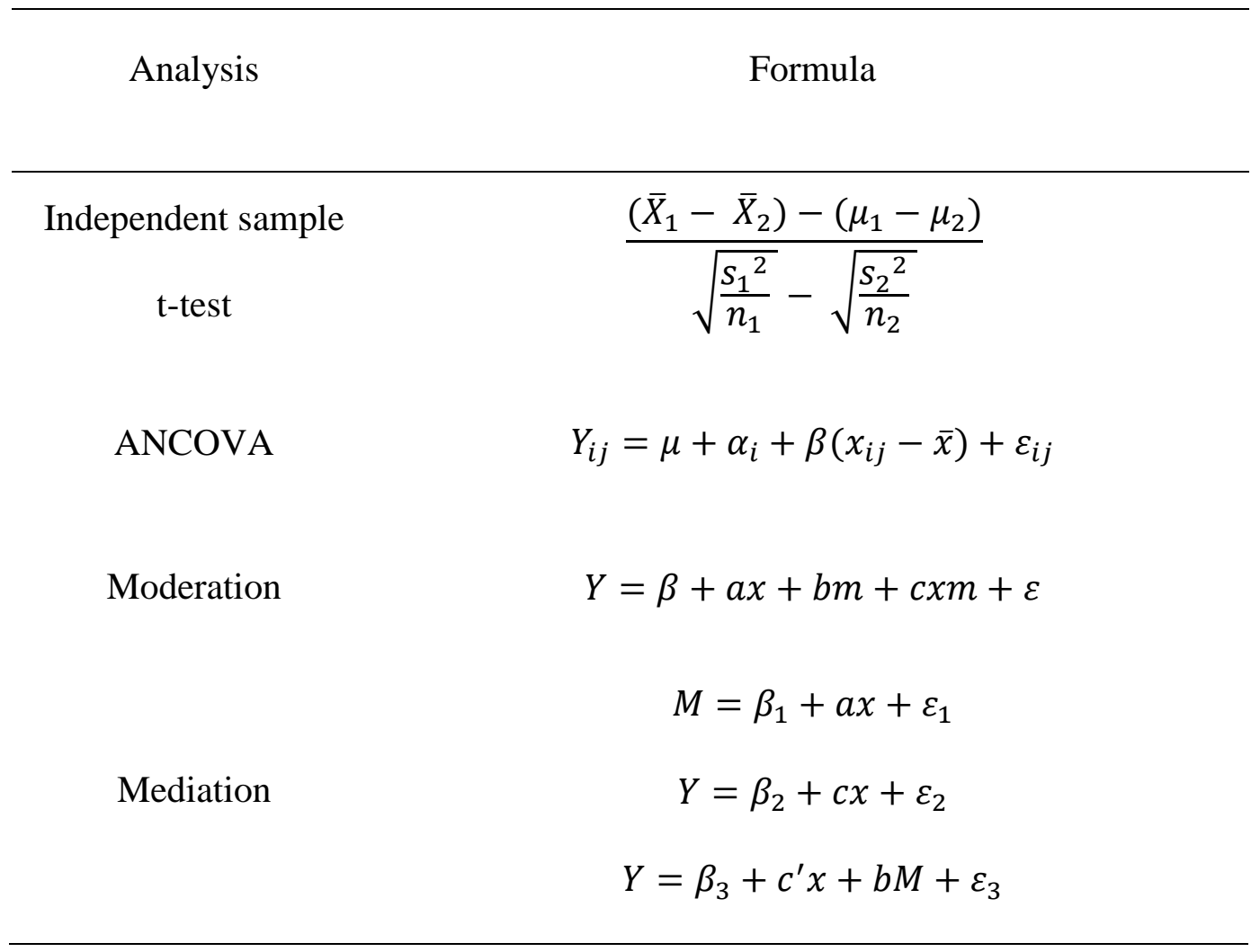


Chapter 4: Results

The following chapter describes the demographic characteristics of the study participants, followed by the findings for each of the research questions and associated hypotheses. The chapter begins by presenting the qualitative analyses teachers' negative comments and stigmatizing negative comments, and follows with the quantitative analyses of the relationships of teachers' negative comments and stigmatizing negative comments with youths' behaviors, school attitudes, and school performance. Findings are reported on observed differences in teachers' negative comments or stigmatizing comments among ethnic groups and by female and male youths in foster care and special education.

Results from the hierarchical regression analyses report the moderation effect of youths' participation in the IEP meetings, youths' participation in the self-determination intervention, and school performance previous to study entry on the linkage between teachers' negative comments or stigmatizing negative comments and youths' school performance measured at Time 2 .

Finally, results from structural equation modeling (SEM) report the impact of teachers' negative comments or stigmatizing negative comments on youths' school performance at Time 2, both directly and through mediation by youths' school attitudes, or problem behaviors.

\section{Sample Characteristics}

The demographic characteristics of 123 participants are summarized in Table 4. The average age of participants was 15.49 , with a range of 14.08 to 17.83 years of age. Females comprised $46.3 \%$ of the overall sample. Half of the sample was Caucasian and 
the largest racial/ethnic minority group was African-American youth at $29.3 \%$. This information was all based on youths' self-report.

Table 4.

Demographic Characteristics of the Participants

\begin{tabular}{|c|c|}
\hline Variable & $\begin{array}{c}\text { Total } \\
(n=123)\end{array}$ \\
\hline Age (mean) & 15.49 \\
\hline Gender ( $\%$ female $)$ & 46.3 \\
\hline \multicolumn{2}{|l|}{ Race/ethnicity (\%) } \\
\hline African American & 29.3 \\
\hline Asian & 0.8 \\
\hline Caucasian & 49.6 \\
\hline Hispanic & 6.5 \\
\hline Native American & 7.3 \\
\hline Multi-ethnic & 5.7 \\
\hline Other & 0.8 \\
\hline \multicolumn{2}{|l|}{ Living situation $(\%)$} \\
\hline Foster care (non-relative) & 82.1 \\
\hline Kinship care & 13.0 \\
\hline Group home/RTC & 4.9 \\
\hline Length of time in foster care (mean years) & 7.05 \\
\hline Total number of placement changes & 7.1 \\
\hline \multicolumn{2}{|l|}{ Maltreatment ( $\%$ non-exclusive) } \\
\hline Physical & 38.2 \\
\hline Sexual & 33.3 \\
\hline Neglect & 27.6 \\
\hline
\end{tabular}


Emotional maltreatment

Threat of harm

Other

Special education eligibility (\% non-exclusive)

Emotional/behavioral

Mental retardation

Speech/language

Physical (deafness \& blindness)

Autism spectrum disorder

Learning

Other Health Impairment
2.4

12.2

1.6

42.3

8.1

14.6

1.6

3.3

26.8

37.4

With regard to living situation, all youth were under the guardianship of Child Welfare when enrolled in the study. At Time 1, only two youth were living with their birth family. At Time 2, twelve youth were living with their birth family, two youth were living alone or with a friend and four youth were imprisoned; the remaining 114 youth were still in certified foster care placements including non-relative, relative foster home, or group home. The youth had spent an average of 7 years in foster care, and they had changed placement an average of 7 times.

With regards to maltreatment type, youth could experience more than one type of maltreatment. In particular, $38.2 \%$ of the youth experienced physical maltreatment and $33 \%$ experienced sexual maltreatment.

With regards to special education eligibility categories, youth could experience more than one type of disability, including emotional/behavioral disability (42.3\%), learning disability (26.8\%), speech and language disability (14.6\%), intellectual disability 
(8.1\%), autism spectrum disorder (3.3\%), and other health impairments (39.0\%): 19 youth $(15.4 \%)$ received developmental disabilities services when enrolled in the study.

Concerning school placement, from study entry to Time 2, just over a quarter of the youth $(26.8 \%)$ changed schools once, while 15 youth $(12.2 \%)$ attended three or more different schools during the period.

\section{Teachers' Negative Comments on IEP Documents}

\section{Research Question I: To what extent were teachers' negative comments}

toward youth in foster youth and special education reflected on IEP documents? The

IEP documents of participants were reviewed and coded for negative comments using the School Archival Records Search (SARS; Walker et al., 1991) as a guide.

As shown in Table 5, among the IEP documents of 123 participants, approximately $90 \%(n=111)$ included teachers' comments about youth' behavior and/or school performance. In total, 724 teachers' comments were described in the IEP documents, averaging approximately seven comments per youth.

The coders independently reviewed each comment, coded negative comments on the list, and then coded relevant negative comments as referring to externalizing or internalizing behaviors. To enhance trustworthiness of the analysis, the coders reviewed coding discrepancies, established rules for coding subtle interpretations, and then independently re-coded the comments. Table 5 shows the results of the iterative process of coding negative comments.

During initial coding, the coders disagreed on 63 negative comments (8.7\%), 55 externalizing behavior comments (7.6\%), and 140 internalizing behaviors comments (19.3\%), respectively. The coders reviewed and discussed comments with discrepant 
Table 5 .

Agreement of Coding Negative Comments between Coders $(n=111)$

\begin{tabular}{|c|c|c|c|c|c|c|c|c|}
\hline & & & \multicolumn{6}{|c|}{ Disagreement } \\
\hline & \multicolumn{2}{|c|}{ Total } & \multicolumn{2}{|c|}{$\begin{array}{l}\text { Negative } \\
\text { Comments }\end{array}$} & \multicolumn{2}{|c|}{$\begin{array}{c}\text { Externalizing } \\
\text { behavior }\end{array}$} & $\begin{array}{c}\text { Inter } \\
\text { beh } \\
\text { com }\end{array}$ & $\begin{array}{l}\text { zing } \\
\text { or } \\
\text { nts }\end{array}$ \\
\hline & $\mathrm{N}$ & $\%$ & $\mathrm{~N}$ & $\%$ & $\mathrm{~N}$ & $\%$ & $\mathrm{~N}$ & $\%$ \\
\hline $1^{\text {st }}$ coding & 724 & 100 & 63 & 8.7 & 55 & 7.6 & 140 & 19.3 \\
\hline $2^{\text {nd }}$ coding & 724 & 100 & 26 & 3.6 & 21 & 2.9 & 41 & 5.7 \\
\hline $3^{\text {rd }}$ coding & 724 & 100 & 3 & 0.4 & 7 & 1.0 & 4 & 0.6 \\
\hline
\end{tabular}

codes, and then established new rules to code negative, externalizing and internalizing behavior comments. Table 6 shows the new coding rules. After reviewing and re-coding comments using the new coding rules, the number of discrepantly-coded-comments was reduced to 26 negative comments (3.6\%), 21 externalizing behaviors comments (2.9\%), and 41 internalizing behavior comments (5.7\%). Finally, after repeating this process of reviewing remaining discrepancies, defining new rules, and re-coding, an inter-rater reliability of agreement of more than 99 percent was achieved among the coders. The small number of comments for which agreement was not achieved were excluded from the analysis.

As shown in Table 6, the new coding rules included teachers' comments describing extreme dependence, poor organization (work habits), self-control problems, and medical issues with consequent behavioral or emotional problems. For coding internalizing behaviors comments, the new rules added teachers' comments including 
youth' emotional (i.e., frustration, less motivation) and interpersonal problems (i.e., not respecting others, extreme dependence, lack of social skill). Whereas the new rules for coding negative comments did not include youth's effort to improve or change their behaviors, neutral descriptions, and medical diagnosis.

Table 6.

Established New Rules of Coding Comments

\begin{tabular}{cll}
\hline Types of & \multicolumn{1}{c}{ Included if } & \multicolumn{1}{c}{ Not included if } \\
comments & & \\
\hline Negative & Poor organization, Work habit, Self-control & Effort to improve and change, \\
& & Neutrality, Medical issues only \\
Externalizing & Medical issues with consequent behavioral & Medical issue only, Neutrality \\
& problems & \\
Internalizing & Extreme dependence, Extreme attention seeking & Medical issues only, Neutrality \\
& from peers or teachers, & \\
& Frustration, Not respecting others, & \\
& Medical issues with consequent emotional & \\
& problems. Less motivation, Lack of social skill
\end{tabular}

Hypothesis \#1: More than half of IEP documents would include teachers'

negative comments. The result of final coding of negative comments presented in Table 7 confirms the hypothesis. Almost three-fourths (72.4\%) of the IEP documents included one or more negative comment; 470 negative comments were identified, averaging 4.6 negative comments per youth.

Teachers' negative comments were coded to detect externalizing behavior and internalizing behavior based on the SARS (Walker et al., 1991). Approximately 44\% ( $\mathrm{n}=$ 
$318)$ of the negative comments referred to externalizing behaviors and $27 \%(n=193)$ referred to internalizing behaviors. Among 470 comments, 103 comments (21.9\%) were found to overlap two categories because they reflected multiple descriptions of behaviors of the youth.

Table 7.

Final Coding of Negative Comments $(n=111)$

\begin{tabular}{|c|c|c|c|c|c|c|c|c|}
\hline \multirow[b]{3}{*}{ Number of } & \multirow{2}{*}{\multicolumn{2}{|c|}{ Total }} & \multirow{2}{*}{\multicolumn{2}{|c|}{ Negative comments }} & \multicolumn{2}{|c|}{ Externalizing } & \multicolumn{2}{|c|}{ Internalizing } \\
\hline & & & & & behav & ments & behavi & aments \\
\hline & $\mathrm{N}$ & $\%$ & $\mathrm{~N}$ & $\%$ & $\mathrm{~N}$ & $\%$ & $\mathrm{~N}$ & $\%$ \\
\hline comments & 724 & 100 & 470 & 65.3 & 318 & 43.9 & 193 & 26.7 \\
\hline
\end{tabular}

Externalizing behavior. The SARS (Walker et al., 1991) suggested two types of externalizing behavior including disruptive behavior and rule-breaking behavior.

The IEP documents suggested youth exhibited various disruptive behaviors such as aggression, noncompliance, hyperactivity, extreme distractibility, defiance, and tantrums. For examples, these comments included, "He becomes louder, stubborn and accusatory", "He has a very difficult time getting himself calm", "He challenged staff requests to comply with directions", "His behavior at school includes defiance, power struggles, classroom disruptions, and inappropriate language," and "He has challenges in the areas of aggressive behavior, distractibility, and impulsiveness." Other descriptions included tardiness, assault/menacing, theft, and willful disobedience.

The IEP documents included teachers' negative comments related to rule-breaking behaviors that were related to school-imposed rules, such as attending class and finishing assignments. For example, comments noted, "His attendance was minimal and despite the 
interventions made and the continued support from his father, he did not make the kind of growth there that was hoped for by the team", "She slept in class," and "Given tasks, at a variety of levels, he demonstrates frequently work avoidance/work refusal."

Internalizing behavior. The SARS (Walker et al., 1991) suggested two types of internalizing behavior including internal problem behavior and interpersonal problem behavior.

The IEP documents included teachers' negative comments referencing youths' internal problem behaviors, such as being excessively shy and timid or severely withdrawn, having a general pervasive mood of unhappiness or depression, or having a tendency to develop physical symptoms or fears associated with personal or school problems. For example, "She may become overwhelmed by her schoolwork load and social situations. These situations may cause her to spiral in a way that she shuts down emotionally", "He often felt the other boys were staring at him," and "She seems to let things slide. It appears that her lack of self-esteem gets in the way."

The IEP documents also included teachers' negative statements referring to youths' inabilities to build or maintain satisfactory interpersonal relationships with peers and teachers and their difficulties in communicating with peers and teachers. For example, comments noted, "He rarely tries to initiate conversations with peers and when he does, appears to lack the appropriate social skills to do so successfully;" "She has difficulty understanding how and why such comments are socially inappropriate;" and "He is almost always by himself during social times and often appears lonely. This limited peer interaction may be what is familiar to him, but not necessarily in his best interest." 
Teachers' negative comments also appeared to mix externalizing and internalizing behaviors. For example, "He get frustrated often when something occurs like schedule changes that he hasn't had advance notice of and will act out in appropriate ways," and "He has severe mood swings, and will fluctuate between anger, refusal, sadness, threatening, and clowning around."

\section{Teachers' Stigmatizing Negative Comments on IEP Documents}

In line with the theoretical association between negative comments and stigma presented in Chapter 2 and earlier pilot findings (Noh et al., 2013), some teachers' negative comments were observed to feature subjective or judgmental attitudes rather than merely objectively describing the youth' behaviors. Therefore, in order to further examine teachers' negative and stigmatizing comments in IEP documents, the following exploratory research question was additionally considered: To what extent were teachers' stigmatizing negative comments toward foster youth in special education reflected on IEP documents?

Teacher's negative comments included all negative descriptions of youths' behavior or school performance, whereas stigmatizing comments were coded when teacher's negative comments specifically included subjective or judgmental features that reflected biased, stereotyped or prejudiced attitudes or perceptions toward the youth. Even though negative comments could include accurate descriptions of a youth's behavior, the addition of stigmatizing features conveyed negative attitudes or perceptions to others through the written descriptions, which one could assume may also have been communicated during conversations at these IEP meetings. Thus, such comments could 
create a negative atmosphere which stigmatizes youths, and have further negative influence on their educational outcomes and lives (Noh et al., 2013).

The pilot study (Noh et al., 2013) suggested four aspects of teachers' stigmatizing attitudes and perceptions within their negative comments: (1) teachers' subjective and judgmental opinions; (2) biased reports noted from other teachers; (3) teachers' low expectation about youths' academic potential and capacities for behavior change; and (4). negative comments with little reference to context or reason for negative behaviors or poor school performance.

This exploratory study sought to further investigate how teachers' negative comments reflect their stigmatizing attitudes and perception toward youth in foster care and special education, applying these four aspects suggested in the pilot study.

The coders independently reviewed and coded teachers' comments, using the same process of coding negative comments. Based on the aspects found in the pilot study (Noh et al., 2013), teachers' stigmatizing comments were coded. The coders also reviewed discrepant codes and established rules for coding subtle interpretations, and then independently re-coded the comments. Table 8 shows the results of the iterative process of coding stigmatizing comments.

Table 8.

Agreement for Coding Stigmatizing Comments between Coders $(n=111)$

\begin{tabular}{|c|c|c|c|c|c|c|c|}
\hline \multirow{2}{*}{\multicolumn{2}{|c|}{ Total }} & \multicolumn{6}{|c|}{ Disagreement } \\
\hline & & \multicolumn{2}{|c|}{$1^{\text {st }}$ coding } & \multicolumn{2}{|c|}{$2^{\text {nd }}$ coding } & \multicolumn{2}{|c|}{$3^{\text {rd }}$ coding } \\
\hline $\mathrm{N}$ & $\%$ & $\mathrm{~N}$ & $\%$ & $\mathrm{~N}$ & $\%$ & $\mathrm{~N}$ & $\%$ \\
\hline 724 & 100 & 94 & 17.0 & 31 & 4.3 & 8 & 1.1 \\
\hline
\end{tabular}


During initial coding, the coders disagreed on 94 stigmatizing comments (17.0\%).

The coders reviewed and discussed comments with discrepant codes, and then established new rules to code stigmatizing comments. The new coding rule included teachers' judgmental comments that attributed youths' negative behaviors or poor school performance only to their lack of effort and will. Whereas, the new coding rule did not include teachers' neutral descriptions about youths' behaviors.

After reviewing, discussing, and re-coding comments using new coding rules, the number of discrepantly coded-comments were reduced to 31 comments (4.3\%). Finally, after repeating this process of reviewing, defining new rules, and re-coding, an inter-rater reliability of agreement of more than 98 percent was achieved among the coders. The small number of comments for which agreement was not achieved was excluded in the analysis.

The results of final coding of stigmatizing comments showed that approximately two-thirds (62.6\%) of negative comments included stigmatizing features; 382 stigmatizing negative comments $(52.8 \%)$ were identified, averaging approximately three stigmatizing negative comments per youth.

This section concludes with examples of teachers' negative comments reflecting their stigmatizing perceptions and attitudes toward the youth.

Type 1: Teachers' subjectivity and judgment. Some teachers' comments included their subjective opinions, judgment and bias. For example, a teacher noted: He can also have the potential to be highly disruptive, difficult, defiant, verbally, abusive, and insubordinate depending on his mood that day or period of the week. 
He must start to be more organized and be willing to work at that skill. He should be taking more responsibility for having his materials here daily at school and not make excuses when he doesn't.

Part of his moodiness is born out of his obsessing about issues and difficulties at home that should not influence what is occurring at school.

Respecting others should be at the forefront of his thinking now.

Now that he is close to attending high school, he needs to think before he acts, because he is beginning to realize people are less tolerant of his numerous apologies for disrespect shown to them, and how that affects his relationship. If he is to fit into high school and society, he has to accept that there are rules and expectations in no matter what he participates in and exists by.

The teacher subjectively concluded that the youth's moodiness was caused by his obsessing about issues and difficulties at home that should not influence what was happening at school. The teacher judged that his unstable mood was linked to his disruptive, defiant, abusive, and insubordinate behaviors in class.

The teacher did not describe any information about what issues and difficulties the youth had experienced at home, and how harmful the experience was. Instead, the teacher subjectively concluded that the youth should have changed his attitude toward schooling, followed the school rules, and made efforts to satisfy the standards expected from teachers and school, regardless of what issues and difficulties the youth had experienced at his home.

Type 2: Biased reports from other teachers. Some teachers' comments described biased reports from other teachers, instead of direct observations. 
For example, a teacher only noted, "His math teacher states that he does not show his work because he does not think this is worth his time to do." Another teacher described, "Teachers feel that he avoids doing his work in this class. A teacher gets him started but when she needs to step away to help others, he loses focus and goes no further on his own."

These two teachers merely restated other teachers' subjective and judgmental opinions, instead of noting objective observations shared by others or offering their own objective and direct observations. This type of teacher report of other's stigmatizing negative comments could convey a general climate of bias toward youth, and foster an unsupportive atmosphere.

Type 3: Low expectations. IEP documents require teachers to write statements about youth in all areas related to their known disabilities, considering the ability of the youth to access the general curriculum as well as how the disability influences the youth's behaviors or school performance. However, teacher's comments explaining the youth's disability and its influences on behaviors or school performance often reflected their low expectations toward the youth. For example, a teacher noted,

When highly agitated he can become "rooted". At times like this he will be incapable of rational thought or talk. He will not move physically. Occasionally he will be physically aggressive. He was suspended twice. He had 12 incident reports in the same time period. He will react emotionally immediately, but his thought processes lag behind significantly.

Another teacher wrote, 
He got in one fight and was disciplined in accordance with school district policy. He attended the majority of this 8th grade year. A teacher reports at that time he could manage his behavior short time but that old behavior problem can eventually remerge. He has some struggles disengaging or telling peers that he does not want to participate in the behavior. He has shown that he is capable of this skill, but it may be a concern in the long run.

Another teacher noted,

Her aggressive behavior has been an issue in the last few years and she will pose a safety risk to herself and others if she is not properly supervised. Review of her discipline history last year and this academic year reveals 11 incident reports to the assistant principal. She also has had three incidents of fighting and one of disruptive conduct. She has been suspended out of school six days. With continued placement with same aged peers in the general education program and the onset of adolescence, her capacity to meet academic and social interaction expectations is very limited.

Type 4: Little context or reason. Some of teachers' negative comments were described with little reference to context or reason for youths' behaviors. Such teachers' comments convey their stigmatizing attitudes or perceptions that youth' negative outcomes would be caused by only a lack of effort or will of the youth.

A teacher noted, "He has very made little progress. He complained today that alphabetizing was too difficult for him. He has made no progress in behavioral skills. He has completed almost none of his class work." 
The teacher did not describe any context or potential reason(s) for his poor progress. Therefore, it seems to be that only a lack of effort was the cause. Another teacher offered the following description:

He fervently dislikes this placement. He did not want to participate in any classroom activities. Early in the placement, on several occasions, he walked out of the room. By the end of the third week he left the building entirely, threatening and swearing at staff who followed him across the campus or attempted to redirected him. At his re-entry meeting on the next school day he walked out and refused to return to school.

The teacher did not provide any concrete contexts or reasons why the youth did not want to participate in any classroom activities. Instead, the teacher subjectively concluded, "He fervently dislikes this placement. He did not want to participate in any classroom activities."

These stigmatizing negative comments also illustrated teacher's lack of understanding about how a specific educational setting, living condition, or family structure of the youth and a variety of interactions with teachers, case managers, caseworkers, or family members could affect a youth's behaviors and school performance.

In the above examples, teachers suggested that the youth had made little progress in their school performance, and that they had not wanted to complete homework or to bring materials for class activities. These comments illustrated teacher's lack of recognition that the youth might not have a suitable place to complete homework in their living conditions. The teachers also did not consider that some of the youth might not turn in assignments or bring materials for class activities if these youth could not receive 
appropriate care or encouragement from their foster care providers. For these youth, rather than a lack of motivation, poor school outcomes could be the result of a lack of access to resources and support for performing school work.

\section{Summary}

These results indicated that the IEP documents included many teachers' negative comments, and descriptions referring to youths' externalizing and internalizing behaviors. A substantial proportion of teacher's negative comments specifically included stigmatizing features that could convey negative attitudes or perception to others, including subjective or judgmental comments, biased reports from other teachers, low expectations, and little attention to context or reason.

This dissertation study further quantitatively investigated how these teachers' negative comments and stigmatizing negative comments influence youths' school performance. For these quantitative analyses, three subcategories of stigmatizing negative comments were incorporated; subjective or judgmental comments, biased reports from other teachers, and low expectations.

The fourth category, referring to teachers' negative comments with little reference to context or reason for negative behaviors or poor school performance, was not included in subsequent quantitative analyses. This category was omitted due to the possibility that teachers may not have described context or reason because it was previously noted or due to other reasons, such as teachers' lack of knowledge of the youths' foster care status.

\section{Preliminary Analyses}

The data file containing the variables of interest was screened prior to the quantitative analyses. Patterns of missing values were examined. All variables to be 
included within the study had less than $5 \%$ of the data points missing, except for school performance data.

All school performance data were extracted directly from the ESIS school databases and youth's transcripts. However, to minimize missing data for this relatively small sample, in some case, school records were supplemented by youth self-report on identical questions asked of youth in the Outcome Survey. This approach was used if the correlations between the school records and Outcome Survey-responses were statistically significant. Table 9 displayed case numbers of the school records and Outcome Surveyresponses and the result of the correlations between two data sources.

Table 9.

Case Numbers of School Performance Data

\begin{tabular}{|c|c|c|c|c|c|}
\hline \multirow{2}{*}{ Variable } & \multirow{2}{*}{ Time } & \multirow{2}{*}{$\begin{array}{c}\text { Transcripts } \\
N\end{array}$} & \multirow{2}{*}{$\begin{array}{c}\text { Outcome survey } \\
N\end{array}$} & \multicolumn{2}{|c|}{ Combined } \\
\hline & & & & $N$ & $\bar{\Gamma}$ \\
\hline \multirow[t]{2}{*}{ Absents } & Previous & 94 & 109 & 120 & $0.23^{*}$ \\
\hline & Time 2 & 90 & 103 & 117 & $0.34^{*}$ \\
\hline \multirow[t]{2}{*}{ Credits } & Previous & 94 & 61 & 110 & $0.65^{* *}$ \\
\hline & Time 2 & 90 & 46 & 106 & $0.30^{* *}$ \\
\hline \multirow[t]{2}{*}{ GPA } & Previous & 92 & 43 & 107 & 0.12 \\
\hline & Time 2 & 91 & 42 & 102 & $0.57^{* *}$ \\
\hline \multirow[t]{2}{*}{ Failed class } & Previous & 86 & - & - & \\
\hline & Time 2 & 90 & - & - & \\
\hline
\end{tabular}


Accordingly, data on the variables of credits obtained and absences were drawn from school records and the Outcome Survey, while data on failed classes and GPA scores was drawn solely from school records.

Univariate descriptives and bivariate analyses were conducted on continuous variables to ensure normality, linearity, and homoscedasticity and identify the presence and influence of outliers through the analysis of frequency distributions, histograms, scatterplots, and casewise diagnostics, including studentized residuals, leverage, Mahalnobis distance values, and Cook's Distance. An inspection of the univariate descriptives showed that there were no out of range values and the distributions appeared normal. There were no outliers revealed by studentized residuals, leverage and Malhalnobis distance diagnostics.

Multicollinearity and singularity were assessed through bivariate correlation matrices, and Variance Inflation Factor (VIF). All Pearson's correlations coefficients $(\gamma)$ were less than .90 (See table 18), and all VIFs did not exceed 10. Therefore, there were no violations of mulicollinearity and singularity.

\section{Bivariate Analyses Examining Difference in Teachers' Negative Comments by Race/ethnicity and Gender of the Youth}

Research Question II: Was there a significant difference in teachers' negative comments included in IEP documents by race, ethnicity, and gender of youth in foster care and special education? For answering this research question, the association of teachers' negative comments with youths' race/ethnicity and gender was analyzed.

This analysis incorporated all forms of negative comments. Table 10 included the means and standard deviations of teachers' negative comments by race/ethnicity and 
gender. Due to the small sample size and exploratory nature of the study, a p-value of < 0.10 was considered significant in all statistical analyses.

Table 10.

Teachers' Negative Comments Descriptives

\begin{tabular}{|c|c|c|c|c|c|c|c|c|}
\hline & & \multirow{3}{*}{$N$} & \multirow{2}{*}{\multicolumn{2}{|c|}{ Negative comments }} & Exte & ing & \multicolumn{2}{|c|}{ Internalizing } \\
\hline \multicolumn{2}{|c|}{ Variable } & & & & \multicolumn{2}{|c|}{ Comments } & \multicolumn{2}{|c|}{ Comments } \\
\hline & & & $\mathrm{M}$ & SD & $\mathrm{M}$ & SD & $\mathrm{M}$ & SD \\
\hline & & 123 & 3.81 & 4.02 & 2.59 & 2.96 & 1.57 & 2.10 \\
\hline Race/ & Caucasian $^{\mathrm{a}}$ & 61 & 3.52 & 3.72 & 2.31 & 2.71 & 1.41 & 2.10 \\
\hline ethnicity & Other groups & 62 & 4.11 & 4.13 & 2.85 & 3.19 & 1.73 & 2.11 \\
\hline \multirow{2}{*}{ Gender } & Male $^{\mathrm{a}}$ & 66 & 4.47 & 4.27 & $3.09^{*}$ & 3.22 & 1.71 & 2.12 \\
\hline & Female & 57 & 3.07 & 3.37 & 2.00 & 2.54 & 1.40 & 2.09 \\
\hline
\end{tabular}

Note. $\dagger p<.10, * p<.05, * * p<.01$.

${ }^{\text {a } I n d e p e n d e n t-s a m p l e ~ T-t e s t . ~}$

Hypothesis \#2: Caucasian youths would be less likely to have teachers' negative comments in IEP documents than other racial and ethnic groups, including African Americans, Asians, Hispanics, and Native Americans, controlling for youths' problem behaviors. An independent sample t-test was used to test mean differences of teachers' negative comments between Caucasian youths and other race/ethnic groups, and then an analysis of covariance (ANCOVA) was run to determine whether observed differences of teachers' negative comments between Caucasian youths and other race/ethnic groups were accounted for by youths' problem behaviors, including externalizing and internalizing behaviors, or associated with teachers' stigma related to youths' race and ethnicity. The dependent variable was teachers' negative comments, and the independent 
variable was race/ethnicity, which was dichotomized with the higher value (1) indicating Caucasian and the lower value (0) representing other ethnic groups. As covariate variables, externalizing behavior, and internalizing behavior scores of the Child Behavior Checklist (CBCL) were analyzed separately and in conjunction with one another.

The equal variances t-test failed to reveal a statistically reliable difference between the average of teachers' negative comments for Caucasian youths $(\mathrm{M}=3.52, \mathrm{SD}$ $=3.72)$ and those of other race/ethnic groups $(\mathrm{M}=4.11, \mathrm{SD}=4.13), t(121)=-0.830, p$ $=.408$.

A preliminary analysis of ANCOVA evaluating the homogeneity-of-regression (slopes) assumption was tested. The test evaluated the interaction between the covariate (CBCL) and the independent variable (race/ethnicity) in the prediction of the dependent variable (teachers' negative comments). A significant interaction between the covariate and the independent variable suggests that the differences on the dependent variable among the two groups of race/ethnicity vary as a function of the covariate. Therefore, if the interaction is significant, the results from an ANCOVA are not meaningful. The result of the homogeneity-of-regression test indicated that the interactions between race and externalizing behaviors of CBCL, and between race and internalizing behaviors of CBCL were not significant, $F(1,108)=2.235, p=.138, F(1,108)=0.175, p=.676$, respectively. However, the interaction between race and the combination of externalizing behaviors and internalizing behaviors of CBCL was significant, $F(1,108)=5,719, p$ $=.004$. Therefore, the combination of externalizing behaviors and internalizing behaviors of CBCL was not included in the ANCOVA. 
The results of ANCOVA suggested that race/ethnicity was not significant, when externalizing behaviors of CBCL was a covariate, $F(1,108)=0.774, p=.381$, and when internalizing behaviors of CBCL was a covariate, $F(1,108)=2.010, p=.159$. Therefore, the results from the independent sample t-test and ANCOVA indicated that there were no significant differences in teachers' negative comments by race and ethnicity of youth in foster care and special education.

\section{Hypothesis \#3: Female youth would be less likely to have teachers' negative} comments in IEP documents related to externalizing behaviors, and be more likely to have teachers' negative comments related to internalizing behaviors than male youths.

An independent sample t-test was run to test mean difference of teachers' negative comments between female and male youths, and then an analysis of covariance (ANCOVA) was run to determine whether observed differences of teachers' negative comments between male and female youths were accounted for by youths' problem behaviors, including externalizing and internalizing behaviors, or associated with teachers' stigma related to youths' race and ethnicity.

The independent variable was gender, which was dichotomized with the higher value (1) indicating male youth in foster care and special education and the lower value (0) indicating female youth in foster care and special education. The dependent variable was the number of teachers' negative comments related to externalizing and internalizing behavior. As covariate variables, externalizing behavior, and internalizing behavior scores of the Child Behavior Checklist (CBCL) were analyzed separately and in conjunction with one another. 
The equal variances t-test revealed a statistically reliable difference between the average of teachers' negative comments related to externalizing behaviors for male youths $(\mathrm{M}=3.09, \mathrm{SD}=3.22)$ and those of female youths $(\mathrm{M}=2.00, \mathrm{SD}=2.54), t(121)=$ $2.062, p<.05$. However, the t-test failed to reveal a statistically reliable difference between the average of teachers' comments related to internalizing behaviors for male youths $(\mathrm{M}=1.71, \mathrm{SD}=2.12)$ and those of female youths $(\mathrm{M}=1.40, \mathrm{SD}=2.09), t(121)=$ $0.810, p=.420$

The result of the homogeneity-of-regression test indicated that the interactions between gender and externalizing behaviors of CBCL, between gender and internalizing behaviors of CBCL, and between gender and the combination of externalizing behaviors and internalizing behaviors of CBCL were significant, $F(1,108)=4.930, p=.009, F(1$, $108)=8.383, p=.000$, and $F(1,108)=8.397, p=.000$, respectively. Given these interactions were significant, the ANCOVAs were not meaningful.

In sum, the results of the independent sample t-test and ANCOVA indicated that fewer negative comments related to externalizing and internalizing behaviors were included in the IEPs of Caucasian youth than the IEPs of youth of color, while not statistically significant. Likewise, the IEPs of males significantly included more teachers' negative comments related to externalizing behaviors than those for female. The IEPs of males also included more teachers negative comments related to internalizing behaviors that those for females, while not statistically significant.

Bivariate Analyses Examining Difference in Teachers' Stigmatizing Negative Comments by Race/ethnicity and Gender of the Youth 
In order to examine differences in teachers' stigmatizing negative comments between race/ethnic groups and between males and females, the following research question was additionally considered: Was there a significant difference in teachers' stigmatizing negative comments included in IEP documents by race, ethnicity, and gender of youth in foster care and in special education?

The three types of stigmatizing negative comments were combined for this analysis. Table 11 included the means and standard deviations of teachers' stigmatizing negative comments by race/ethnicity and gender.

Table 11.

Teachers' Stigmatizing Negative Comments Descriptives

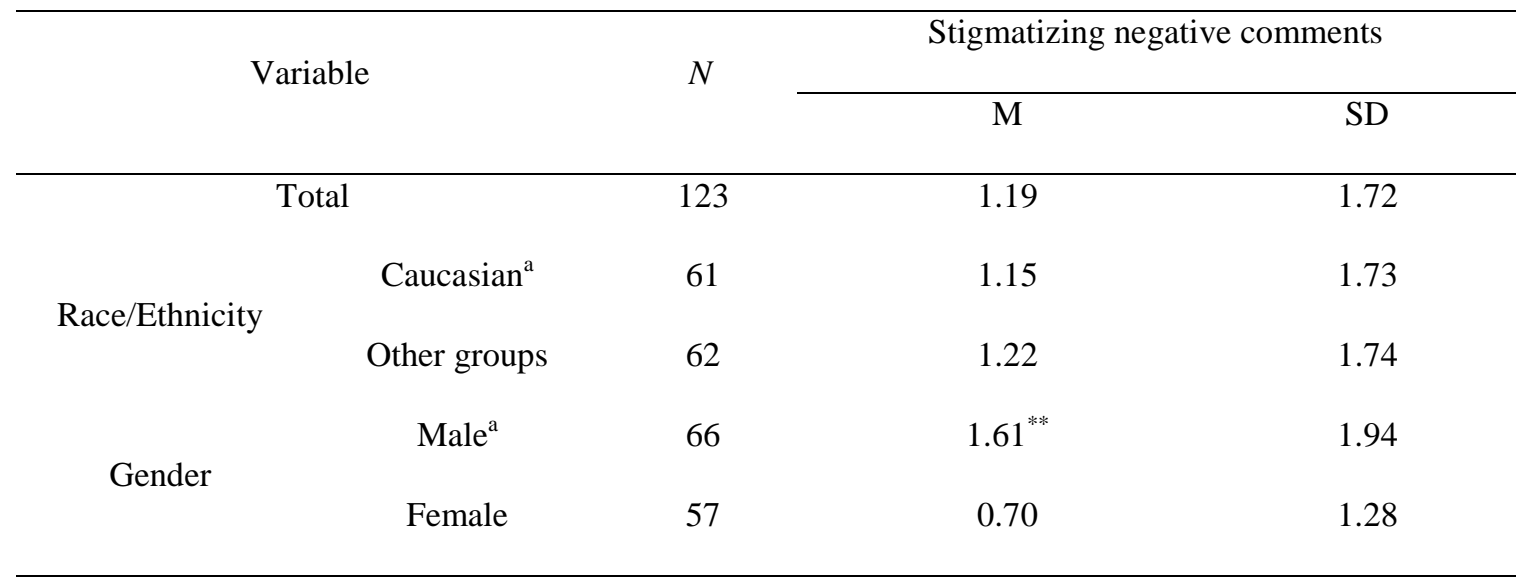

Note. $\dagger p<.10, * p<.05, * * p<.01$.

${ }^{\text {a } I n d e p e n d e n t-s a m p l e ~ T-t e s t . ~}$

An independent sample t-test was used to test mean differences of teachers' stigmatizing negative comments between Caucasian youths and other race/ethnic groups, and then an analysis of covariance (ANCOVA) was run to determine whether observed differences of teachers' stigmatizing negative comments between Caucasian youths and other race/ethnic groups were accounted for by youths' problem behaviors, including 
externalizing and internalizing behaviors, or associated with teachers' stigma related to youths' race and ethnicity.

The dependent variable was teachers' stigmatizing negative comments, and the independent variable was race/ethnicity, which was dichotomized with the higher value (1) indicating Caucasian and the lower value (0) representing other race/ethnic groups. As covariate variables, externalizing behavior, and internalizing behavior scores of the Child Behavior Checklist (CBCL) were analyzed separately and in conjunction with one another.

The equal variances t-test failed to reveal a statistically reliable difference between the average of teachers' stigmatizing negative comments for Caucasian youths $(\mathrm{M}=1.15, \mathrm{SD}=1.73)$ and those of other race/ethnic groups $(\mathrm{M}=1.22, \mathrm{SD}=1.74), t$ $(121)=0.270, p=0.787$.

The result of the homogeneity-of-regression test indicated that the interaction between race/ethnicity and internalizing behaviors of CBCL was not significant, $F(1,108)$ $=1.488, p=.231$. However, the interactions between race/ethnicity and externalizing behaviors of CBCL, and between race/ethnicity and the combination of externalizing behaviors and internalizing behaviors of CBCL were significant, $F(1,108)=2.661, p$ $=.074$, and $F(1,108)=2.779, p=.067$, respectively. Given these interactions were significant, the ANCOVAs were not meaningful. Therefore, internalizing behaviors of CBCL was only included in the ANCOVA as a covariate.

The results of the ANCOVA analyses suggested that race/ethnicity was not significant, when internalizing behaviors of the CBCL was a covariate, $F(1,108)=0.001$, $p=.971$. Therefore, the results from the independent sample t-test and ANCOVA 
indicated that there were no significant differences in teachers' stigmatizing negative comments by race and ethnicity of youth in foster care and special education.

To test whether female youths would be less likely to have teachers' stigmatizing comments than male youths, an independent sample t-test was run to test mean difference of teachers' stigmatizing negative comments between female and male youth, and then an analysis of covariance (ANCOVA) was run to determine whether observed differences of teachers' stigmatizing negative comments between male and female youths were accounted for youths' problem behaviors, including externalizing and internalizing behaviors, or associated with teachers' stigma related to youths' gender.

The independent variable was gender, which was dichotomized with the higher value (1) indicating male youth in foster care and special education and the lower value (0) indicating female youth in foster care and special education. The dependent variable was the number of teachers' stigmatizing negative comments. As covariate variables, externalizing behavior, and internalizing behavior scores of the Child Behavior Checklist (CBCL) were analyzed separately and in conjunction with one another.

The equal variances t-test revealed a statistically reliable difference of the average of teachers' stigmatizing comments between male youths $(\mathrm{M}=1.61, \mathrm{SD}=1.28)$ and female youths $(\mathrm{M}=0.70, \mathrm{SD}=1.28), \mathrm{t}(121)=-2.994, \mathrm{p}<.01$. Thus, male youth had significantly more teachers' stigmatizing negative comments on their IEPs, compared to female youth.

The result of the homogeneity-of-regression test indicated that the interactions between gender and externalizing behaviors of CBCL, between gender and internalizing behaviors of CBCL, and between gender and the combination of externalizing behaviors 
and internalizing behaviors of CBCL were significant, $F(1,108)=8.017, p=.001, F(1$, $108)=6.118, p=.003$, and $F(1,108)=8.402, p=.000$, respectively. Given these interactions were significant, the ANCOVAs were not meaningful.

In sum, the results from the independent sample t-test indicated that fewer teachers' stigmatizing negative comments were included in the IEPs of Caucasian youth than the IEPs of youth of color, while not statistically significant. The IEPs of males significantly included more stigmatizing negative comments than those for females. These results of teachers' stigmatizing negative comments were very similar with those of teachers' negative comments, while most were not statistically significant. Both of the results indicated that the IEPs of Caucasian youth consistently included fewer negative comments related to externalizing and internalizing behaviors, and stigmatizing negative comments than IEPs of youth of color. Likewise, the IEPs of males consistently included more negative comments related to externalizing and internalizing behaviors, and stigmatizing negative comments than those for females.

The results from the ANCOVA indicated that there were no significant differences of teachers' negative comments and stigmatizing negative comments by race/ethnicity and gender of youth, when controlling for youths' problem behaviors.

\section{Bivariate Relationships between Teachers' Negative Comments and Youths' School Performance}

School performance. Table 12 included the means and standard deviations of the youths' school performance at Time1 and Time 2. To determine whether there were mean difference between Time 1 and Time 2, the paired samples t-test was used for each of the four variables. 
With regards to failed classes, $42.3 \%$ of youth failed one or more classes previous to study entry, whereas $38.3 \%$ of the youth failed one or more classes at Time 2 . At Time 2 , the average number of days absents $(\mathrm{M}=12.31, \mathrm{SD}=17.31)$ was higher than the average number of days absents previous to study entry $(\mathrm{M}=11.22, \mathrm{SD}=13.889)$. However, there were no statistically significant mean difference of failed classes and days absents between previous to study entry and Time 2 .

Table 12.

School Performances Descriptives

\begin{tabular}{|c|c|c|c|c|}
\hline \multicolumn{2}{|c|}{ Variable } & $\%$ & Mean & SD \\
\hline \multirow{2}{*}{ Failed Classes } & Previous to study entry & 42.3 & - & - \\
\hline & Time 2 & 38.3 & - & - \\
\hline (yes or no, $\%$ ) & Difference & 4.0 & _- & _- \\
\hline & Previous to study entry & - & 4.55 & 3.90 \\
\hline \multirow{2}{*}{ (Average number of credits) } & Tim? & & 0 & O 71 \\
\hline & Difference & - & $3.73^{* *}$ & \\
\hline Absences & Previous to study entry & - & 11.22 & 13.88 \\
\hline (Average number of days & Time 2 & - & 12.31 & 17.31 \\
\hline absent) & Difference & - & 1.09 & \\
\hline \multirow{2}{*}{ GPA } & Previous to study entry & - & 1.91 & 1.10 \\
\hline & Time 2 & - & 2.17 & 0.98 \\
\hline (0 to 4.0 scale) & Difference & - & $0.26 \dagger$ & \\
\hline
\end{tabular}

Note. $\dagger p<.10, * p<.05, * * p<.01$.

At Time 2, as would be expected, the average number of credits obtained $(\mathrm{M}=$ $8.28, \mathrm{SD}=9.71)$ was higher than the average number of credits previous to study entry 
$(\mathrm{M}=4.55, \mathrm{SD}=3.90)$. At Time 2 , GPA score $(\mathrm{M}=2.17, \mathrm{SD}=0.98)$ also was higher than the score previous to study entry $(\mathrm{M}=1.91, \mathrm{SD}=1.10$. There were statistically significant differences of the mean number of credits obtained between previous to study entry and Time $2, t(114)=-4.320, p=.000$, and of GPA score between previous to study entry and Time $2, t(82)=-1.863, p<.10$.

Research Question III: To what extent did teachers' negative comments influence their youths' school performance, controlling for youths' participation in the IEP meeting, youths' participation in the self-determination intervention, and their school performance previous to entry into the study? Pearson correlation analyses were conducted to examine the relationships among all the variables, and then hierarchical regression analyses were run to examine the moderating effect of youths' participation in the IEP meetings, youths' participation in the self-determination intervention, and school performance previous to study entry on the linkage between teachers' negative comments and four indicators addressing youths' school performance measured at Time 2 (i.e., credits, failed classes, absences, and GPA).

The interaction of teachers' negative comments and youths' participation in the IEP meeting, teachers' negative comments and youths' participation in the selfdetermination intervention, and teachers' negative comments and youths' school performance previous to study entry were examined.

Hypothesis \#4: Youths who participated in the IEP meeting would be more likely to have higher level of effect of teachers' negative comments on their youth performance measured at Time 2 than those who did not participate in the IEP meeting. As shown in Table 13, the results from the correlation analyses revealed that 
youths' participation in the IEP meeting had no significant correlation with the indicators of school performance at Time 2, except for the relationship between youths' participation in the IEP meeting and the number of credits obtained, $\gamma=.208, \mathrm{p}<0.1$.

Table 13.

Correlation Analyses for Teachers' Negative Comments and Other Variables

\begin{tabular}{|c|c|c|c|c|c|c|c|c|c|c|}
\hline & 1 & 2 & 3 & 4 & 5 & 6 & 7 & 8 & 9 & 10 \\
\hline 1.T2 failed class & - & & & & & & & & & \\
\hline $2 . \mathrm{T} 2$ credits & .098 & & & & & & & & & \\
\hline 3.T2 absents & .102 & -.019 & - & & & & & & & \\
\hline 4.T2 GPA & $-.663^{* *}$ & .043 & -.132 & & & & & & & \\
\hline $\begin{array}{l}\text { 5Negative } \\
\text { Comments }\end{array}$ & .021 & -.070 & -.011 & .051 & & & & & & \\
\hline $\begin{array}{l}\text { 6.T1 Self- } \\
\text { Determination }\end{array}$ & .044 & -.008 & -.024 & .008 & -.076 & & & & & \\
\hline $\begin{array}{l}\text { 7.T1 IEP } \\
\text { meeting }\end{array}$ & -.080 & $.200 \dagger$ & -.009 & .065 & -.088 & .065 & & & & \\
\hline 8.T1 failed class & $.275^{*}$ & $-.191 \dagger$ & .101 & $-.400^{* *}$ & -.096 & .043 & -.113 & & & \\
\hline 9.T1 credits & .121 & $.330^{* *}$ & -.010 & .033 & $-.210^{*}$ & $.208^{*}$ & $.382^{* *}$ & $-.246^{*}$ & & \\
\hline 10.T1 absents & .097 & -.021 & $.566^{* *}$ & $-.237^{*}$ & -.107 & -.024 & -.030 & $.271^{* * *}$ & -.049 & \\
\hline 11.T1 GPA & $-.201 \dagger$ & .035 & $-.245^{*}$ & $.408^{* *}$ & -.049 & -.008 & .169 & $-.652^{* *}$ & $.342^{* *}$ & $-.308^{* *}$ \\
\hline
\end{tabular}

The hierarchical regression analyses also revealed that there were no significant associations between teachers' negative comments and the four indictors of youths' school performance at Time 2 (i.e., failed classes, credits obtained, absences and GPA). The effect that assessed Hypothesis \#4 was the interaction of teachers' negative 
comments and youths' participation in the IEP meeting in predicting youths' failed classes $(\mathrm{F}$ change $[85]=0.806, p=.494)$, credits obtained $(\mathrm{F}$ change $[94]=1.659, p$ $=.181)$, absences $(F$ change $[104]=0.076, p=.973)$, and GPA score $(F$ change $[85]$ $=.509, p=.677)$ at Time 2 .

Therefore, there was no statistically significant moderation effect of youths' participation in the IEP meetings on the relationship between teachers' negative comments and youths' school performance at Time 2 .

Hypothesis \#5: Youths who participated in the self-determination intervention would be more likely to have lower level of effect of teachers' negative comments on their school performance measured at Time 2 than those who did not participated in the self-determination intervention. As shown in Table 13, the results from the correlation analyses revealed that youths' participation in the self-determination intervention had no significant correlation with the four indicators of school performance at Time 2. Teachers' negative comments also had no significant correlation with the four indicators of the youths' school performance at Time 2 (i.e., failed classes, credits obtained, absences, and GPA), and with youths' participation in the self-determination intervention.

The hierarchical regression analyses also revealed that there was no significant correlation between teachers' negative comments and four indictors of youths' school performance at Time 2 (i.e., failed classes, credits obtained, attendance and GPA). The effect that assessed the Hypothesis \#5 was the interaction of teachers' negative comments and youths' participation in the self-determination intervention in predicting youths' failed classes $(F$ change $[93]=0.625, p=.600)$, credits obtained $(F$ change $[105]=0.207, p$ 
$=.891)$, absences $(F$ change $[116]=.074, p=.970)$, and GPA score $(F$ change $[93]=$ $0.361, p=.782)$ at Time 2 .

Therefore, there was no statistically significant moderation effect of youths' participation in the self-determination intervention on the relationship between teachers' negative comments and youths' school performance at Time 2 .

Hypothesis \#6: Youths with lower level of school performance previous to study entry would be more likely to have higher level of effect of teachers' negative comments on their school performance measured at Time 2 than those with higher level of school performance previous to study entry. The results from the correlation analyses shown in Table 13 revealed that a significant correlation between youths' school performance previous to study entry and youths' school performance at Time 2; failed classes previous to study entry was significantly correlated with failed classes at Time $2, \gamma=.275, p<.05$, credits obtained previous to study entry was significantly correlated with credits obtained at Time $2, \gamma=.330, p<.01$, attendance previous to study entry was significantly correlated with attendance at Time $2, \gamma=.566, p<.01$, and GPA score previous to study entry was significantly correlated with GPA score at Time $2, \gamma=.408, p<.01$.

However, there was also not significant correlations between teachers' negative comments and the indicators of youths' school performance previous to study entry except for the number of credits obtained, $\gamma=-.210, p<.05$.

The hierarchical regression analyses revealed that there was no evidence to conclude that the indicators of youths' school performance previous to study entry moderated the relationship between teachers' negative comments and youths' school performance at Time 2. As shown in Table 14, the interaction of teachers' negative 
comments and youths' school performance previous to study entry, which was assessed to examine the hypothesis \#6, was not significant in predicting youths' school performance at Time 2 .

Table 14.

Hierarchical Regression Analysis for Moderation Effects of Youths' School Performance

Previous to Study Entry

School Performance at Time 2

\begin{tabular}{llll}
\cline { 3 - 3 } Regression equation & Failed classes & Credits & Absences
\end{tabular}

\begin{tabular}{llllllll}
\hline$R^{2} \Delta$ & $B$ & $R^{2} \Delta$ & $\beta$ & $R^{2} \Delta$ & $B$ & $R^{2} \Delta$ & $B$
\end{tabular}

Step 1

1. Teachers' Negative Comments

$0.005 \quad 0.061$

0.007

$-0.857 \quad 0.000$

$\begin{array}{lll}-1.21 & 0.000 & 0.008\end{array}$

Step 2

2. School $\quad$ Failed classes $0.079 \quad 0.145^{* *}$



Previous

Absences

$0.3249 .940^{* *}$

GPA

$0.167 \quad 0.408^{* *}$

Step 3

$1 \times 2 \quad$ Failed classes $\quad 0.013 \quad 0.061$

$\begin{array}{lll}\text { Credits } & 0.085 & -0.794\end{array}$

$\begin{array}{lll}\text { Absences } & 0.001 & -0.637\end{array}$

GPA

$0.002-0.043$

$$
\Delta \mathrm{F}(78)=1.116 \quad \Delta \mathrm{F}(95)=3.928^{*} \quad \Delta \mathrm{F}(114)=17.760^{* *} \quad \Delta \mathrm{F}(82)=5.350^{* *}
$$

Note. $\dagger p<.10,{ }^{*} \mathrm{p}<.05,{ }^{* *} \mathrm{p}<.01,{ }^{* * *} \mathrm{p}<.001$.

Bivariate Relationships between Teachers' Stigmatizing Negative comments and

Youths' School Performance at Time 2 
Additionally, in order to examine the effect of teachers' stigmatizing negative comments on youths' school performance at Time 2, controlling for youths' participation in the IEP meeting, youths' participation in the self-determination intervention, and school performance previous to entry into the study, the following research question was considered: To what extent did teachers' stigmatizing negative comments influence their youths' school performance, controlling for youths' participation in their IEP meeting, youths' participation in the self-determination intervention, and their school performance previous to entry into the study?

As the examinations of teachers' negative comments, Pearson correlation analyses were conducted to examine the relationships among all the variables, and then hierarchical regression analyses were run to examine the moderating effect of youths' participation in the IEP meeting, youths' participation in the self-determination intervention, and school performance previous to study entry on the linkage between teachers' stigmatizing negative comments and the four indicators addressing youths' school performance measured at Time 2 (i.e., credits, failed classes, absences, and GPA).

The interaction of teachers' stigmatizing negative comments and youths' participation in the IEP meeting, teachers' stigmatizing negative comments and youths' participation in the self-determination intervention, and teachers' stigmatizing negative comments and youths' school performance previous to study entry were examined.

As shown in Table 15, the results from the correlation analyses revealed that teachers' stigmatizing negative comments had no significant correlation with the four indicators of the youths' school performance at Time 2 (i.e., failed classes, credits obtained, attendance and GPA), with youths' participation in the self-determination 
intervention, and with the youths' participation in the IEP meeting. There was also no significant correlation between teachers' stigmatizing negative comments and the indicators of youths' school performance previous to study entry except for the number of credits obtained, $\gamma=-.211, \mathrm{p}<.05$.

Table 15.

Correlation Analyses for Teachers' Stigmatizing Comments and Other Variables

\begin{tabular}{|c|c|c|c|c|c|c|c|c|c|c|}
\hline & 1 & 2 & 3 & 4 & 5 & 6 & 7 & 8 & 9 & 10 \\
\hline 1.T2 failed class & - & & & & & & & & & \\
\hline $2 . \mathrm{T} 2$ credits & .098 & & & & & & & & & \\
\hline 3.T2 absents & .102 & -.019 & - & & & & & & & \\
\hline 4.T2 GPA & $-.663^{* *}$ & .043 & -.132 & & & & & & & \\
\hline 5.Stig.Comments & s -.003 & -.070 & -.046 & .067 & & & & & & \\
\hline $\begin{array}{l}\text { 6.T1 Self- } \\
\text { Determination }\end{array}$ & .044 & -.008 & -.024 & .008 & -.090 & & & & & \\
\hline $\begin{array}{l}\text { 7.T1 IEP } \\
\text { meeting }\end{array}$ & -.080 & $.200 \dagger$ & -.009 & .065 & -.027 & .065 & & & & \\
\hline 8.T1 failed class & $.275^{*}$ & $-.191 \dagger$ & .101 & $-.400^{* *}$ & -.167 & .043 & -.113 & & & \\
\hline 9.T1 credits & .121 & $.330^{* * *}$ & -.010 & .033 & $-.211^{*}$ & $.208^{*}$ & $.382^{* *}$ & $-.246^{*}$ & & \\
\hline 10.T1 absents & .097 & -.021 & $.566^{* *}$ & $-.237^{*}$ & -.100 & -.024 & -.030 & $.271^{* *}$ & -.049 & \\
\hline 11.T1 GPA & $-.201 \dagger$ & .035 & $-.245^{*}$ & $.408^{* *}$ & -.027 & -.008 & .169 & $-.652^{* *}$ & $.342^{* *}$ & $-.308^{* *}$ \\
\hline
\end{tabular}

Note. $\dagger p<.10, * p<.05, * * p<.01$.

The hierarchical regression analyses also revealed that there was no significant correlation between teachers' stigmatizing negative comments and the four indictors of youths' school performance at Time 2 (i.e., failed classes, credits obtained, absences and GPA), and no significant evidence to conclude that youths' participation in the IEP 
meeting and youths' participation in the self-determination intervention moderated the relationship between teachers' stigmatizing negative comments and youths' school performance at Time 2.

Table 16.

Hierarchical Regression Analysis for Moderation Effects of Youths' School Performance Previous to Study Entry

\begin{tabular}{|c|c|c|c|c|c|c|c|c|c|}
\hline \multirow{3}{*}{\multicolumn{2}{|c|}{ Regression equation }} & \multicolumn{8}{|c|}{ School Performance at Time 2} \\
\hline & & \multicolumn{2}{|c|}{ Failed classes } & \multicolumn{2}{|c|}{ Credits } & \multicolumn{2}{|c|}{ Absences } & \multicolumn{2}{|c|}{ GPA } \\
\hline & & $R^{2} \Delta$ & $\beta$ & $R^{2} \Delta$ & $\beta$ & $R^{2} \Delta$ & $\beta$ & $R^{2} \Delta$ & $B$ \\
\hline \multicolumn{10}{|l|}{ Step 1} \\
\hline 1. Stigmatiz & Comments & 0.002 & 0.021 & 0.006 & -0.777 & 0.001 & -0.668 & 0.002 & 0.040 \\
\hline \multicolumn{10}{|l|}{ Step 2} \\
\hline 2. School & Failed classes & 0.081 & $0.145^{* *}$ & & & & & & \\
\hline Performanc & Credits & & & 0.103 & $3.467^{* *}$ & & & & \\
\hline \multirow[t]{2}{*}{ e Previous } & Absences & & & & & 0.320 & $9.865^{* *}$ & & \\
\hline & GPA & & & & & & & 0.167 & $0.408^{* *}$ \\
\hline \multicolumn{10}{|l|}{ Step 3} \\
\hline \multirow[t]{5}{*}{$1 \times 2$} & Failed classes & 0.010 & 0.055 & & & & & & \\
\hline & Credits & & & 0.005 & -0.796 & & & & \\
\hline & Absences & & & & & 0.001 & -0.799 & & \\
\hline & GPA & & & & & & & 0.009 & -0.099 \\
\hline & & \multicolumn{2}{|c|}{$\Delta \mathrm{F}(81)=2.669 \dagger$} & \multicolumn{2}{|c|}{$\Delta \mathrm{F}(95)=3.929^{*}$} & \multicolumn{2}{|c|}{$\Delta \mathrm{F}(114)=17.564^{* *}$} & \multicolumn{2}{|c|}{$\Delta \mathrm{F}(82)=5.685^{* *}$} \\
\hline
\end{tabular}

Note. $\dagger p<.10,{ }^{*} \mathrm{p}<.05,{ }^{* *} \mathrm{p}<.01,{ }^{* * *} \mathrm{p}<.001$. 
The interaction of teachers' stigmatizing negative comments and youths' participation in the IEP meeting did not significantly predict failed classes (F change [85] $=1.172, p=.326)$, credits obtained $(\mathrm{F}$ change $[94]=1.564, p=.204)$, absences $(\mathrm{F}$ change $[104]=.280, p=.840)$, or GPA (F change $[85]=0.676, p=.569)$ at Time 2 . The interaction of teachers' stigmatizing negative comments and youths' participation in the self-determination intervention did not significantly predict failed classes ( $F$ change [93] $=0.845, p=.473)$, credits obtained $(F$ change $[105]=0.130, p=.942)$, attendance $(F$ change $[116]=.279, p=.840)$, and GPA $(F$ change $[93]=0.709, p=.549)$ at Time 2 . As shown in Table 16, the interaction of teachers' stigmatizing negative comments and youths' school performance previous to study entry did not significantly predict youths' school performance at Time 2 .

The Mediational Effect of Youths' School Attitude and Problem Behavior on the Relationship between Teachers' Negative comments on Youths' School Performance measured at Time 2

Youths' School Attitudes and Problem Behaviors. Table 17 included the means and standard deviations of the youths' Child Behavior Checklist (CBCL), and School Attitudes Measure (SAM).

With regards to school attitudes and problem behaviors, which were measured at Time 1, the average motivation to schooling and sense of control over performance scores were $1.90(\mathrm{SD}=0.54)$ and $2.15(\mathrm{SD}=0.44)$, respectively, and the average external problem behaviors and internal problem behaviors scores were $62.14(\mathrm{SD}=9.33)$ and $57.62(\mathrm{SD}=9.53)$, respectively. 
Table 17.

School Attitudes and CBCL Descriptives

\begin{tabular}{cccc}
\hline & Sub-scales & \multicolumn{2}{c}{ Total $(\mathrm{n}=123)$} \\
\cline { 3 - 4 } & & $\mathrm{M}$ & $\mathrm{SD}$ \\
\hline School Attitude & Motivation to schooling & 1.90 & 0.54 \\
Measure & Sense of control over performance & 2.15 & 0.44 \\
& & & \\
CBCL & External problem behaviors & 62.14 & 9.33 \\
& Internal problem behaviors & 57.62 & 9.53 \\
\hline
\end{tabular}

As shown in Table 18, the result from the correlation analysis revealed that teachers' negative comments had no significant correlations with two indicators of youths' school attitudes, including motivation to schooling and sense of control over performance. Among four indicators of school performance measured at Time 2, only youths' absences had significant correlations with their motivation to schooling and sense of control over performance, $\gamma=-.158, p<.10$, and $\gamma=-.299, p<.01$, respectively.

Among the four indicators of school performance previous to study entry, motivation to schooling had a significant correlation with failed classes, $\gamma=-.238, p<.05$, and sense of control over performance had significant correlations with absences, $\gamma$ $=.356, p<.01, \mathrm{GPA}, \gamma=.209, p<.05$, and failed classes, $\gamma=-.211, p<.05$.

Teachers' negative comments had significant correlations with youths' external problem behaviors, $\gamma=.280, p<.01$ and internal problem behaviors, $\gamma=.194, p<.05$, and youths' external problem behaviors had a significant correlation with youths' absences among the four indictors of youths' school performance at Time $2, \gamma=.198, p$ 
Table 18.

Correlation Analyses for Teachers' Negative Comments and Other Variables

\begin{tabular}{|c|c|c|c|c|c|c|c|c|}
\hline & 1 & 2 & 3 & 4 & 5 & 6 & 7 & 8 \\
\hline 1. T2 failed class & - & & & & & & & \\
\hline 2. $\mathrm{T} 2$ credits & .098 & - & & & & & & \\
\hline 3. T2 absents & .102 & -.019 & - & & & & & \\
\hline 4. T2 GPA & $-.663^{* *}$ & .043 & -.132 & - & & & & \\
\hline 5. Negative & .021 & -.070 & -.011 & .051 & - & & & \\
\hline \multicolumn{9}{|l|}{ Comments } \\
\hline 6. SAM: Motivation & -.158 & -058 & $-.158 \dagger$ & .109 & .000 & - & & \\
\hline \multicolumn{9}{|l|}{ to Schooling } \\
\hline 7. SAM: Sense of & -.157 & -.093 & $-.299^{* *}$ & $.175 \dagger$ & -.021 & $.618^{* *}$ & - & \\
\hline \multicolumn{9}{|l|}{ Control over } \\
\hline \multicolumn{9}{|l|}{ Performance } \\
\hline 8. CBCL: & -.043 & .028 & .068 & .148 & $.194^{*}$ & -.142 & $-.222^{*}$ & - \\
\hline \multicolumn{9}{|l|}{ Internalizing } \\
\hline 9. CBCL: & -.016 & -.121 & $.198^{*}$ & -.031 & $.280^{* * *}$ & $-.232^{*}$ & $-.369^{* *}$ & $.461^{* *}$ \\
\hline \multicolumn{9}{|l|}{ Externalizing } \\
\hline 10. T1 Self- & .044 & -.008 & -.024 & .008 & -.076 & .096 & -.059 & -.145 \\
\hline \multicolumn{9}{|l|}{ Determination } \\
\hline $\begin{array}{l}\text { 11. T1 Participation } \\
\text { in IEP meeting }\end{array}$ & -.080 & $.200 \dagger$ & -.009 & .065 & -.088 & .033 & -.044 & .073 \\
\hline 12. $\mathrm{T} 1$ failed class & $.275^{*}$ & $-.191 \dagger$ & .101 & $-.400^{* *}$ & -.096 & $-.238^{*}$ & $-.211^{*}$ & $-.236^{*}$ \\
\hline 13. T1 credits & .121 & $.330^{* *}$ & -.010 & .033 & $-.210^{*}$ & .126 & .069 & .025 \\
\hline 14. T1 absents & .097 & -.021 & $.566^{* *}$ & $-.237^{*}$ & -.107 & -.123 & $-.356^{* *}$ & .013 \\
\hline 15. T1 GPA & $-.201 \dagger$ & .035 & $-.245^{*}$ & $.408^{* *}$ & -.049 & .147 & $.209^{*}$ & .151 \\
\hline
\end{tabular}




$\begin{array}{llllllll}8 & 9 & 10 & 11 & 12 & 13 & 14 & 15\end{array}$

1. T2 failed class

2. $\mathrm{T} 2$ credits

3. T2 absents

4. T2 GPA

5. Negative

\section{Comments}

6. SAM: Motivation

to Schooling

7. SAM: Sense of

Control over

Performance

8. CBCL:

Internalizing

9. CBCL:

$.461^{* *} \quad-$

Externalizing

10. T1 Self-

$-.145-.062-$

Determination

11. T1 Participation

$.073 \quad-.046 \quad .065$

in IEP meeting

12. $\mathrm{T} 1$ failed class

$\begin{array}{lllll}-.236^{*} & -.016 & .043 & -.113 \quad-\end{array}$

13. $\mathrm{T} 1$ credits

$.025 \quad-.222^{*} \quad .208^{*} \quad .382^{* *} \quad-.246^{*}$

14. $\mathrm{T} 1$ absents

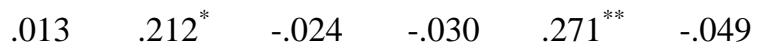

15. T1 GPA

$.151 \quad-.224^{*} \quad-.008 \quad .169$

$-.652^{* *} \quad .342^{* *} \quad-.308^{* *} \quad-$

Note. $\dagger p<.10, * p<.05, * * p<.01$. 
$<.05$. However, there was no significant correlation between youths' internal problem behaviors and the four indictors of youths' school performance at Time 2 .

The results indicated that youths' external problem behaviors had significant correlations with indicators of youths' school performance previous to study entry, including credits obtained, $\gamma=-.222, p<.05$, absences, $\gamma=.212, p<.05$, and GPA, $\gamma=-$ $.224, p<.05$, and that youths' internal problem behaviors also had significant correlations with failed classes, $\gamma=-.236, p<.05$, among the four indicators of school performance previous to study entry. However, youths' participation in the IEP meeting, and youths' participation in the self-determination intervention had no significant correlations with any indicators of youths' school attitudes and problem behaviors.

Research Question IV: To what extent did youth's school attitudes mediate the impact of teachers' negative comments on their school performance at Time 2, controlling for youths' participation in the self-determination intervention, youths' participation in the IEP meeting, and youths' school performance previous to study entry? For testing the impact of teachers' negative comments on youths' school performance, both directly and through mediation by youths' school attitudes, a Structural Equation Modeling (SEM) was used.

Hypothesis \#7: Youths' school attitudes would be a partial mediator in the relationship between teachers' negative comments and youths' school performance at Time 2, controlling for youths' participation in IEP meeting, youths' participation in the self-determination intervention, and youths' school performances previous to study entry. 
Direct effects of teachers' negative comments and youths' school attitudes on

youths' school performance. To test this hypothesis, four structural equation models were developed that included only the direct relationships of the constructs models (See Figure $5)$.

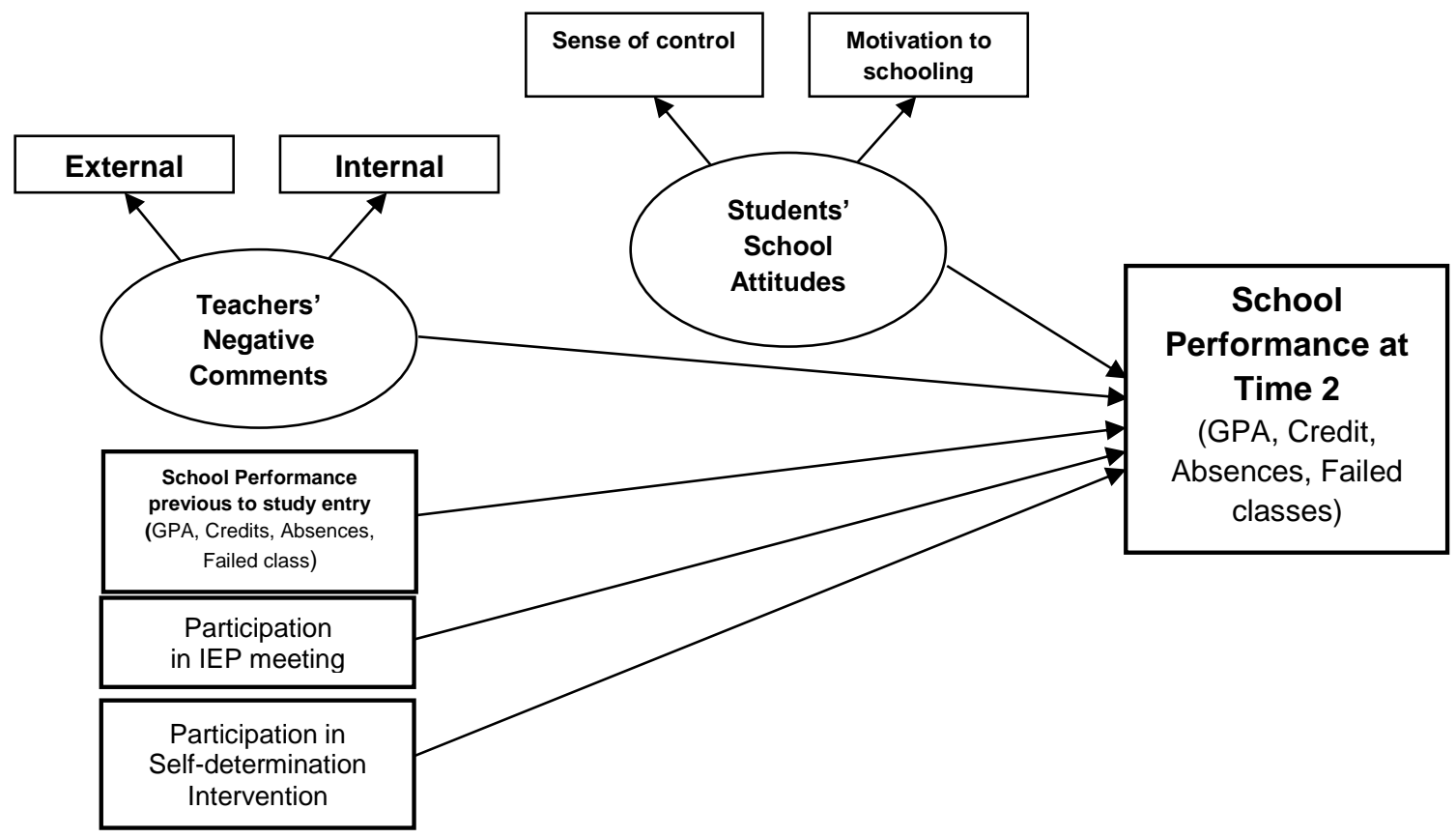

Figure 5. The multiple regression model of direct effects of teachers' negative comments and youths' school attitudes on youths' school performance measured at Time 2.

Table 19.

Fit Indices for Direct Effects of the Predictors on School Performance at Time 2.

\begin{tabular}{lccccccc}
\hline \multicolumn{1}{c}{ Model } & $N$ & $\chi^{2}$ & $D f$ & $p$ & $\chi^{2}: d f$ & CFI & RMSEA \\
\hline Failed class & 75 & 4.890 & 9 & 0.844 & 0.543 & 1.000 & 0.000 \\
Credits obtained & 87 & 3.642 & 9 & 0.933 & 0.405 & 1.000 & 0.000 \\
Absences & 103 & 7.483 & 9 & 0.587 & 0.831 & 1.000 & 0.000 \\
GPA & 76 & 8.426 & 9 & 0.492 & 0.936 & 1.000 & 0.000 \\
\hline
\end{tabular}


Table 19 displayed fit indices of the models, and Table 20 revealed the standardized regression coefficients and total $R^{2}$ values.

Table 20.

Parameter Estimates of Direct Effects of the Predictors on School Performance at Time 2.

\begin{tabular}{|c|c|c|c|c|c|}
\hline Outcome & Predictors & $\beta$ & $B$ & & $R^{2}$ \\
\hline \multirow[t]{5}{*}{ Failed class } & Teachers' negative comments & -0.025 & -0.019 & & .12 \\
\hline & IEP meeting & -0.014 & -0.016 & & \\
\hline & Self-determination & -0.070 & -0.069 & & \\
\hline & Failed class previous to study entry & 0.274 & 0.279 & $*$ & \\
\hline & School attitudes & -0.145 & -0.150 & & \\
\hline Credits & Teachers' negative comments & -0.075 & -0.105 & & .13 \\
\hline \multirow[t]{4}{*}{ obtained } & IEP meeting & 0.097 & 2.235 & & \\
\hline & Self-determination & -0.057 & -1.186 & & \\
\hline & Credits previous to study entry & 0.292 & 0.791 & $*$ & \\
\hline & School attitudes & -0.008 & -0.035 & & \\
\hline \multirow[t]{5}{*}{ Absences } & Teachers' negative comments & 0.051 & 0.396 & & .34 \\
\hline & IEP meeting & 0.029 & 1.157 & & \\
\hline & Self-determination & -0.013 & -0.485 & & \\
\hline & Absences previous to study entry & 0.571 & 0.722 & $* * *$ & \\
\hline & School attitudes & -0.051 & -4.157 & & \\
\hline \multirow[t]{5}{*}{ GPA } & Teachers' negative comments & -0.011 & 0.000 & & .18 \\
\hline & IEP meeting & 0.020 & 0.046 & & \\
\hline & Self-determination & 0.051 & 0.103 & & \\
\hline & GPA previous to study entry & 0.374 & 0.343 & $* * *$ & \\
\hline & School attitudes & 0.112 & 0.321 & & \\
\hline
\end{tabular}

Note. $\dagger p<.10,{ }^{*} \mathrm{p}<.05,{ }^{* *} \mathrm{p}<.01,{ }^{* * *} \mathrm{p}<.001$ 
In the direct model with failed class, the model fit well $\left(\chi^{2}: d f=.543, \mathrm{CFI}=1.000\right.$, RMSEA $=0.000$ ). However, when controlling for youths' participation in IEP meeting, youths' participation in the self-determination intervention, and failed class previous to study entry, failed classes at Time 2 was not predicted by teachers' negative comments $(\beta$ $=-.025, p>.10)$ and youths' school attitudes $(\beta=-.145, p>.10)$. Only failed class previous to study entry significantly predicted failed class at Time $2(\beta=.274, p<.05)$. This model accounted for $12 \%$ of the variance in failed class at Time 2 .

In the direct model with credits obtained, the model fit well $\left(\chi^{2}: d f=.405, \mathrm{CFI}\right.$ $=1.000$, RMSEA $=0.000)$. However, when controlling for youths' participation in IEP meeting, youths' participation in the self-determination intervention, and credits obtained previous to study entry, credits obtained at Time 2 was not predicted by teachers' negative comments $(\beta=-.075, p>.10)$ and youths' school attitudes $(\beta=-.008, p>.10)$. Only credits obtained previous to study entry significantly predicted credits obtained at Time $2(\beta=.292, p<.05)$. This model accounted for $13 \%$ of the variance in credits obtained at Time 2 .

In the direct model with absences, the model fit well $\left(\chi^{2}: d f=.831, \mathrm{CFI}=1.000\right.$, RMSEA $=0.000$ ). However, when controlling for youths' participation in IEP meeting, youths' participation in the self-determination intervention, and absences previous to study entry, absences at Time 2 was not predicted by teachers' negative comments $(\beta=-$ $.051, p>.10)$ and youths' school attitudes $(\beta=-.051, p>.10)$. Only absences previous to study entry significantly predicted absences at Time $2(\beta=.571, p<.001)$. This model accounted for $34 \%$ of the variance in absences at Time 2. 
In the direct model with GPA, the model fit well $\left(\chi^{2}: d f=.936, \mathrm{CFI}=1.000\right.$, RMSEA $=0.000)$. However, when controlling for youths' participation in IEP meeting, youths' participation in the self-determination intervention, and GPA previous to study entry, GPA at Time 2 was not predicted by teachers' negative comments $(\beta=-.011, p$ $>.10)$ and youths' school attitudes $(\beta=.112, p>.10)$. Only GPA previous to study entry significantly predicted GPA at Time $2(\beta=.374, p<.001)$. This model accounted for $18 \%$ of the variance in GPA at Time 2.

In sum, youths' school attitudes had no significant direct effect on all indicators of school performance at Time 2, including failed class, credits obtained, absences, and GPA. Based on Baron and Kenny (1986)'s criteria for testing mediation relationship, these mediational models did not provide evidences of mediation effect of youths' school attitudes on the relationships between teachers' negative comments and youths' school performance at Time 2, controlling for youths' participation in IEP meeting, youths' participation in the self-determination intervention, and absences previous to study entry.

Research Question V: To what extent did youth's problem behaviors mediate the impact of teachers' negative comments on their school performance, controlling for youths' participation in the self-determination intervention, youths' school performance previous to study entry, and youths' participation in the IEP meeting? For testing the impact of teachers' negative comments on youths' school performance, both directly and through mediation by youths' problem behaviors, a Structural Equation Modeling (SEM) was used.

Hypothesis \#8: Youths' problem behaviors would be a partial mediator in the relationship between teachers' negative comments and youths' school performance at 
Time 2, controlling for youths' participation in IEP meeting, youths' participation in the self-determination intervention, and school performances previous to study entry.

Direct effects of teachers' negative comments, and youths' problem behaviors on youths' school performance. To test this hypothesis, four structural equation models were developed that included only the direct relationships of the constructs models (See Figure $6)$.

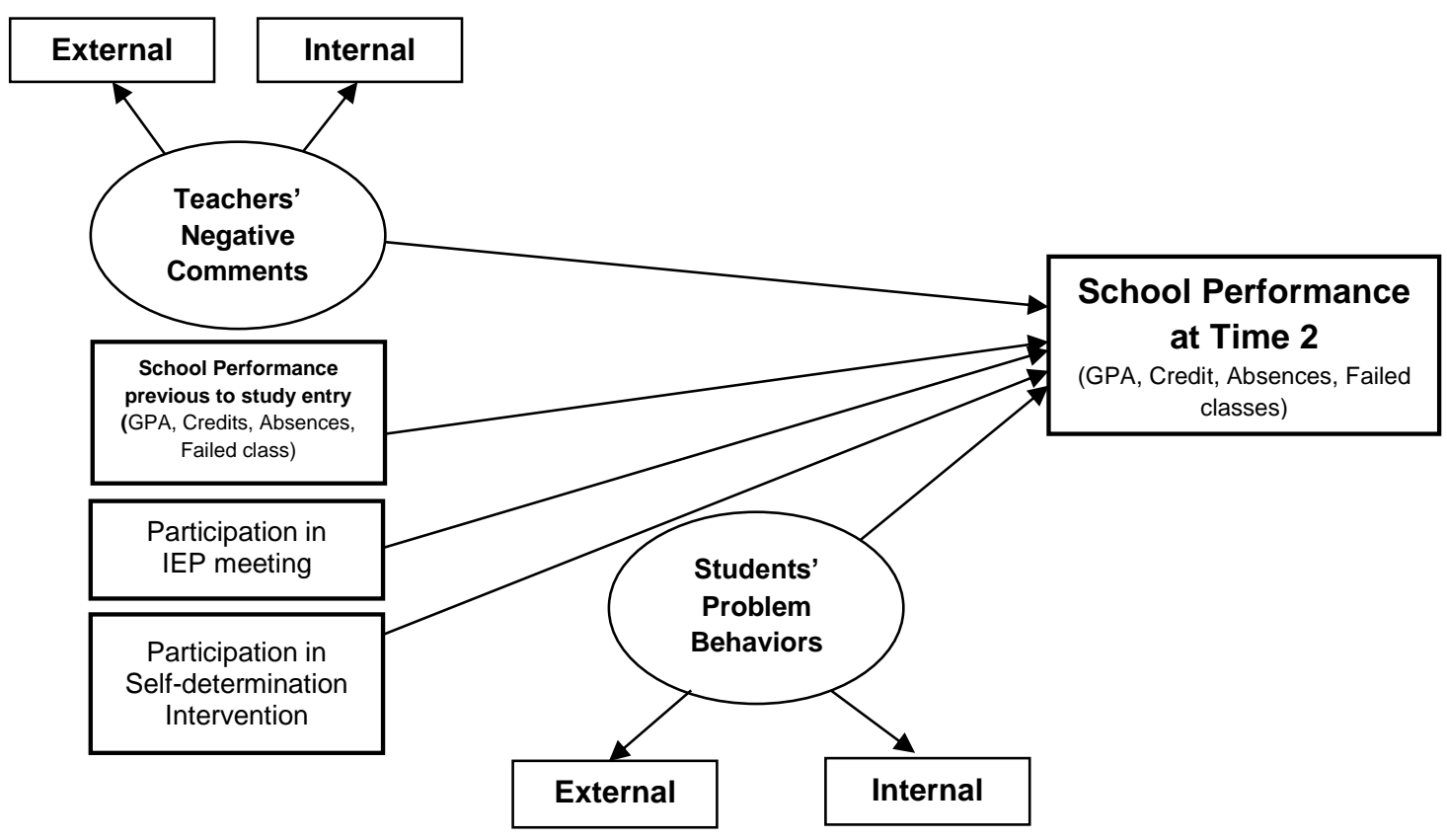

Figure 6. The multiple regression model of direct effects of teachers' negative comments and youths' problem behaviors on youths' school performance measured at Time 2 .

Table 21 displayed fit indices of the models, and Table 22 revealed the standardized regression coefficients and total $R^{2}$ values.

In the direct model with failed class, the model fit well $\left(\chi^{2}: d f=.807, \mathrm{CFI}=1.000\right.$, RMSEA $=0.000$ ). However, when controlling for youths' participation in IEP meeting, youths' participation in the self-determination intervention, and failed class previous to 
study entry, failed classes at Time 2 was not predicted by teachers' negative comments $(\beta$ $=.129, p>.10)$ and youths' problem behaviors $(\beta=-.143, p>0.10)$. Only failed class previous to study entry significantly predicted failed class at Time $2(\beta=.322, p<0.01)$. This model accounted for $13 \%$ of the variance in failed class at Time 2 .

Table 21.

Fit Indices for Direct Models on School Performance at Time 2

\begin{tabular}{lccccccc}
\hline \multicolumn{1}{c}{ Model } & $N$ & $\chi^{2}$ & $D f$ & $P$ & $\chi^{2}: d f$ & CFI & RMSEA \\
\hline Failed class & 72 & 7.251 & 9 & 0.611 & 0.807 & 1.000 & 0.000 \\
Credits obtained & 82 & 13.591 & 9 & 0.138 & 1.510 & 0.948 & 0.079 \\
Absences & 97 & 10.542 & 9 & 0.308 & 1.171 & 0.987 & 0.042 \\
GPA & 72 & 13.036 & 9 & 0.161 & 1.448 & 0.942 & 0.079 \\
\hline
\end{tabular}

In the direct model with credits obtained, the model fit well $\left(\chi^{2}: d f=1.510, \mathrm{CFI}\right.$ $=.948$, RMSEA = .079). However, when controlling for youths' participation in IEP meeting, youths' participation in the self-determination intervention, and credits obtained previous to study entry, credits obtained at Time 2 was not predicted by teachers' negative comments $(\beta=-.133, p>.10)$ and youths' problem behaviors $(\beta=-.026, p$ $>$.10). Only credits obtained previous to study entry significantly predicted credits obtained at Time $2(\beta=.258, p<.05)$. This model accounted for $13 \%$ of the variance in credits obtained at Time 2.

In the direct model with absences, the model fit well $\left(\chi^{2}: d f=1.171, \mathrm{CFI}=.987\right.$, RMSEA = .042). When controlling for youths' participation in IEP meeting, youths' participation in the self-determination intervention, and absences previous to study entry, absences at Time 2 was not predicted by teachers' negative comments $(\beta=-.031, p>.10)$. 
Table 22.

Parameter Estimates of Direct Effects of the Predictors on School Performance at Time 2

\begin{tabular}{|c|c|c|c|c|c|}
\hline Outcome & Predictors & $\beta$ & $B$ & & $R^{2}$ \\
\hline \multirow[t]{5}{*}{ Failed class } & Teachers' negative comments & 0.129 & 0.031 & & .13 \\
\hline & IEP meeting & -0.016 & -0.018 & & \\
\hline & Self-determination & -0.090 & -0.089 & & \\
\hline & Failed class previous to study entry & 0.322 & 0.328 & $* *$ & \\
\hline & Problem behaviors & -0.143 & -0.009 & & \\
\hline \multirow[t]{5}{*}{ Credits obtained } & Teachers' negative comments & -0.133 & -0.315 & & .13 \\
\hline & IEP meeting & 0.102 & 2.362 & & \\
\hline & Self-determination & -0.065 & -1.369 & & \\
\hline & Credits previous to study entry & 0.258 & 0.700 & $*$ & \\
\hline & Problem behaviors & -0.026 & -0.152 & & \\
\hline \multirow[t]{5}{*}{ Absences } & Teachers' negative comments & -0.031 & -0.232 & & .38 \\
\hline & IEP meeting & 0.019 & 0.738 & & \\
\hline & Self-determination & -0.003 & -0.116 & & \\
\hline & Absences previous to study entry & 0.582 & 0.716 & $* * *$ & \\
\hline & Problem behaviors & 0.155 & 0.850 & $\dagger$ & \\
\hline \multirow[t]{5}{*}{ GPA } & Teachers' negative comments & 0.001 & 0.000 & & .18 \\
\hline & IEP meeting & 0.028 & 0.065 & & \\
\hline & Self-determination & 0.078 & 0.161 & & \\
\hline & GPA previous to study entry & 0.394 & 0.371 & $* * *$ & \\
\hline & Problem behaviors & 0.189 & 0.026 & & \\
\hline
\end{tabular}

Note. $\dagger p<.10,{ }^{*} \mathrm{p}<.05,{ }^{* *} \mathrm{p}<.01,{ }^{* * *} \mathrm{p}<.001$ 
Whereas, youths' problem behaviors significantly predicted absences at Time $2(\beta=.155$, $p<.10)$, and absences previous to study entry significantly predicted absences at Time 2 $(\beta=.582, p<.001)$. This model accounted for $38 \%$ of the variance in absences at Time 2 . In the direct model with GPA, the model fit well $\left(\chi^{2}: d f=1.448, \mathrm{CFI}=.942\right.$, RMSEA = .079). However, when controlling for youths' participation in IEP meeting, youths' participation in the self-determination intervention, and GPA previous to study entry, GPA at Time 2 was not predicted by teachers' negative comments $(\beta=.001, p$ $>.10)$ and youths' problem behaviors $(\beta=.189, p>.10)$. Only GPA previous to study entry significantly predicted GPA at Time $2(\beta=.394, p<.001)$. This model accounted for $18 \%$ of the variance in GPA at Time 2.

In sum, youths' problem behaviors had a significant direct effect on absences among the four indicators of school performance measured at Time 2 . Therefore, only the mediational model with absences could provide an supportive evidence of mediation effect of youths' problem behaviors attitudes on the relationships between teachers' negative comments and absences at Time 2.

Mediational effect of youths' problem behaviors on the relationship between teachers' negative comments on youths' absences at Time 2. To test the mediational effect of youths' problem behaviors on the relationship between teachers' negative comments on absences at Time 2, a SEM model were developed to examine both the direct and indirect relationships of the constructs with absences at Time 2 (See Figure 7).

Since it was already determined that teachers' negative comments, youths' participation in the IEP meeting, youths' participation in the self-determination 
intervention did not have significant direct relationship with youths' school performance at Time 2, these paths were excluded from the mediation model.

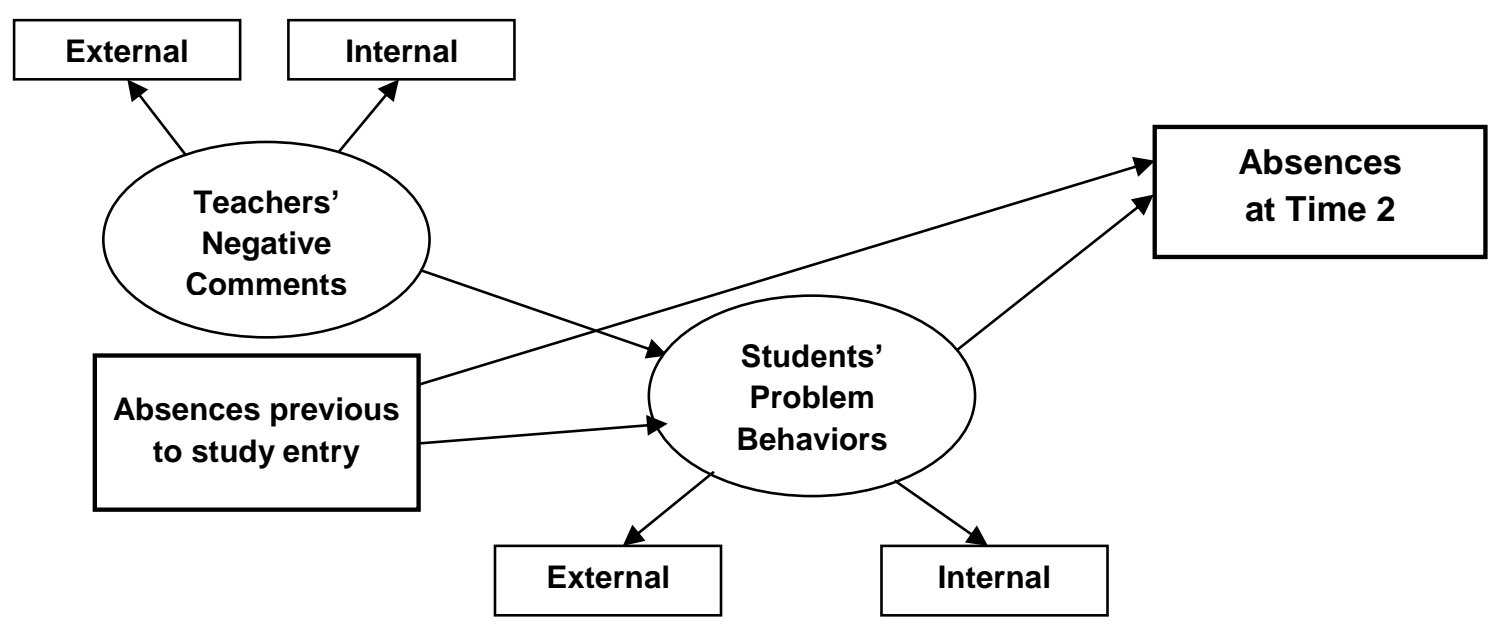

Figure 7. The multiple regression model of mediation effect of youths' problem behaviors between teachers' negative comments and absences at Time 2 .

Table 23.

Model Comparisons of Direct Model with Mediational Model with Youths' Problem

Behaviors

\begin{tabular}{|c|c|c|c|c|c|c|c|c|c|c|}
\hline \multicolumn{2}{|c|}{ Model } & $N$ & $\chi^{2}$ & $\overline{D f}$ & $P$ & $\chi^{2}: d f$ & CFI & RMSEA & $\Delta \chi^{2}$ & $\Delta d f$ \\
\hline \multirow[t]{3}{*}{$\overline{\text { Absences }}$} & Direct & 97 & 10.542 & 9 & 0.308 & 1.171 & 0.987 & 0.042 & & \\
\hline & $\begin{array}{l}\text { Mediational } \\
\text { (Problem }\end{array}$ & 97 & 6.377 & 6 & 0.382 & 1.063 & 0.997 & 0.026 & -4.165 & -3 \\
\hline & behaviors) & & & & & & & & & \\
\hline
\end{tabular}

As Table 23 revealed, the mediational model fit well $\left(\chi^{2}: d f=1.063, \mathrm{CFI}=.997\right.$, RMSEA $=.026)$ with little decrease in fit $\left(\Delta \chi^{2}(-3, \mathrm{n}=97)=-4.165, \Delta \chi^{2}: d f=.108, p\right.$ $>$.05), compared to the direct model. 
Table 24 indicated that the relationship between teachers' negative comments and absences at Time 2 was mediated through an indirect pathway of youths' problem behaviors, controlling for absences previous to study entry. To begin with, an increase of teachers' negative comments predicted an increase of youths' problem behaviors $(\beta=.441$, $p<.05)$, and an increase of youths' problem behaviors predicted an increase of absences at Time $2(\beta=.137, p<.10)$.

The result also indicated that absences previous to study entry predicted absences at Time 2 both directly and through mediation by youths' problem behaviors. An increase of absences previous to study entry directly predicted an increase of absences at Time 2 $(\beta=.573, p<.001)$, and indirectly through youths' problem behaviors $(\beta=.310, p<.05)$ (See Figure 8). This mediational model explained 38\% of the variance in absences at Time 2.

Table 24.

Parameter Estimates of All Paths in the Mediational Model of Youths' Problem Behaviors on the Relationship between Teachers' Negative comments and Absences at

Time 2.

\begin{tabular}{llcccc}
\hline Outcome & \multicolumn{1}{c}{ Predictors } & $\beta$ & & $B$ & $R^{2}$ \\
\hline Absences at & Negative comments $\rightarrow$ Problem behaviors & 0.441 & 0.869 & $*$ & .38 \\
Time 2 & Negative comments $\rightarrow$ Absences (Time 2) & & & \\
& Absences (previous) $\rightarrow$ Problem behaviors & 0.000 & 0.000 & & \\
& Absences (previous) $\rightarrow$ Absences (Time 2) & 0.573 & 0.100 & 0.709 & $* * *$ \\
& Problem Behaviors $\rightarrow$ Absences (Time 2) & 0.137 & 0.525 & $\dagger$
\end{tabular}

Note. $\dagger p<.10,{ }^{*} p<.05,{ }^{* *} p<.01,{ }^{* * *} p<.001$.

${ }^{\text {a }}$ Path contained to 0 due to earlier analyses on direct effects. 


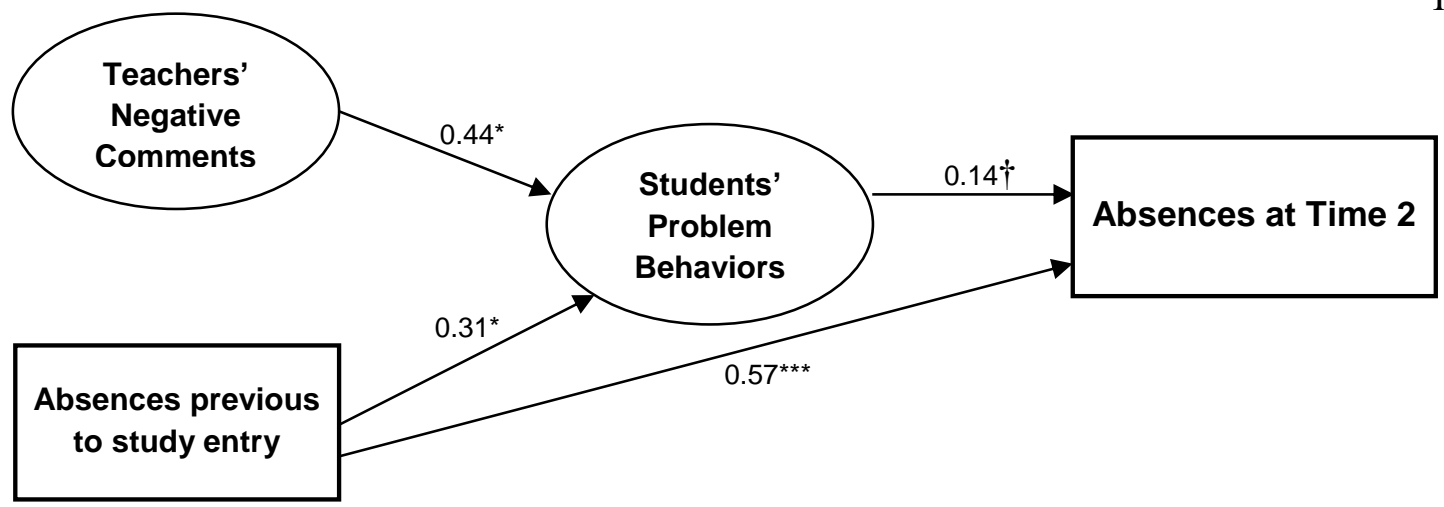

Note. $\dagger p<.10,{ }^{*} p<.05,{ }^{* *} p<.01,{ }^{* * *} p<.001$.

Figure 8. The mediational model of youths' problem behaviors on absences at Time 2 .

Simultaneous model of teachers' negative comments on absences at Time 2. With the significant findings revealed in above analyses, this dissertation study explored a simultaneous model including teachers' negative comments, youths' school attitudes, absences previous to study entry, and absences at Time 2, as seen in Figure 9.

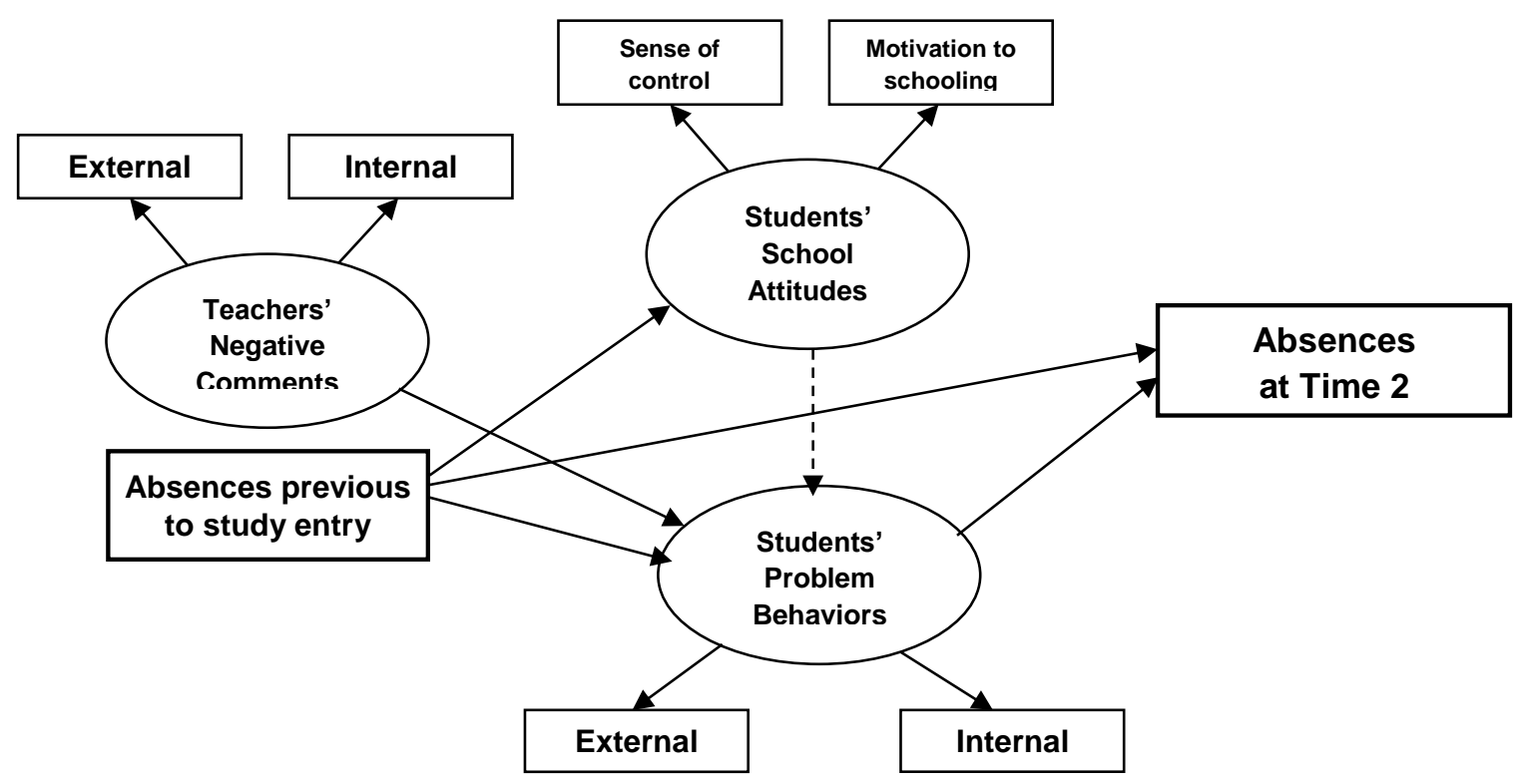

Figure 9. The simultaneous model of mediation effect of youths' school attitudes and problem behaviors on the relationship between teachers' negative comments, and youths' absences at Time 2 . 
While teachers' negative comments, and youths' school attitudes did not have significant direct relationship with youths' school performance at Time 2, and these paths were excluded from the simultaneous model, a pathway of youths' school attitudes on youths' problem behaviors was added.

As Table 25 revealed, the simultaneous was refined to a better model of the constructs $\left(\chi^{2}: d f=.627, \mathrm{CFI}=1.000, \mathrm{RMSEA}=0.000\right)$ with little decrease in fit $\left(\Delta \chi^{2}(6\right.$, $\left.\mathrm{n}=97)=-1.139, \Delta \chi^{2}: d f=.544, p>.05\right)$, compared to the mediational model with only youths' problem behaviors.

Table 25.

Model Fit Comparisons of 3 Models.

\begin{tabular}{ccccccccccc}
\hline \multicolumn{1}{c}{ Model } & $n$ & $\chi^{2}$ & $D f$ & $p$ & $\chi^{2}: d f$ & CFI & RMSEA & $\Delta \chi^{2}$ & $\Delta d f$ \\
\hline Absences & Direct & 97 & 10.542 & 9 & 0.308 & 1.171 & 0.987 & 0.042 & & \\
Mediational & 97 & 6.377 & 6 & 0.382 & 1.063 & 0.997 & 0.026 & -4.165 & -3 \\
& (Problem & & & & & & & & & \\
Behaviors) & & & & & & & & & \\
Mediational & 97 & 9.403 & 15 & 0.856 & 0.627 & 1.000 & 0.000 & -1.139 & 6 \\
$\quad$ (School & & & & & & & & & \\
attitudes \& & & & & & & & & & & \\
Problem & & & & & & & & & & \\
Behaviors) & & & & & & & & & & \\
\end{tabular}

Table 26 indicated that the relationship between teachers' negative comments and absences at Time 2 was mediated through an indirect pathway of youths' problem behaviors. To begin with, an increase of teachers' negative comments predicted an 
increase of youths' problem behaviors $(\beta=.452, p<.05)$, and an increase of youths' problem behaviors also predicted an increase of absences at Time $2(\beta=.149, p<.10)$.

Table 26.

Parameter Estimates of All Paths in the Mediational Model of Youths' School Attitudes and Youths' Problem Behaviors on the Relationship between Teachers' Negative comments and Absences at Time 2.

\begin{tabular}{|c|c|c|c|c|c|}
\hline Outcome & Predictors & $\beta$ & & & $R^{2}$ \\
\hline Absences & Negative comments $\rightarrow$ Problem behaviors & 0.452 & 0.902 & $*$ & \multirow{7}{*}{.39} \\
\hline \multirow[t]{6}{*}{ at Time 2} & Negative comments $\rightarrow$ Absences (Time 2$)^{\mathrm{a}}$ & 0.000 & 0.000 & & \\
\hline & Absences (previous) $\rightarrow$ Problem behaviors & 0.207 & 0.069 & $*$ & \\
\hline & Absences (previous) $\rightarrow$ Absences (Time 2) & 0.569 & 0.706 & $* * *$ & \\
\hline & Absences (previous) $\rightarrow$ School attitudes & -0.340 & -0.006 & $*$ & \\
\hline & School Attitudes $\rightarrow$ Problem behaviors & -0.308 & -5.591 & $*$ & \\
\hline & Problem Behaviors $\rightarrow$ Absences (Time 2) & 0.149 & 0.551 & $\dagger$ & \\
\hline
\end{tabular}

The result also indicated that absences previous to study entry predicted absences at Time 2 through a complex mechanism incorporating both direct and indirect pathways involving youths' school attitudes, and youths' problem behaviors. An increase of absences previous to study entry significantly predicted an increase of absences at Time 2 $(\beta=.569, p<.001)$. An increase of absences previous to study entry significantly predicted absences at Time 2 indirectly through an increase of youths' problem behaviors $(\beta=.207, p<.05)$ 
An increase of absences previous to study entry also significantly predicted absences at Time 2 indirectly through a decrease of youths' school attitudes $(\beta=-.340, p$ $<.05)$ and indirectly through a decrease of youths' problem behaviors $(\beta=-.308, p<.05)$. Finally, an increase of youths' problem behaviors predicted absences at Time $2(\beta=0.149$, $p<.10)$ (See Figure 10). This simultaneous model explained 39\% of the variance in absences at Time 2 .

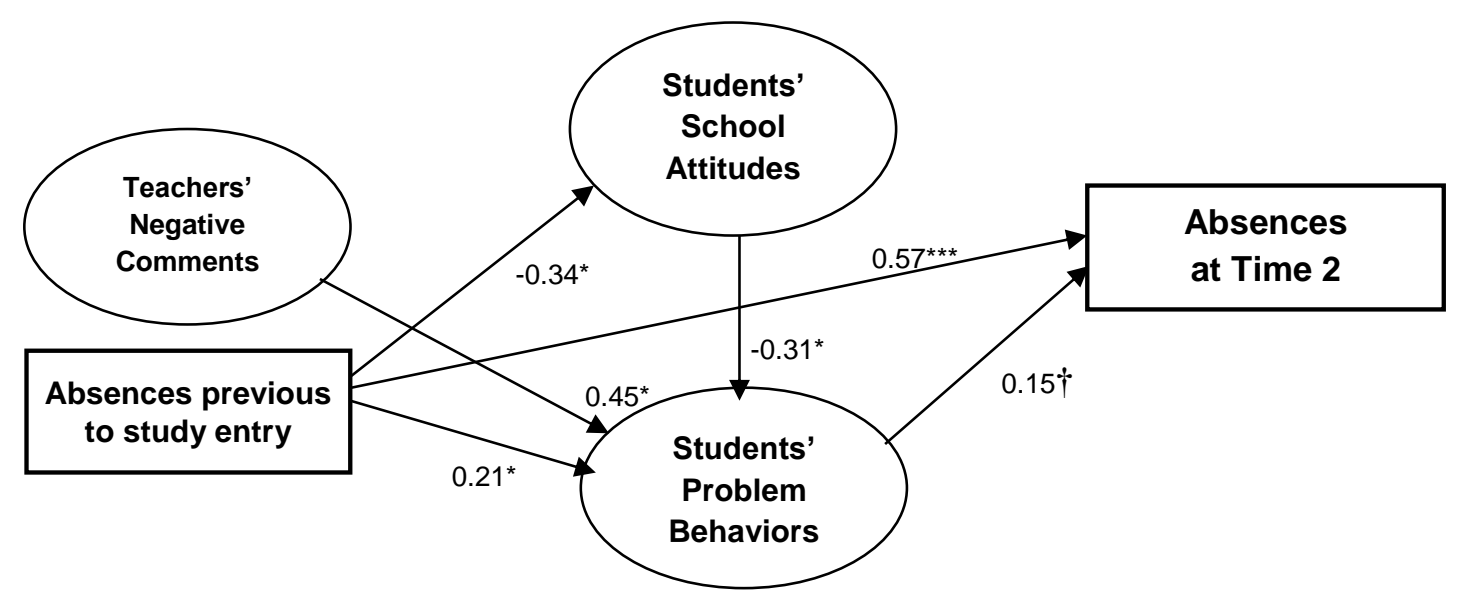

Note. $\dagger p<.10,{ }^{*} p<.05,{ }^{* *} p<.01,{ }^{* * *} p<.001$.

Figure 10. The simultaneous model of youths' school attitudes and problem behaviors on absences at Time 2 .

The Mediational Effect of Youths' School Attitude and Problem Behavior on the Relationship between Teachers' Stigmatizing Negative comments on Youths' School Performance at Time 2

Additionally, to test the impact of teachers' stigmatizing negative comments on youths' school performance, both directly and through mediation by youths' school attitudes and problem behaviors, the following research question was considered: To what extent did youth's school attitudes and problem behaviors mediate the impact of teachers' stigmatizing negative comments on their school performance, controlling for 
youths' participation in the self-determination intervention, youths' school performance previous to study entry, and youths' participation in the IEP meeting?

Direct effects of teachers' stigmatizing negative comments, and other predictors on youths' school performance at Time 2. Four structural equation models were developed that included only the direct relationships of the constructs models (See Figure 11).

Table 27 displayed fit indices of the models, and Table 28 revealed the standardized regression coefficients and total $R^{2}$ values.

Table 27.

Fit Indices of Models for Direct Effects of Teachers' Stigmatizing Negative Comments and Other Predictors on School Performance at Time 2

\begin{tabular}{lccccccc}
\hline \multicolumn{1}{c}{ Model } & $N$ & $\chi^{2}$ & $D f$ & $p$ & $\chi^{2}: d f$ & CFI & RMSEA \\
\hline Failed class & 72 & 11.594 & 11 & 0.395 & 1.054 & 0.991 & 0.028 \\
Credits obtained & 82 & 11.061 & 11 & 0.438 & 1.006 & 0.999 & 0.008 \\
Absences & 97 & 11.869 & 11 & 0.374 & 1.079 & 0.993 & 0.029 \\
GPA & 72 & 14.078 & 11 & 0.229 & 1.280 & 0.961 & 0.063 \\
\hline
\end{tabular}

In the direct model with failed class, the model fit well $\left(\chi^{2}: d f=1.054, \mathrm{CFI}=.991\right.$, RMSEA = .028). However, when controlling for youths' participation in IEP meeting, youths' participation in the self-determination intervention, and failed class previous to study entry, failed classes at Time 2 was not predicted by teachers' negative comments $(\beta$ $=.062, p>.10)$, youths' school attitudes $(\beta=-.163, p>0.10)$, and youths' problem behaviors $(\beta=-.159, p>.10)$. Only failed class previous to study entry significantly 
predicted failed class at Time $2(\beta=.292, p<.05)$. This model accounted for $14 \%$ of the variance in failed class at Time 2.

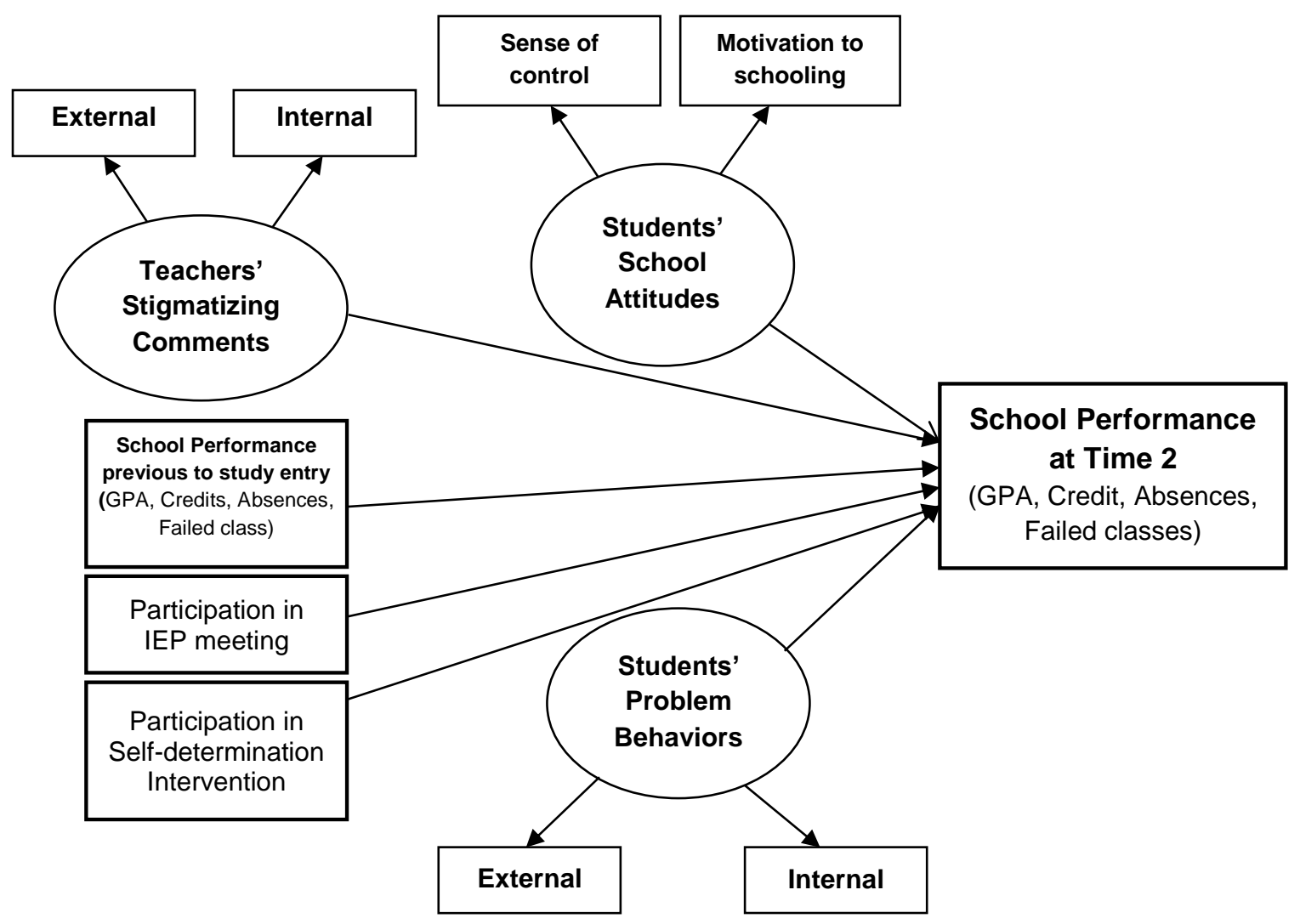

Figure 11. The multiple regression model of direct effects of teachers' stigmatizing negative comments and other predictors on youths' school performance measured at Time 2.

In the direct model with credits obtained, the model fit well $\left(\chi^{2}: d f=1.006\right.$, CFI $=.999$, RMSEA $=.008)$. However, when controlling for youths' participation in IEP meeting, youths' participation in the self-determination intervention, and credits obtained previous to study entry, credits obtained at Time 2 was not predicted by teachers' negative comments $(\beta=-.078, p>.10)$, youths' school attitudes $(\beta=-.035, p>.10)$, and youths' problem behaviors $(\beta=-.075, p>.10)$. Only credits obtained previous to study 
entry significantly predicted credits obtained at Time $2(\beta=.266, p<.05)$. This model accounted for $12 \%$ of the variance in credits obtained at Time 2 .

Table 28.

Parameter Estimates of Direct Effects of Teachers' Stigmatizing Negative Comments and other Predictors on School Performance at Time 2.

\begin{tabular}{|c|c|c|c|c|}
\hline Outcome & Predictors & $\beta$ & $B$ & $R^{2}$ \\
\hline \multirow[t]{6}{*}{ Failed class } & Teachers' stigmatizing comments & 0.062 & 0.017 & \multirow{6}{*}{.14} \\
\hline & IEP meeting & -0.055 & -0.062 & \\
\hline & Self-determination & -0.104 & -0.103 & \\
\hline & Failed class previous to study entry & 0.292 & $0.297 *$ & \\
\hline & School attitudes & -0.163 & -0.348 & \\
\hline & Problem behaviors & -0.159 & -0.013 & \\
\hline \multirow[t]{6}{*}{ Credits obtained } & Teachers' stigmatizing comments & -0.013 & -0.078 & \multirow{6}{*}{.12} \\
\hline & IEP meeting & 0.104 & 2.429 & \\
\hline & Self-determination & -0.071 & -1.504 & \\
\hline & Credits previous to study entry & 0.266 & $0.722 *$ & \\
\hline & School attitudes & -0.035 & -2.506 & \\
\hline & Problem behaviors & -0.075 & -0.157 & \\
\hline \multirow[t]{6}{*}{ Absences } & Teachers' stigmatizing comments & -0.061 & -0.612 & \multirow{6}{*}{.38} \\
\hline & IEP meeting & 0.020 & 0.791 & \\
\hline & Self-determination & -0.002 & -0.068 & \\
\hline & Absences previous to study entry & 0.577 & $0.711 * * *$ & \\
\hline & School attitudes & -0.002 & -0.168 & \\
\hline & Problem behaviors & 0.106 & 0.360 & \\
\hline \multirow[t]{2}{*}{ GPA } & Teachers' stigmatizing comments & 0.024 & 0.014 & \multirow{2}{*}{.20} \\
\hline & IEP meeting & 0.044 & 0.101 & \\
\hline
\end{tabular}




$\begin{array}{lll}\text { Self-determination } & 0.078 & 0.160 \\ \text { GPA previous to study entry } & 0.389 & 0.366 * * * \\ \text { School attitudes } & 0.141 & 0.622 \\ \text { Problem behaviors } & 0.166 & 0.029\end{array}$

Note. $\dagger p<.10,{ }^{*} p<.05,{ }^{* *} p<.01,{ }^{* * *} p<.001$.

In the direct model with absences, the model fit well $\left(\chi^{2}: d f=1.079, \mathrm{CFI}=.993\right.$, RMSEA = .029). However, when controlling for youths' participation in IEP meeting, youths' participation in the self-determination intervention, and absences previous to study entry, absences at Time 2 was not predicted by teachers' negative comments $(\beta=-$ $.061, p>.10)$, youths' school attitudes $(\beta=-.002, p>.10)$, and youths' problem behaviors $(\beta=.106, p>.10)$. Only absences previous to study entry significantly predicted absences at Time $2(\beta=.577, p<.001)$. This model accounted for $38 \%$ of the variance in absences at Time 2 .

In the direct model with GPA, the model fit well $\left(\chi^{2}: d f=1.280, \mathrm{CFI}=.961\right.$, RMSEA = .063). However, when controlling for youths' participation in IEP meeting, youths' participation in the self-determination intervention, and GPA previous to study entry, GPA at Time 2 was not predicted by teachers' negative comments $(\beta=.024, p$ $>.10)$, youths' school attitudes $(\beta=.141, p>.10)$, and youths' problem behaviors $(\beta$ $=.166, p>.10)$. Only GPA previous to study entry significantly predicted GPA at Time 2 $(\beta=.374, p<.001)$. This model accounted for $20 \%$ of the variance in GPA at Time 2.

In sum, youths' school attitudes and youths' problem behaviors had no significant direct effect on all indicators of school performance at Time 2, including failed class, credits obtained, absences, and GPA. Based on Baron and Kenny (1986)'s criteria for 
testing mediation relationship, these mediational models did not provide evidences of mediation effect of youths' school attitudes and problem behaviors on the relationships between teachers' stigmatizing negative comments and youths' school performance at Time 2. 


\section{Chapter 5: Discussion}

This chapter discusses the study findings related to teachers' negative comments and stigmatizing negative comments toward youth in foster care on IEP documents; the impact of teachers' negative comments and stigmatizing negative comments on youths' school performance; and the mediational effect of youths' school attitudes and problem behaviors on the relationship between teachers' negative and stigmatizing negative comments and youths' school performance. The findings are considered in the context of the theoretical and empirical literature, and the limitations of this research. The theoretical, policy and research implications of the study are discussed. Suggestions for future research and brief conclusion conclude the chapter.

\section{Major Findings}

Findings from the qualitative analysis of teachers' negative and stigmatizing negative comments support most of the hypotheses posited. Qualitative analysis of IEP documents revealed that almost three-fourths (72.4\%) of the IEPs included one or more negative comments and more than half (52.8\%) included one or more stigmatizing negative comments. The findings reveal that teachers' negative comments included youths' externalizing behavior, including disruptive behavior and rule-breaking behavior, and internalizing behavior, including internal problem behavior and interpersonal problem behavior. The findings also suggest that a substantial proportion of teacher's negative comments specifically included stigmatizing features that could convey negative attitudes or perceptions about the youth to others, including subjective or judgmental comments, biased reports from other teachers, low expectations, and little attention to context or reason. 
Similar to the findings from the preliminary research (Noh et al., 2013), this study reveals that foster youth receiving special education services were exposed to teachers' negative and stigmatizing attitudes and perceptions. It is possible that some of teachers' negative comments accurately described the youth's behaviors and school performance. However, rather than merely objectively describing the youth's problem behaviors or poor school performance, teachers' negative comments in the IEP documents often were expressed as subjective or judgmental comments.

Findings from the IEP analysis also suggest that some teachers describe other teachers' subjective and judgmental opinions, absent objective information and direct observations. This finding supports labeling theory, and is consistent with earlier studies which found that teachers label youths based on biased information obtained indirectly from other teachers or school documents (Babad \& Inbar, 1981; Babad et al., 1982; Good, 1987; Graham, 1991; Kelley \& Michaela, 1980).

Furthermore, some of the teachers' negative comments did not provide concrete context or reason for the youths' behaviors and school performance. Such comments, offered with little reference to context or reason, also convey stigmatizing attitudes or perceptions by indirectly conveying that a youth's negative outcomes could be caused by only a lack of effort or will. This interpretation is consistent with Attribution theory, suggesting that teachers often fail to understand the behaviors of the youth as situational cues (Weiner, 1985). For example, teachers may have overlooked that the youth's poor school outcomes could be the result of lack of access to resources and support for performing school work (e.g., lack of access to a computer for homework). 
Findings from the quantitative analysis support hypotheses that the IEP documents of youth of color would include more negative comments related to externalizing and internalizing behaviors, and more stigmatizing negative comments, compared to the IEP documents of Caucasian youth. Likewise, the IEP documents of males consistently included more negative comments related to externalizing and internalizing behaviors, and stigmatizing negative comments than those for females. These findings are consistent with earlier studies which found similar results about gender (Eagly \& Steffen, 1986; Hudley et al., 2001) and race/ethnicity (Keller, 1986; Murray, 1996; Pigott \& Cowen, 2000; Plewis, 1997) differences in teachers' negative and stigmatizing attitudes and perceptions.

However, the findings do not support the hypothesis that female youth would receive more internalizing negative comments than male youth. Other studies have reported that female youth were perceived as higher than male youth on negative internalizing aspects of behavior, including extraversion, anxiety, sadness and tendermindedness (Fischer, 1993; Frijda et al., 1989; Oliver \& Toner, 1990). Conversely, this study revealed that male youth received more internalizing negative comments than female youth.

The findings also do not support the respective hypotheses that youths' participation in the self-determination intervention and youths' participation in the IEP meeting would moderate the impact of teachers' negative comments and stigmatizing negative comments on youths' school performance. The latter finding could reflect that many youth do not see what is actually written in their IEP documents, or that teachers and other IEP team members may not discuss with youth what is written in their IEP 
documents, during or after the meeting. This finding also could suggest that youth would be less likely to recognize teachers' negative and stigmatizing attitudes and perceptions in the IEP meeting, and perhaps they would be more likely to be affected by these negative attitudes and perceptions in direct relationships with teachers in school. In the IEP documents analyzed, teachers described how they had intervened when the youth showed problem behaviors in classes, and how the youth responded to teachers' discipline.

Although teachers' interactions with youth were not specifically investigated in this study, it is possible that in this process of interacting and communicating with teachers, youth could perceive teachers' negative and stigmatizing attitudes and perception toward them.

In this regard, the findings do not support the hypothesis that teachers' negative comments and stigmatizing negative comments directly predict youths' school performance, however they reveal that teachers' negative comments indirectly predict youths' school absences through a mediational effect of youths' problem behaviors such as anxiety and depression, as well as aggressive and disruptive behaviors. This finding aligns with labeling theory by suggesting that teachers' negative attitudes or perceptions toward the youth, which are overtly or covertly conveyed by teachers, could negative influence self-identity and behaviors of youth (Lemert, 1951). Labeling theory suggests that a youth who received teachers' negative comments would internalize the perceived negative label, and strengthen or justify her or his deviant behaviors as a means of defense or adjustment in response to teachers' and peers' negative attitudes or comments. The finding also extends previous works that found a potential influence of teachers' negative attitudes and perceptions on youths' school performance (Brophy, 1985; Good, 1987; Silva \& Morgado, 2004). 
This study also highlights that youths' problem behaviors, including external problem behaviors and internal problem behaviors, could play important predictive and potentially protective roles for the youth with higher levels of absences, as the previous studies found (Fletcher, 2008; Kupersmidt \& Coie, 1990). However, the findings do not provide significant evidence of a mediational effect of youths' school attitudes on the relationship between teachers' negative comments and youths' school performance.

The relationship between current youth absences and future youth absences was partially mediated through a complex mechanism incorporating both direct and indirect pathways involving youths' school attitudes, and youths' problem behaviors. In other words, current absences significantly predict future absences, and current and future absences are connected via their links to youths' school attitudes, including motivation to schooling and sense of control over school performance, as well as problem behaviors, including internal problem behaviors and external problem behaviors. These findings suggest the possibility of a vicious cycle of absenteeism connected with youths' poor school attitudes and increased problem behaviors. This has important implications for both policy and practice as will be discussed more fully later in this chapter.

\section{Limitations of the Study}

Several limitations of this dissertation study make it difficult to generalize the results and to understand more clearly the nature and influence of teachers' negative comments and stigmatizing negative comments on foster youth receiving special education services.

First, the small size of sample may limit generalizability of the findings. The sample was collected from foster youth receiving special education services in school 
districts in one region of Oregon. This limitation makes it difficult to generalize the findings of this study to other populations in other geographic areas and at different historical times.

The small size sample also limited the structural equation model (SEM) methodology used, given the complexity of the models estimated. As Kline (2005) noted "as the ratio of cases to the number of parameters in smaller, the statistical stability of the estimates becomes more doubtful. Cases to parameter rations less than 10:1 may be a cause for concern" (p.319). It is important to note that several of the paths tested in the hypothesized models did not achieve statistical significance.

Second, because this study was a secondary data analysis, there are limitations to drawing general conclusions regarding teachers' negative comments and stigmatizing negative comments toward foster youth receiving special education. While IEP documents are intended to be multi-purpose in regards to describing the plan for supports and services for youth in special education, this information is not designed to examine teachers' attitudes and perceptions toward the youth. Therefore, teachers' negative comments and stigmatizing negative comments found in the IEP documents could provide only a snapshot of how the youth were described, and may not reflect teachers' overall attitudes or perceptions toward the youth.

Because of this limitation, this study also could not evaluate teachers' negative and stigmatizing negative comments based on the severity and types of disabilities of the youth, and it could not compare the findings with other youth groups, such as youth in special education who were not also in foster care. 
Third, while the study focused on the nature and impact of teachers' negative comments and stigmatizing negative comments on the youth, it did not consider teachers' positive comments described in IEP documents. Analyzing and comparing two different types of teachers' comments at the same time would be helpful for more clearly understanding the effect of teachers' attitudes and perceptions toward the youth.

A fourth study limitation is the problem of self-report on surveys, particularly on the items for measuring youths' school attitudes. This problem can produce a nonresponse bias, as was the case in this study, particularly in regards to the youth who did not answer the questions about lack of motivation to schooling or sense of control over performance, which made it difficult to impute missing responses. Conversely, the youth could have reported what they thought was a socially acceptable answer.

Fifth, only two of five subscales of the School Attitude Measure (SAM; Dolan et al., 1980; Wick, 1990) were used to measure youths' school attitudes. Limited use of the SAM subscales could have impeded detection of the mediational effects of youths' school attitudes on the relationship between teachers' negative comments and stigmatizing negative comments, and youths' school performance.

Sixth, while teachers' negative comments and stigmatizing negative comments were coded and interpreted through a complex process to enhance trustworthiness of the analysis, all these analyses were produced by only two coders, which limits the reliability of the findings.

Lastly, even though this study was longitudinal in nature and the predictor variables (teachers' negative comments, stigmatizing negative comments, youths' school attitudes, and problem behaviors) preceded the outcome variable (youths' school 
performance), the mediators of youths' school attitudes and problem behaviors were measured at a similar time point. This limits the ability to infer a causal relationship between these constructs.

Despite these limitations, both the qualitative and quantitative analyses are informative. As an exploratory study, results from the qualitative analysis provide information to increase understanding of the nature of teachers' negative and stigmatizing attitudes and perceptions toward foster youth in special education. This study also provides quantitative evidence about the impact of teachers' negative attitudes and perceptions on youths' absences to the degree that, in particular, absenteeism is connected to youths' problem behaviors. The following section discusses in detail the implications of the findings for theory, practice, policy, and future research.

\section{Implications}

\section{Theoretical Implications}

The findings of this dissertation enrich the theoretical understanding of the roles of teachers' negative and stigmatizing attitudes and perceptions on foster youth in special education, by supporting labeling theory and attribution theory. The results appear to confirm the proposition found within labeling theory that a youth who received teachers' negative or stigmatizing negative comments would internalize the perceived negative label, and in turn would strengthen or justify her or his deviant behaviors as a means of defense or adjustment in response to teachers' negative attitudes or comments (Lemert, 1951). The results support labeling theory by demonstrating that a substantial proportion of teachers' negative comments included stigmatizing features, including subjective or judgmental comments, biased information from other teachers (Babad \& Inbar, 1981; 
Babad et al., 1982; Good, 1987; Graham, 1991; Kelley \& Michaela, 1980), and low expectation (Aloia \& MacMillan, 1983; Center \& Ward, 1987). Findings from this study offer further support for another tenet of labeling theory, showing teachers' negative and stigmatizing attitudes and perceptions toward ethnic minority youth (Aloia \& MacMillan, 1983; Aloia et al., 1981; Center \& Ward, 1987). However, this study did not explore teachers' negative and stigmatizing attitudes and perceptions based on the severity and type of disabilities as labeling theory and related studies suggest (Parish et al., 1977; Rolison \& Medway, 1985). Whether teachers' negative and stigmatizing attitudes and perceptions are similar across different levels of severity and types of disabilities of the youth needs further research.

Findings from the study support the tenet of attribution theory which suggests that teachers often may fail to understand the behaviors of these youth as situational cues (Reyna, 2000). Teachers' negative comments were described with little reference to context or reason for youths' behaviors, which could illustrate a teacher's lack of understanding about how a specific educational setting, living condition, or family structure of a youth, and a variety of interactions with teachers, case managers, caseworkers, or family members, could affect the youth's behaviors and school performance. These comments also could convey stigmatizing attitudes or perceptions that a youth's negative outcomes could be caused by only lack of effort or will, as Reyna (2000) suggests.

Specifically, Reyna (2000) explains that a teacher who considers the poor school outcomes of a youth to be the result of lack of effort or will could have negative reactions such as anger, punishment, and denial of help. When such teacher's negative attitudes are 
conveyed through written statements, or verbal or physical behaviors, the youth could be become frustrated, depressed, or exhibit aggressive and disruptive behaviors which may reinforce the earlier attributions of the teacher. The youth could express negative attitudes toward the teacher and school, show poor motivation for school work and, in turn, have poor academic performance. The results of the structural models identified partially support Reyna's (2000) perspective. While the findings of this study do not reveal the mediational effect of youths' school attitudes on the association between teachers' negative and stigmatizing negative comments and youth school performance, they suggest that teachers' negative attitudes and perceptions are connected to youths' absences to the degree that they are connected to youths' problem behaviors such as anxiety, frustration, and depression, as well as aggressive and disruptive behaviors.

\section{Practice Implications}

Results of this study provide useful information that could be used to improve practices for youth in foster care and special education. Specifically, understanding the nature and impact of teachers' negative comments and stigmatizing negative comments on youth in foster care and special education can help teachers, social workers, and other school personnel to recognize their attitudes and perceptions as an important factor that can affect youths' behaviors and school performance. The profession of social work also can benefit from understanding these youths, and the barriers and challenges they experience related to being in special education and foster care.

The findings also suggest that school staff and other professionals in child welfare require education and training for recognizing misconceptions they may have about these youth, and for appropriately interpreting and responding to problems that arise. Both 
school personnel and social workers can increase their awareness of the impact of negative comments toward youth in foster care with disabilities, and learn to exercise restraint on IEP documents.

Specifically, findings from this study suggest that some teachers may benefit from learning how to note youths' behaviors and school performance in accordance with the purpose of IEP documents. IEP documents must be objectively described in order to help other teachers or other service providers understand why the youth has made little progress in his school performance, and especially how the disability and other situational factors have affected his learning progress, assessing the youth in all areas related to his behavior and school performance.

For example, when teachers accurately describe youths' poor school performance and problem behaviors, they may have little choice but to use negative expressions. However, negative comments can have a useful purpose only if such comments are objectively and carefully described, ruling out teachers' subjective or judgmental attitudes and perceptions, low expectations, and biased reports from other teachers.

Negative comments also can serve a useful purpose if stated in constructive ways. This study suggests that some teachers could benefit from learning how to note strategies that could improve youths' educational outcomes or support their needs, as well as the context or reasons related to youths' behaviors and school performance.

\section{Policy Implications}

This study also suggests policy efforts to provide improved services to foster youth in special education. Specifically, it is important to provide teachers and other school personnel with concrete guidelines for writing IEP documents. Without such 
guidelines, teachers may have difficulties in determining what to write in IEP documents. Additionally, IEP documents need to be structured to encourage teachers and other school personnel to note youths' strengths, goals, and accomplishments. Specific sections are needed for describing factors that may be affecting youths' behaviors and school performance, and for providing strategies and action plans to support the youths. Providing this structure will encourage teachers to communicate beliefs that the youths can achieve their IEP goals.

Another implication arising from this study is the need for policy efforts to reduce youths' absences. This study reveals that current youths' absences significantly predict their future absences, and that youths' absences are connected to their future absences to the degree that they are connected to their school attitudes and problem behaviors. Therefore, this study suggests that youths' school attitudes and problem behaviors play important predictive and potentially protective roles for future school attendance of the youth.

Higher levels of school absences could be associated with the higher rate of foster care and school placement turnover among youth in foster care with disabilities (Geenen \& Powers, 2006; Rumberger \& Larson, 1998). Instability in foster care, which leads to frequent changes in schools, produces educational challenges for all foster youth, but adapting to new educational circumstances may be especially difficult for a foster youth with a disability (Geenen \& Powers, 2006).

Although increasing attention is being focused on keeping youth in the same school when their foster care placement changes, youth who are moved to distant foster placements may be burdened with extensive travel time and effort in order to maintain 
their school placement. Therefore, it is essential that transportation services and supports be provided that ensure youth are not overly burdened in their efforts to attend school.

Furthermore, maximizing continuity of workers and helping youth to build relationships with new teachers and peers are needed to lesson youths' stress level and to support youths' adaptation of new educational circumstances.

\section{Research Implications}

To date, there has been no research on teachers' negative and stigmatizing attitudes and perceptions toward foster youth with disabilities. Therefore, the findings from this study can be used to advance social work research knowledge related to youth in foster care and special education.

First, the use of a qualitative method provides in-depth information to increase understanding of teachers' negative and stigmatizing comments in IEP documents. Specifically, this study revealed that data such as papers, documents, or records can be resources that provide useful information for examining a variety of issues and populations.

Second, this study used a variety of quantitative techniques to examine the characteristics and impact of teachers' negative and stigmatizing negative comments on youths' school performance, including ANCOVA, independent sample t-test, paired sample t-test, Pearson correlation, hierarchical regression, and Structural Equation Modeling (SEM). Specifically, using Structural Equation Modeling (SEM) provided a holistic picture of the direct and mediational effects of teachers' negative and stigmatizing negative comments on youths' school performance, with testing both separately and in a comprehensive model. 
Lastly, this study used a longitudinal design in contrast to previous studies that have used cross-sectional designs. By controlling the effects of youths' school performance previous to study entry, the methodology provided an opportunity to examine the effect of teachers' negative and stigmatizing attitudes and perceptions on youths' school performance over the course of youths' development.

\section{Suggestions for Future Research}

Building from the implications of this research, there are four major areas where future research could substantially refine and improve our knowledge about foster youth in special education, and ultimately lead to practices and policies that more effectively address the needs of these youth.

First, further research is needed with larger samples of foster youth in special education, including specific measures of type and severity of disability, in order to further explore differences in teachers' negative and stigmatizing attitudes and perceptions. Comparative research also is needed to examine if and how teachers' negative and stigmatizing attitudes and perceptions vary for different groups of the population including youth in foster care only (not in special education), youth in special education only (not in foster care), and youth in foster care and special education.

Second, further research efforts that collect and analyze larger quantities of teachers' comments are needed to more clearly examine teachers' negative and stigmatizing attitudes and perceptions toward foster youth in special education.

Third, further research is needed to code and interpret teachers' comments with more coders and interpreters who are well-trained. Such research could increase the reliability of findings. 
Fourth, further research efforts that examine the effect of additional risk and protective factors (as mediators or moderators) on the association between teachers' negative attitudes and perceptions and youths' school performance are needed. There may be a variety of important factors on the individual, family, society, and community level that could influence on the connection between teachers' negative attitudes and perceptions and youths' school performance.

Lastly, further research effort that examines the nature and the extent of both teachers' positive comments and negative comments toward youth in foster care and special education is needed. It could provide greater understanding of how much teachers could negatively or positively affect youths' school performance through their comments toward youth in foster care and special education.

\section{Conclusion}

As an exploratory effort, this study provides important information about the nature and impact of teachers' negative and stigmatizing attitudes and perceptions, reflected in IEP documents, on youth in foster care and special education. IEP documents aim to describe youths' behaviors and school performance with the goal of providing useful information to other teachers or services providers, whose roles are to support youth. However, findings from this study suggest that IEPs reveal substantial negative and stigmatizing attitudes and perceptions toward youth. Further, the findings suggest that teachers' negative attitudes indirectly influence youths' school absences through a mediational effect of youths' problem behaviors. These findings further highlight the important predictive and potentially protective role that youths' problem behaviors could have in affecting youths' absences. Successful schooling is very critical for foster youth 
in special education who must successfully transition into adulthood after aging out of the child welfare system. Understanding this risk and protective process is an important first step for improving youths' school performance. 


\section{References}

Achenbach, T. M. (1991). Integrative guide for the 1991 CBCL /4-8, YSR, and TRF profiles. Burlington, VT: University of Vermont, Department of Psychiatry.

Achenbach, T. M., \& Edelbrock, C. S. (1978). The classification of child psychopathology: A review and analysis of empirical efforts. Psychological Bulletin, 85(6), 1275-1301. doi:10.1037/0033-2909.85.6.1275

Achenbach, T. M., McConaughy, S. H., \& Howell, C. T. (1987). Child/adolescent behavioral and emotional problems: Implication of cross-informant correlations for situational specificity. Psychological bulletin, 101(2), 213-232. doi:10.1037/0033-2909.101.2.213

Adams, M. S., Robertson, C. T., Gray-Ray, P., \& Ray, M. C. (2003). Labeling and delinquency. Adolescence, 38(149), 171-186.

Aiken, L. S., \& West, S. G. (1991). Multiple regression: Testing and interpreting interactions. Newbury Park, CA: Sage

Alioa, G. F., \& MacMillan, D. L. (1983). Influence of the EMR label on initial expectations of regular-classroom teachers. American Journal of Mental Deficiency, 88(3), 255-262.

Alioa, G. F., Maxwell, J. A., \& Alioa, S. D. (1981). Influence of a child's race and the EMR label on initial impressions of regular-classroom teachers. American Journal of Mental Deficiency, 85(6), 619-623.

Alvidrez, J., \& Weinstein, R. S. (1999). Early teacher perceptions and later student academic achievement. Journal of Educational Psychology, 91(4), 731-746. doi:10.1037/0022-0663.91.4.731 
Arbuckle, J. W., \& Wothke, W. (2007). Amos 7.0 (Computer software). Chicago, IL: SmallWaters Corporation.

Babad, E. Y., Bernieri, F., \& Rosenthal, R. (1989). Nonverbal communication and leakage in the behavior of biased and unbiased teachers. Journal of Personality and Social Psychology, 56(1), 89-94. doi:10.1037/0022-3514.56.1.89

Babad, E. Y., \& Inbar, J. (1981). Performance and personality correlates of teachers' susceptibility to biasing information. Journal of Personality and Social Psychology, 40(3), 553-561. doi:10.1037/0022-3514.40.3.553

Babad, E. Y., Inbar, J., \& Rosenthal, R. (1982). Pygmalion, galatea, and the golem: Investigations of biased and unbiased teachers, Journal of Educational Psychology, 74(4), 459-474. doi:10.1037/0022-0663.74.4.459

Baker, J. A. (1999). Teacher-student interaction in urban at-risk classrooms: Differential behavior, relationship quality, and student satisfaction with school. The Elementary School Journal, 100(1), 57-70.

Bannai, H., \& Cohen, D. A. (1985). The passive-methodical image of Asian American students in the school system. Sociology and Social Research, 70(1), 79-81.

Bardone, A. M., Moffitt, T. E., Caspi, A., Dickson, N., \& Silva, P. (1996). Adult mental health and social outcomes of adolescent girls with depression and conduct disorder. Development and Psychopathology, 8(4), 811-829. doi:10.1017/S0954579400007446

Baron, R. M., \& Kenny, D. A. (1986). The moderator-mediator variable distinction in social psychological research: Conceptual, strategic, and statistical considerations, 
Journal of Personality and Social Psychology, 51(1), 1173-1182.

doi:10.1037/0022-3514.51.6.1137

Battin-Pearson, S., Abbott, R. D., Hill, K. G., Catalano, R. F., Hawkins, J. D., \& Newcomb, M. D. (2000). Predictors of early high school dropout: A test of five theories. Journal of Educational Psychology, 92(3), 568-582. doi:10.1037//00220663.92.3.568

Becker, H. S. (1963). Outsiders New York. London: Free Press.

Ben-Porath, D. D. (2002). Stigmatization of individuals who receive psychotherapy: An interaction between help-seeking behavior and the presence of depression. Journal of Social and Clinical Psychology, 21(4), 400-413. DOI:10.1521/JSCP.21.4.400.22594

Bentler, P. M. (1990). Comparative fit indexes in structural models. Psychological Bulletin, 107(2), 238-246. doi:10.1037/0033-2909.107.2.238

Bilaver, L. A., Jaudes, P. K., Koepke, D., \& George, R. M. (1999). The health of children in foster care. Social Service Review, 73(3), 401-417.

Block-Pedego, A. (1990). Early identification and prediction of students at risk for dropping out of school using the school archival records search (SARS). Dissertation Abstracts International. Ann Arbor, MI.

Blome, W. W. (1997). What happens to foster kids: Educational experiences of a random sample of foster care youth and a matched group of non-foster care youth. Child and Adolescent Social Work Journal, 14(1), 41-53.

doi:10.1023/A:1024592813809 
Brophy, J. (1985). Teachers' expectation, motives and goals for working with problem students. In C. Ames \& R. Ames, Research on motivation in education (Vol. 2). New York, NY: Academic Press.

Brown, R. P., \& Lee, M. N. (2005). Stigma consciousness and the race gap in college academic achievement. Self and Identity, 4(2), 149-157. doi:10.1080/13576500444000227

Brown, R. P., \& Pinel, E. C. (2003). Stigma on my mind: Individual differences in the experience of stereotype threat. Journal of Experimental Social Psychology, 39(6), 626-633. doi:10.1016/S0022-1031(03)00039-8

Browne, M. W., \& Cudeck, R. (1993). Alternative ways of assessing model fit. In K. A. Bollen \& J. S. Long (Eds.), Testing structural equation models (pp. 136-162). Newbury Park, CA: Sage.

Buell, M., Hallam, R., Gamel-McCormick, M., \& Scheer, S. (1999). A survey of general and special education teachers' perceptions and inservice needs concerning inclusion. International Journal of Disability, Development, and Education, 46(2), 143-156.

Burnberg, J. G., Krohn, M. D., \& Rivera, C. J. (2006). Official labeling, criminal embeddedness, and subsequent delinquency: A longitudinal test of labeling theory. The Journal of Research in Crime and Delinquency, 43(1), 67-88. doi:10.1177/0022427805280068

Byrne, B. M. (2001). Structural equation modeling with AMOS: Base concepts, applications, and programming. Mathwah, NJ: Erlbaum.

Campbell, J., Gilmore, L., \& Cuskelly, M. (2003). Changing student teachers' attitudes 
toward disability and inclusion. Journal of intellectual \& Development Disability, 28(4), 369-379. doi:10.1080/136682503410001616407

Center for Public Education (2009). "Special education: At a glance." Alexandria, VA:

Center for Public Education. Retrieved on March 29, 2010, from

http://www.centerforpubliceducation.org/site/apps/nlnet/content3.aspx?c=lvIXIiN

$0 \mathrm{JwE} \& b=5518999 \& \mathrm{ct}=7559269$

Center, Y., \& Ward, J. (1987). Teachers' attitudes towards the integration of disabled children into regular schools. The Exceptional Child, 34(1), 41-56.

doi:10.1080/0156655870340105

Chang, D. F., \& Sue, S. (2003). The effects of race and problem type on teachers' assessment of student behavior. Journal of Consulting and Clinical Psychology, 71(2), 235-242. doi:10.1037/0022-006X.71.2.235

Chen, X., Rubin, K. H., \& Li, D. (1997). Relation between academic achievement and social adjustment: Evidence from Chinese children. Developmental Psychology, 33(3), 518-525. doi:10.1037/0012-1649.33.3.518

Chernoff, R., Combs-Orme, T., Risley-Curtiss, C., \& Heisler, A. (1994). Assessing the health status of children entering foster care. Pediatrics, 93(4), 594-601.

Cheung, S. Y., \& Heath, A. (1994). After care: The education and occupation of adults who have been in care. Oxford Review of Education, 20(3), 361-374. doi:10.1080/0305498940200309

Chipungu, S. S., \& Bent-Goodley, T. B. (2004). Meeting the challenges of contemporary foster care. The Future of Children: Children, Families and Foster Care, 14(1), 74-93. 
Choice, P., D' Andrade, A., Gunther, K., Downes, D., Schaldach, J., Csiszar, C., \& Austin, M. (2001). Education for foster children: Removing barriers to academic success. Berkeley, CA: University of California, Bay Area Social Services Consortium, Center for Social Services Research, School of Social Welfare.

Clausen, J. M., Landsverk, J., Ganger, W., Chadwick, D., \& Litrownik, A. (1998). Mental health problems of children in foster care. Journal of Child and Family Studies, 7(3), 283-296. doi:10.1023/A:1022989411119

Cohen, J., Cohen, P., West, S. G., \& Aiken, L. S. (2003). Applied multiple regression/correlation analysis for the behavioral sciences $\left(3^{\text {rd }}\right.$ ed.). Hillsdale, NJ: Erlbaum.

Colangelo, N., Kerr, B., Christensen, P., \& Maxey, J. (1993). A comparison of gifted underachievers and gifted high achievers. Gifted Child Quarterly, 37(4), 155-160. doi:10.1077/001698629303700404

Coleman, D. A., Martin, J. M., Powers, B., \& Truglio, R. (1996). Modeling causal relations between academic and social competence and depression: A multitraitmultimethod longitudinal study of children. Journal of Abnormal Psychology, 105(2), 258-270. doi:10.1037/0021-843X.105.2.258

Conger, D., Rebeck, A., \& Vera Institute of Justice. (2001). How children's foster care experience affect their education. New York, NY: NYC Administration for Children's Services.

Cooper, H. (1977). Controlling personal rewards: Professional teachers' differential use of feedback and the effects of feedback on the student's motivation. Journal of Educational Psychology, 69(4), 419-427. doi:10.1037/0022-0663.69.4.419 
Corrigan, P. W. (2004). How stigma interferes with mental health care. The American Psychologist, 59(7), 614-625. doi:10.1037/0003-066X.59.7.614

Corrigan, P. W., \& Watson, A. C. (2000). The paradox of self-stigma and mental illness. Clinical Psychology: Science and Practice, 9(1), 35-53. doi:10.1093/clipsy.9.1.35

Corrigan, P. W., \& Watson, A. C. (2002). Understanding the impact of stigma on people with mental illness. World Psychiatry, 1(1), 16-20.

Corrigan, P. W., Watson, A. C., \& Barr, L. (2006). The self-stigma of mental illness: Implications for self-esteem and self-efficacy. Journal of Social \& Clinical Psychology, 25(8), 875-884. doi:10.1521/jscp.2006.25.8.875

Courtney, M. E., \& Dworsky, A. (2006). Early outcomes for young adults transitioning from out-of-home care in the USA. Child and Family Social Work, 11(3), 209219. doi:10.1111/j.1365-2206.2006.004333.x

Courtney, M. E., Piliavin, I., Grogan-Kaylor, A., \& Nesmith, A. (2001). Foster youth transitions to adulthood: A longitudinal view of youth leaving care. Child Welfare, $80(6), 685-717$.

Courtney, M. E., Terao, S., \& Bost, N. (2004). Midwest evaluation of the adult functioning of former foster youth: Conditions of youth preparing to leave state care in Illinois. Chicago, IL: University of Chicago, Chapin Hall Center for Children.

Crisp, A. H., Gelder, M. G., Rix, S., Meltzer, H. I., \& Rowlands, O. J. (2000). Stigmatization of people with mental illnesses. British Journal of Psychiatry, 177(1), 4-7. doi:10.1192/bjp.177.1.4 
Crocker J. (1999). Social stigma and self-esteem: Situational construction of self-worth. Journal of Experimental Social Psychology, 35, 89-107.

Crocker, J., Major, B., \& Steele, C. (1998). Social Stigma. In D. Gilbert, S. T. Fiske, \& G. Lindzey (Eds.), Handbook of social psychology (4 ${ }^{\text {th }}$ ed., pp. 504-553). Boston: McGraw-Hill.

DeBaryshe, B. D., Patterson, G. R., \& Capaldi, D. M. (1993). A performance model for academic in early adolescent boys. Developmental Psychology, 29(5), 795-804. doi:10.1037/0012-1649.29.5.795

Diaz, E. I. (1998). Perceived factors influencing the academic underachievement of talented students of Puerto Rican descent. Gifted Child Quarterly, 42(2), 105-122. doi:10.1177/001698629804200205

Dolan, L. J. (1983). Validity analyses for the school attitude measures at three grade levels. Educational and Psychological Measurement, 43, 295-303. doi:10.1177/001316448304300140

Dolan, L. J., Enos, M. M., Wick, J., \& Smith, J. (1980). School attitude measure. Glenview, IL: Scott, Foresman, and Company.

Dovidio, J. F., Major, B., \& Crocker, J. (2000). Stigma: Instruction and overview. In T. F. Heatherton, R. E. Kleck, M. R. Hehl, \& J. G. Hull (Eds.), Stigma: Social psychological perspectives (pp. 1-28). NY: Guilford.

Dusek, J. B., \& Joseph, G. (1983). The bases of teacher expectancies: A meta-analysis. Journal of Educational Psychology, 75(3), 327-345.

Dweck, C. S., Davidson, W., Nelson, S., \& Enna, B. (1978). Sex differences in learned helplessness: II. The contingencies of evaluative feedback in the classroom and III. 
An experimental analysis. Developmental Psychology, 14(3), 268-276. doi:10.1037/0012-1649.14.3.268

Eagly, A. H., \& Steffen, V. J. (1986). Gender and aggressive behavior: A meta-analytic review of the social psychological literature. Psychological Bulletin, 100(3), 309330. doi:10.1037/0033-2909.100.3.309

Emerson, J., \& Lovitt, T. (2003). The educational plight of foster children in schools and what can be done about it. Remedial and Special Education, 24(4), 199-203. doi:10.1077/07419325030240040301

Estroff, S. E. (1989). Self, identity, and subjective experiences of schizophrenia: In search of the subject. Schizophrenia Bulletin, 25(2), 189-196.

Ferguson, R. F. (2003). Teachers' perceptions and expectations and the black-white test score gap. Urban Education, 38(4), 460-506. doi:10.1177/0042085903038004006

Fine, M., \& Asch, A. (1988). Disability beyond stigma: Social interaction, discrimination, and activism, Journal of Social Issues, 44(1), 3-22. doi:10.1111/j.15404560.1988.tb02045.x

Fischer, A. H. (1993). Sex differences in emotionality: Fact or Stereotype? Feminism \& Psychology, 3(3), 303-318. doi:10.1177/0959353593033002

Fisher, M., Barkley, R. A., Edelbrock, C. S., \& Smallish, L. (1990). The adolescent outcome of hyperactive children diagnosed by research criteria: II. Academic, attentional, and neuropsychological status. Journal of Consulting and Clinical Psychology, 58(5), 580-588. doi:10.1037/0022-006X.58.5.580 
Fiske, S. T. (1998). Stereotyping, prejudice, and discrimination. In D. T. Gilbert, S. T. Fiske, \& G. Lindzey, The Handbook of Social Psychology (Eds., pp. 357-411). Boston, MA: McGraw Hill.

Fletcher, J. M. (2008). Adolescent depression: Diagnosis, treatment, and educational attainment. Health Economics, 17(1), 1215-1235. doi:10.1002/hec.1319

Frick, P. J., Kamphaus, R. W., Lahey, B. B., Loeber, R.\& Tannebaum, L. E. (1991). Academic underachievement and the disruptive behavior disorders. Journal of Consulting and Clinical Psychology, 59(2), 289-294. doi:10.1037/0022006X.59.2.289

Frijda, N. H., Kuipers, P., \& ter Schure, L. (1989). Relations among emotion, appraisal and action tendency. Journal of Personality and Social Psychology, 57(2), 212228. doi:10.1037/0022-3514.57.2.212

Fröjd, S. A., Nissinen, E. S., Pelkonen, M, U. I., Marttunen, M. J., Koivisto, A., \& Kaltiala-Heino, R. (2008). Depression and School performance in middle adolescent boys and girls. Journal of Adolescence, 31(4), 485-498. doi:10.1016/j.adolescence.2007.08.006

Geenen, S. J., \& Powers, L. E. (2006). Transition planning for foster youth. The Journal for Vocational Special Needs Education, 28(2), 4-15.

Geenen, S., Powers, L. E., Powers, J., Cunningham, M., McMahon, L., Nelson, M., .. . Fullerton, A. (2012). Experimental study of a self-determination intervention for youth in foster care. Career Development and Transition for Exceptional Individuals. Advance online publication. doi:10.1177/2165143412455431 
Goerge, R. M., Van Voorhis, J., Grant, S., Casey, K., \& Robinson, M. (1992). Specialeducation experience of foster children: An empirical study. Child Welfare, 71(5), 419-437.

Goffman, E. (1963). Stigma: Note on the management of a spoiled identity. New York, NY: Touchstone.

Good, T. L. (1987). Two decades of research on teacher expectations: Findings and future directions. Journal of Teacher Education, 38(4), 32-47. doi:10.1177/002248718703800406

Good, T. L., \& Brophy, J. E. (1974). Behavioral expression of teacher attitudes. Journal of Educational Psychology, 63(6), 617-624. doi:10.1037/h0034069

Graham, S. (1990). Communicating low ability in the classroom: Bad things good teachers sometimes do. In S. Graham \& V. Folkes (Eds.), Attribution theory: Applications to achievement, mental health and interpersonal conflict (pp. 17-36). Hillsdale, NJ: Lawrence Erlbaum.

Graham, S. (1991). A review of attribution theory in educational contexts. Educational Psychology Review, 3(1), 5-39.

Green, S., Davis, C., Karshmer, E., Marsh, P., \& Straight, B. (2005). Living stigma: The impact of labeling, stereotyping, separation, status loss, and discrimination in the lives of individuals with disabilities and their families. Sociological Inquiry, 75(2), 197-215. doi:10.1111/j.1475-682X.2005.00119.x

Harden, B. J. (2004). Safety and stability for foster children: A developmental perspective. The Future of Children: Children, Families and Foster Care, 14(1), $30-47$. 
Hastings, R. P., Hewes, A., Lock, S., \& Witting, A. (1996). Do special educational needs courses have any impact on student teachers' perceptions of children with severe learning difficulties? British Journal of Special Education, 23(3), 139-144. doi:10.1111/j.1467-8578.1996.tb00965.x

Hill, K. (2012). Permanency and placement planning for older youth with disabilities in out-of-home placement. Children and Youth Services Review, 34(8), 1418-1424. doi:10.1016/j.childyouth.2012.03.012

Hoge, R. D., \& Butcher, R. (1984). Analysis of teacher judgments of pupil achievement levels. Journal of Educational Psychology, 76(5), 777-781.

Howard, J. A., \& Levinson, R. (1985). The overdue courtship of attribution and labeling. Social Psychology Quarterly, 48(3), 191-202.

Huba, G. J., \& Harlow, L. L. (1987). Robust structural equation models: Implications for developmental psychology. Child Development, 58(1), 147-166.

Hudley, C., Wakefield, W. D., Britsch, B., Cho, S., Smith, T., \& DeMorat, M. (2001). Multiple perceptions of children's aggression: Differences across neighborhood, age, gender, and perceiver. Psychology in the Schools, 38(1), 43-56. doi:10.1002/1520-6807(200101)38:<43::AID-PIT55>3.0.60;2-5

Jackson, S. (1994). Educating Children in Residential and Foster Care. Oxford Review of Education, 20(3), 267-279. doi:10.180/0305498940200301

Jones, E. E., \& Nisbett, R. E. (1972). The actor and the observer: Divergent perceptions of the causes of behavior. In E. E. Jones, D. E. Kanouse, H. H. Kelly, R. E. Nisbett, S. Valins, \& B. Weiner (Eds.), Attribution: Perceiving the Causes of Behavior. Morristown, NJ: General Learning Press. 
Kagan, D. M., \& Tippins, D. J. (1991). How student teachers describe their pupils. Teaching and Teaching Education, 7(5-6), 455-466. doi:10.1016/0742051X(91)9004-M

Kedar-Voibodas, G., \& Tannenbaum, A. J. (1979). Teachers' attitudes toward youth deviant children. Journal of Educational Psychology, 71(6), 800-808. doi:10.1037/0022-0663.71.6.800

Keller, H. (1986). In-school adaptive behavior: Assessment domains of behavior rating scales and child characteristics. Journal of Psychoeducational Assessment, 4(1), 1-12. doi:10.1177/073428298600400101

Kelley, H. H., \& Michela, J. L. (1980). Attribution theory and research. Annual Review of Psychology, 31(1), 457-501. doi:10.1146/annurev.ps.31.020180.002325

Kidd, R. F., \& Amabile, T. (1981). Causal explantations in social interaction: Some dialogues on dialogue. In J. H. Harvey, W. J. Ickes, \& R. F. Kidd (Eds.), New directions in attribution research, Volume 3 (pp. 307-328). Hillsdale, NJ: Lawrence Erlbaum Asssociates, Inc.

Kitano, H., \& Sue, S. (1973). The model minorities. Journal of Social Issues, 29(2), 1-10. doi:10.1111/j.1540-4560.1973.tb00069.x

Kline, R. B. (2005). Principles and practices of structural equation modeling ( $2^{\mathrm{nd}}$ ed.). New York, NY: Guilford.

Kolko, D. J., \& Kazdin, A. E. (1993). Emotional/behavioral problems in clinic and nonclinic children: Correspondence among child, parent and teachers reports. Journal of Child Psychology and Psychiatry, 34(6), 991-1006. doi:10.1111/j.1469-7610.1993.tb01103.x 
Kortenkamp, K., \& Ehrle, J. (2002). The well-being of children involved with the child welfare system: A national overview. Washington, DC: The Urban Institute, 1-7.

Kupersmidt, J. B., \& Coie, J. D. (1990). Preadolescent peer status, aggression, and school adjustment as predictors of externalizing problems in adolescent. Child Development, 61(5), 1350-1362. doi:10.1111/j.1467-8624.1990.tb02866.x

Lay, C., Ziegler, M., Hershfield, L., \& Miller, D. (1974). The perception of situational consistency in behaviour: Assessing the actor-observer bias. Canadian Journal of Behavioural Science, 6(4), 376-384. doi:10.1037/h0081883

Leary, M. R., \& Schreindorfer, L. S. (1998). The stigmatization of HIV and AIDS: Rubbing salt in the wound. In V. Derlega, \& A. Barbee (Eds.), HIV and Social Interaction (pp. 12-29). Thousand Oaks, CA: Sage Publications.

Lemert, E. M. (1951). Social pathology: A systematic approach to the theory of sociopathic behavior. New York, NY: McGraw-Hill.

Link, B. G., Cullen, F. T., Frank, J., \& Wozniak, J. F. (1987). The social rejection of former mental patients: Understanding why labels matter. American Journal of Sociology, 92(6), 1461-1500.

Link, B. G., \& Phelan, J. C. (2001). Conceptualizing stigma. Annual Review of Sociology, 27(1), 363-385. doi:10.1046/aanurev.soc.27.1.363

Loeber, R., \& Schmaling, K. B. (1985). The utility of differentiating between mixed and pure forms of antisocial child behavior. Journal of Abnormal Child Psychology, 13(2), 315-335. doi:10.1007/BF00910651 
Majoribanks, K. (1992). The predictive validity of an attitudes-toward-school scale in relation to children's academic achievement. Educational and Psychological Measurement, 52(4), 945-949. doi:10.1177/0013/64492052004017

Mandel, H. P., \& Marcus, S. I. (1988). The psychology of underachievement: Differential diagnosis and differential treatment. New York, NY: John Wiley.

Martin, J. K., Pescosolido, B. A., \& Tuch, S. A. (2000). Of fear and loathing: The role of 'disturbing behavior,' labels, and causal attributions in shaping public attitudes toward people with mental illness. Journal of Health and Social Behavior, 41(2), 208-223.

Martz, E. (2004). A philosophical perspective to confront disability stigmatization and promote adaptation to disability. Journal of Loss and Trauma, 9(2), 139-158. doi:10.1080/15325020490423343

Masten, A. S., \& Coatsworth, J. D. (1995). Competence, resilience, and psychopathology. In D. Cicchetti \& D. J. Cohen (Eds.), Developmental Psychopathology: Risk, disorder, and adaptation, Volume 2 (pp. 715-752). New York, NY: Wiley.

Masten, A. S., Coatsworth, J. D., Neemann, J., Gest, S. D., Tellegen, A., \& Garmezy, N. (1995). The structure and coherence of competence from childhood through adolescence. Child Development, 66(6), 1635-1659. doi:10.1111/j.14678624.1995.tb00956.x

Masten, A. S., Roisman, G. I., Long, J. D., Burt, K. B., Obradović, J., Riley, J. R., . . Tellegen, A. (2005). Developmental cascades: Linking achievement and externalizing and internalizing symptoms over 20 years. Developmental Psychology, 41(5), 733-746. doi:10.1037/0012-1649.41.5.733 
Maughan, B., Gray, G., \& Rutter, M. (1985). Reading retardation and antisocial behavior: A follow-up into employment. Journal of Child Psychology and Psychiatry, 26(5), 741-758. doi:10.1111/j.1469-7610.1985.tb00588.x

McMillen, J. C., \& Tucker, J. (1999). The status of older adolescents at exit from out-ofhome care. Child Welfare, 78, 339-360.

Montague, M., \& Rinaldi, C. (2001). Classroom dynamics and children at risk: A followup. Learning Disability Quarterly, 24(2), 75-83.

Morkos, H. B., Poznanski, E. O., \& Merrick, W. A. (1989). Depression and learning disabilities in children: A test of a hypothesis. Journal of Learning Disabilities, 22(4), 230-244. doi:10.1177/002221948902200406

Murray, C. B. (1996). Estimating achievement performance: A confirmation bias. Journal of Black Psychology, 22(1), 67-85. doi:10.1177/009579849660221006

Nadler, A., \& Fisher, J. D. (1986). The role of threat to self-esteem and perceived control in recipient reaction to help: Theory development and empirical validation. In L. Berkowitz, (Eds.), Advances in experimental social psychology (pp. 81-122), San Diego, CA: Academic.

National Association of Social Workers (1997, June). Individuals with disabilities education act amendments of 1997 (IDEA): Implications for social workers. Washington, DC: Author. Retrieved from https://www.socialworkers.org/archives/advocacy/updates/1997/idea.htm

Newcomb, M. D. (1994). Drug use and intimate relationships among women and men: models. Journal of Consulting and Clinical Psychology, 62(3), 463-476. doi:10.1037/0022_006X.62.3463 
Noh, S., Powers, J., \& Powers, L. E. (2013). Planning for future or documenting failure?: Negative comments in Individualized Education Plans (IEP) of foster youth with disabilities. Manuscript submitted for publication.

Oliver, S. J., \& Toner, B. B. (1990). The influence of gender role typing on the expression of depressive symptom. Sex Roles, 22(11-12), 775-791. doi:10.1007/BF00292060

Parish, T. S., Eads, G. M., Reece, N. H., \& Piscitello, M. A. (1977). Assessment and attempted modification of future teachers' attitudes toward handicapped children. Perceptual and Motor Skills, 44(2), 540-542. doi:10.2466/pms.1977.44.2.540

Pecora, P. J., Kessler, R. C., O'Brien, K., White, C. R., Williams, J., Hiripi, E., . . Herrick, M. A. (2006). Educational and employment outcomes of adults formerly placed in foster care: Results from the Northwest foster care alumni study. Children and Youth Services Review, 28(12), 1459-1481.

Pigott, R. L., \& Cowen, E. L. (2000). Teacher race, child race, racial congruence, and teacher ratings of children's school adjustment. Journal of School Psychology, 38(2), 177-195. doi:10.1016/S0022-4405(99)00041.2

Plewis, I. (1997). Inferences about teacher expectations from national assessment at Key Stage One. British Journal of Educational Psychology, 67(2), 235-247. doi:10.1111/j.2044-8279.1997.tb01240.x

Plummer, K. (2001). Labeling theory. In C. Bryant (Eds.), In encyclopedia of criminology and deviant behavior: Sexual deviance, Volume 37 (p. 191-194). Philadelphia, PA: Brunner-Routledge. 
Powers, L. E., Geenen, S., Powers, J., Pommier-Satya, S., Turner, A., Dalton, L., . . Swank, P. (2012). My Life: Effects of a longitudinal, randomized study of selfdetermination enhancement on the transition outcomes of youth in foster care and special education. Children and Youth Services Review, 34(11), 2179-2187. doi:10.1016/j.childyouth.2012.07.018

Rapport, M. D., Denny, C. B., Chung, K., Hustace, K. \& Hustace, K. (2001). Internalizing behavior problems and scholastic achievement in children: Cognitive and behavioral pathways as mediators of outcome, Journal of Clinical Child \& Adolescent Psychology, 30(4), 536-551. doi:10.1207/s15374424JCCP3004_10

Ray, M., \& Downs, W. R. (1986). An empirical test of labeling theory using longitudinal data. Journal of Research Crime and Delinquency, 23(2), 169-194. doi:10.1177/0022427886023002004

Reis, S. M., \& McCoach, D. B. (2000). The underachievement of gifted students: What do we know and where do we go? Gifted Child Quarterly, 44(3), 152-170. doi:10.1177/001698620004400302

Reyna, C. (2000). Lazy, dumb, or industrious: When stereotypes convey attribution information in the classroom. Educational Psychology Review, 12(1), 85-110. doi:10.1023/A:1009037101170

Richman, N., Stevenson, J., \& Graham, P. J. (1982). Preschool to school: A behavioral study. London: Academic Press. 
Ritsher, J. B., \& Phelan, J. C. (2004). Internalized stigma predicts erosion of morale among psychiatric outpatients. Psychiatry Research, 129(3), 257-265. doi:10.1016/j.psychres.2004.08.003

Ritzer, G. (2005). Encyclopedia of social theory. Thousand Oaks, CA: SAGE Publications.

Roeser, R. w., Eccles, J. S., \& Sameroff, A. J. (2000). School as a context of early adolescents' academic and social-emotional development: A summary of research findings. The Elementary School Journal, 100(5), 443-471.

Rolison, M. A., \& Medway, F. J. (1985). Teachers' expectations and Attributions for student achievement: Effects of label, performance pattern, and special education intervention. American Educational Research Journal, 22(4), 561-573. doi:10.3102/00028312022004567

Rosenthal, R., \& Jacobson, L. (1966). Teachers' expectancies: Determinants of pupils' IQ gains. Psychological Reports, 19(1), 115-118. doi:10.2466/pr0.1966.19.1.115

Rousseau, C., Drapeau, A., \& Corin, E. (1996). School performance and emotional problems in refugee children. American Journal of Orthopsychiatry, 66(2), 239251. doi:10.1037/h0080175

Rumberger, R. W., \& Larson, K. A. (1998). Student mobility and the increased risk of high school dropout. American Journal of Education, 107(1), 1-35.

Runyan, D. K., \& Gould, C. L. (1985). Foster care for child maltreatment. II. Impact on school performance. Pediatrics, 76(5), 841-847.

Sack, W. H., Angell, R. H., Kinzie, J. D., \& Rath, B. (1986). The psychiatric effects of massive trauma on Cambodian children: II. The family, the home and the school. 
Journal of the American Academy of Child and Adolescent Psychiatry, 25(3), 377-383.

Sawyer, R. J., \& Dubowitz, H. (1994). School performance of children in kinship care. Child Abuse and Neglect, 18(7), 587-597. doi:10.1016/0145-2134(94)90085-X

Sayce, L. (1998). Stigma, discrimination and social exclusion: What's in a word. Journal of Mental Health, 7(4), 331-343. doi:10.1080/09638239817932

Schlosberg, A. (2002). Psychiatric stigma and mental health professional (Stigamatizers and destigmatizers). In A. Levy, D. Nachshon, \& A. Carmi (Eds.), Psychiatry \& Law (pp. 453-462). Tel Aviv, Israel: Yozmot Publishing.

Schneider, B., \& Lee, Y. (1990). A model for academic success: The school and home environment of East Asia students. Anthropology and Education Quarterly, 21(4), 358-377. doi:10.1525/aeq.1990.21.4x0596x

Schneider, J. W. (1988). Disability as moral experience: Epilepsy and self in routine relationships. Journal of Social Issues, 44(1), 63-78. doi:10.1111/j.15404560.1988.tb02049.x

Schur, E. M. (1971). Labeling deviant behavior: Its sociological implications, New York, NY: Harper \& Row.

Silva, J. C., \& Morgado, J. (2004). Support teachers' beliefs about the academic achievement of students with special educational needs. British Journal of Special Education, 31(4), 207-214. doi:10.1111/j.0952-3383.2004.00356.x

Simon-Morton, S., Crump, A., Haynie, D., \& Saylor, K. (1999). Student-school bonding and adolescent problem behavior. Health Education Research, 14(1), 99-107. doi:10.1093/her/14.1.99 
Simonson, T. A., \& Strein, W. (1997). The effects of teachers' verbal behaviors on kindergartners' perceptions of competence. Psychology in the Schools, 34(4), 363371. doi:10.1002/(SICI)1520-6807(199710)34:4<363::AID-PITS8>3.0.co;2-M

Stafford, M. C., \& Scott, R. R. (1986). Stigma deviance and social control: Some conceptual issues. In S. C. Ainlay, G. Becker, \& L. M. Coleman, The dilemma of difference (Eds.). New York, NY: Plenum.

Steele, C. M. (1997). A threat in the air: How stereotypes shape intellectual identity and performance. American Psychologist, 52(6), 613-629. doi:10.1037/0003066X.52.6.613

Stein, E., Evans, B., Mazumdar, R., \& Rae-Grant, N. (1996). The mental health of children in foster care: A comparison with community and clinical samples. The Canadian Journal of Psychiatry, 41(6), 385-391.

Thompson, A. H., \& Fuhr, D. (1992). Emotional disturbance in fifty children in the care of the child welfare system. Journal of Social Service Research, 15(3-4), 95-112. doi:10.1300/J079v15n03_06

U.S. Department of Education. (2000). A guide to the individualized education program. Washington, DC: Author. Retrieved, from http://www.ed.gov/parents/needs/speced/iepguide/iepguide.pdf

U.S. Department of Health and Human Services, Administration for Children and Families, Children's Bureau. (2006). The AFCARS Report: Preliminary FY 2005 Estimates as of September 2006. Retrieved from http://www.acf.hhs.gov/programs/cb/stats_research/afcars/tar/report13.htm 
U.S. Department of Health and Human Services, Administration for Children and Families, Children's Bureau. (2009). The AFCARS Report: Preliminary FY 2006 estimates as of February 2009. Retrieved from http://www.childwelfare.gov/pubs/factsheets/foster.cfm\#key

U.S. Department of Health and Human Services, Administration for Children and Families, Children's Bureau (2012). The AFCARS Report: Preliminary FY 2011 estimates as of July, 2012. Retrieved from http://www.acf.hhs.gov/sites/default/files/main/afcarsreport19.pdf

U.S. General Accounting Office (1999). Foster care: Effectiveness of independent living services unknown. Report no. GAO/HEHS-00-13. Washington, D.C.: U.S. General Accounting Office.

Vandivere, S., Chalk, R., \& Moore, K. A. (2003). Children in foster home: How are they faring? Child Trends Research Brief, 23, 1-8.

Vogel, D. L., Wade, N. G., \& Hackler, A. H. (2007). Perceived public stigma and the willingness to seek counseling: The mediating roles of self-stigma and attitudes toward counseling. Journal of Counseling Psychology, 54(1), 40-50. doi:10.1037/0022-0167.54.1.40

Walker, H. M, Block-Pedego, A., Todis, B \& Severson, H. (1991). School Archival Records Search (SARS): User's guide and technical manual. Longmont, CO: Sopris West.

Walker, J. S., Coleman, D., Lee, J., Squire, P. N., \& Friesen, B. (2008). Children's stigmatization of childhood depression and ADHD: Magnitude and demographic 
variation in a national sample. Child and Adolescent Psychiatry, 47(8), 1-9. doi:10.1097/CHI.0b013e318179961a

Weinberg, L. A., Zetlin, A. G., \& Shea, N. M. (2001). Who should be responsible for the education of children in foster care: A literature review. Los Angeles, CA: Mental Health Advocacy Services, Inc.

Weinberg, L. A., Zetlin, A. G., \& Shea, N. M. (2003). Improving educational prospects for foster youth. Los Angeles, CA: Mental Health Advocacy Services, Inc.

Weiner, B. (1985). An attribution theory of achievement motivation and emotion. Psychological Review, 92(4), 548-573. doi:10.1037/0033-295X.92.4.548

Weiner, B., Perry, R. P., \& Magnusson, J. (1988). An attributional analysis of reactions to stigmas. Journal of Personality and Social Psychology, 55(5), 738-748. doi:10.1037/0022-3514.55.5.738

Weisel, A., \& Tur-Kaspa, H. (2002). Effects of labels and personal contact on teachers' attitudes toward students with special needs. Exceptionality, 10(1), 1-10. doi:10.1207/S15327035EX1001_1

Wertheimer, R. (2002, December). Youth who "age out" of foster care: Troubled lives, troubling prospects. Child Trends Research Brief, Retrieved from http://www.childtrends.org/Files/Child_Trends-2002_12_01_RB_FosterCare.pdf

West, S. G., Finch, J. F., \& Curran, P. J. (1995). Structural equation models with nonnormal variables. In R. H. Hoyle (Ed.), Structural equation modeling: Concepts, issues and applications (pp. 56-75). Thousand Oaks, CA: Sage. 
Westat, Inc. (1991). A national evaluation of Title IV-E Foster Care Independent Living Programs for Youth Phase 2 Final Report (Contract No. OHDS 105-87-1608). Rockville, MD: Author.

Westwood, P. (1984). Attitude change in second year teacher education preservice teachers following an introductory special education course. South Pacific Journal of Teacher Education, 12(2), 55-61. doi:10.1080/0311213840120206

Wick, J. W. (1990). Comprehensive assessment program: SAM attitude measures technical manual. Iowa City, IA: American Testronics.

Woolfson, L., Grant, E., \& Campbell, L. (2007). A comparison of special, general and support teachers' controllability and stability attributions for children's difficulties in learning. Educational Psychology, 27(2), 295-306.

doi:10.1080/014434/0601066826

Zapf, D., Dormann, C., \& Frese, M. (1996). Longitudinal studies in organizational stress research: A review of the literature with reference to methodological issues. Journal of Occupational Health Psychology, 1(2), 145-169. doi:10.1037/10768998.1.2.145

Zima, B, T., Bussing, R., Freeman, S., Yang, X., Belin, T. R., \& Forness, S. R. (2000). Behavior problems, academic skills delays and school failure among school-aged children in foster care: their relationship to placement characteristics. Journal of Child and Family Studies, 9(1), 87-103. doi:10.1023/A:1009415800475 